\title{
AN EXAMINATION OF REFUGEE PROTECTION ATTITUDES IN SOUTHEAST
} ASIA

$$
\text { By }
$$

Yin Cheung Lam

A thesis submitted to the Victoria University of Wellington in fulfilment of the requirements for the degree of

Master of Arts

in

International Relations

Victoria University of Wellington 


\begin{abstract}
This thesis examines how Southeast Asian countries such as Thailand and Malaysia sought to articulate attitudes towards refugee protection during the Indochinese and Rohingya refugee crises. While countries in Southeast Asia are known to be reluctant to discuss and participate in refugee protection, preferring to follow the norm of non-interference encapsulated in the 'ASEAN Way' in recent years, over time, attitudes towards refugee protection have varied significantly. The thesis explores the internal and external pressures that have impacted on changing perceptions of refugee protection in Southeast Asia. To explore changes in refugee protection attitudes, I conduct a comparative case study between the Indochinese and Rohingya refugee crises, analysing the responses and the rationale justifying the level of refugee protection in Thailand and Malaysia. These two countries have employed a variety of arguments such as ethnicity, religion and economic costs of treaty accession to inform their practices of refugee protection. In addition, regional/international dynamics and the labelling of refugees have also affected the level of refugee protection as well. Overall, their selective engagement with international refugee law; ethnic considerations; regional influences and the securitisation of refugee crises contribute most to arguments as to why refugee protection attitudes in Southeast Asia have remained poor. My findings indicate that due to the overlapping nature of these factors, any examination of refugee protection attitudes cannot be answered adequately by a single explanation, be it the practice of non-interference or a non-ratification of the 1951 Refugee Convention. These attitudes are mostly influenced by internal pressures, with national and regional factors interacting in tandem to produce higher levels of insecurity for the refugees studied in this thesis. Ultimately, this thesis will demonstrate that while refugee protection attitudes in the two refugee crises were influenced by shifting notions of national security, race and regional dynamics, not much has changed in terms of the consequences for refugees.
\end{abstract}




\section{TABLE OF CONTENTS}

ABSTRACT I I

TABLE OF CONTENTS II

LIST OF ABBREVIATIONS IV

LIST OF TABLES $\quad$ VI

LIST OF MAPS $\quad$ VII

ACKNOWLEDGEMENTS $\quad$ VIII

CHAPTER 1 - INTRODUCTION 1

I. Statement of the Problem and Research Questions 1

II. Overview of Refugee Protection in Southeast Asia 2

III. Outline of the Study and Research Methodology 5

1. Structure of the Thesis 5

2. Statement of Methodology 5

IV. Literature Review 8

1. Competing Perspectives to Refugee Protection in Southeast Asia 8

2. How this Thesis differs from, and Adds to, the Existing Literature 13

CHAPTER 2 - The Indochina Exodus of 1975 - 1989

I. Origins and Background of the Indochinese refugees 15

1. Vietnam 15

2. Cambodia 17

3. Laos 19

II. Refugee Movement During the Indochina Refugee Crisis 19

III. The Ordinary Departure Programme 23

IV. Comprehensive Plan of Action 24

V. Responses to the Indochinese Refugee Crisis 26

1. Malaysia 26

2. Thailand 28

VI. Factors Affecting Attitudes Towards Refugee Protection 29

1. Domestic Socio-Political Issues 30 
2. Legal Aspects of Refugee Protection and its Impact on the Indochinese Refugees

3. Conceptualisation of the Refugee 37

4. Regional Dynamics In Southeast Asia 38

5. International Influences 42

VII. Conclusion 44

CHAPTER 3 - The Rohingya Refugee Crisis in Southeast Asia 46

I. Origins and Background of the Rohingya Refugees 46

II. Refugee Movement during the Rohingya Refugee Crisis 50

III. Responses to the Rohingya Refugee Crisis 53

1. Malaysia 53

2. Thailand 55

IV. Factors Affecting Attitudes towards Refugee Protection 56

1. Domestic Socio-Political Issues 57

2. Legal Aspects of Refugee Protection and its Impact on the Rohingya 60

3. Conceptualisation of the Refugee 66

4. Regional Dynamics in Southeast Asia 67

5. International Influences 71

$\begin{array}{lll}\text { V. Conclusion } & 73\end{array}$

$\begin{array}{ll}\text { CHAPTER } 4 \text { - Conclusion } & 75\end{array}$

I. Causality of Changes in Refugee Protection Attitudes in Southeast Asia 75

1. Domestic Socio-Political Issues $\quad 75$

2. Legal Aspects of Refugee Protection and its Impact on Refugees 77

3. Conceptualisation of the Refugee 80

4. Regional Dynamics in Southeast Asia 81

5. International Influences 83

II. Whither Refugee Protection in Southeast Asia? 83

III. Limitations and Contributions of This Study 87

$\begin{array}{ll}\text { REFERENCE LIST } & 90\end{array}$ 


\section{LIST OF ABBREVIATIONS}

AALCO

ASEAN

AHRD

AICHR

CAT

CERD

COMECON

CPA

ICCPR

NAB

NEZ

NRC

ODP

OIC

OHCHR

PRK

RHA

RSD

SUARAM

UN
Asian-African Legal Consultative Organisation

Association of Southeast Asian Nations

Association of Southeast Asians (ASEAN) Human Rights Declaration

ASEAN Intergovernmental Commission on Human Rights

Convention against Torture

International Convention on the Elimination of All Forms of Racial

Discrimination

Council for Mutual Economic Assistance

Comprehensive Plan of Action

International Covenant on Civil and Political Rights

Burma News Agency

New Economic Zones

National Registration Certificates

Ordinary Departure Programme

Organisation of Islamic Cooperation

Office of the High Commissioner for Human Rights

People's Republic of Kampuchea

Refugee Hosting Area

Refugee Status Determination

Suara Rakyat Malaysia

United Nations 
UNGA

UNHCR

UNECOSOC

US

USCR
United Nations General Assembly

United Nations High Commissioner for Refugees

United Nations Economic and Social Council

United States

United States Committee for Refugees and Immigrants 


\section{LIST OF TABLES}

Table 1 Distribution of Indochinese Refugees in Country/Territory of First Asylum

Table 2 Ratification Status on Refugee-related International Legal Provisions in Thailand and Malaysia 


\section{LIST OF MAPS}

Map 1 Refugee Flows within/from Southeast Asia During the Indochinese Conflict

Map 2 Rohingya Refugee Flows within/from Southeast Asia 


\section{ACKNOWLEDGEMENTS}

I am grateful to Associate Professor David Capie for his support and patience in guiding me through my studies at the Victoria University of Wellington. I also need to thank Jonette Crysell for her excellent administrative support during the academic year. I have benefited greatly from their academic support.

I am thankful to my parents who have given me with this opportunity to study. 


\section{Chapter 1: Introduction}

\section{Statement of the Problem and Research Questions}

Southeast Asia today is an increasingly active and important actor in global refugee politics. A major cause of this development has been the proliferation of global conflicts, creating massive refugee outflows from Afghanistan, Iran, and Iraq, with people travelling through Southeast Asia by sea in order to get to Australia and Canada (UN Office on Drugs and Crime 2012, 39). The sources of refugees are not only confined to the Middle East, countries closer to Southeast Asia have also contributed to increased levels of refugee movement. Since 2012, nearly " 170,000 refugees and migrants - equal to about $5 \%$ of the combined populations of the bordering districts of Cox's Bazaar in Bangladesh and Maungdaw in Myanmar - are believed to have travelled by sea from Bangladesh and Myanmar" (UNHCR Regional Office for Southeast Asia 2015). Given the high concentration of refugees in Southeast Asia, the international and regional responses to such crises have been less than satisfactory. Australia's Operation Sovereign Borders; its bilateral refugee swap with Malaysia and mass graves of refugees discovered in Thailand's Songkhla province demonstrate that attempts at refugee protection in Southeast Asia have remained mostly unsuccessful.

While Southeast Asia's problems with refugee protection have been well documented since the 1970s, few attempts have been made to trace the trajectory of refugee protection attitudes in Southeast Asia. This thesis seeks to contextualise the regional process of refugee protection by looking closely at two different historical cases: the Indochina refugee crisis from 1975 to 1989 and the Rohingya refugee crisis from 1990 to 2017, to evaluate if attitudes towards refugee protection have changed. In particular, it identifies some of the factors influencing the policy responses of selected regional governments such as Thailand and Malaysia that often shape how refugee protection attitudes are developed. This thesis is framed around the following questions: Have attitudes towards refugee protection in Southeast Asia changed over the last 50 years? What are some of the factors that affected the provision of refuge to asylum seekers and have they changed over time as well? More importantly, what does a study of such factors tell us about attitudes towards refugee protection in Southeast Asia today? 


\section{Overview of Refugee Protection in South-East Asia}

Large movements of refugees have long been endemic to the region of Southeast Asia. The origins of a Southeast Asian refugee narrative could be found in the aftermath of the Second World War, where ethnic Chinese from Southeast Asia, forced into China during the war, sought to return to the Southeast Asian countries that were their states of origin (UNECOSOC 1949, 38-39). Barely three decades later, ideological rivalry between the United States and the Soviet Union culminated in the flight of more than three million people from Indochina (UNHCR 2000, 102).

Despite the Syrian refugee crisis having a major impact on global refugee figures recently, the Asia-Pacific region remains host to the largest refugee population of any region in the world (UNHCR 2015a, 10). Southeast Asia represents about 16 percent of Asia-Pacific's refugee population, with 523,592 confirmed refugees (UNHCR Regional Office for Southeast Asia 2014, 1). It is also estimated that there is a large number of people who could claim refugee status but do not do so (US Committee for Refugees and Immigrants 2002, 11). These people do not know if they are able to seek refuge or fear their case for refugee status will not be recognised under the United Nations High Commissioner for Refugees, also known as UNHCR (US Committee for Refugees and Immigrants 2002, 11). If the figures for individuals with indeterminate status were included, Southeast Asia would have around 2.7 million people of concern, including 1.4 million stateless and over 700,000 internally displaced (UNHCR Regional Office for Southeast Asia 2014, 1).

Globally, approaches to refugee protection are highly varied. However, the key instrument guiding all efforts at refugee protection is the 1951 Convention Relating to the Status of Refugees and its 1967 Protocol. The Convention established a common international legal framework for defining, processing and the resettlement of refugees. The Convention defines a refugee as someone who has fled his or her own country owing to a well-founded fear of being persecuted because of "race, religion, nationality, membership of a particular social group or political opinion" (UN Refugee Convention 1951). However, the 1951 Convention was limited by its geographical and time constraints. A refugee could only be granted asylum if they could demonstrate a fear of persecution due to events in Europe before 1 January 1951. Subsequently, the 1967 Protocol amended the basic premises of the 1951 Convention by removing such geographical and time constraints. The legal framework outlined by the 1951 Convention and the 1967 Protocol seeks to enshrine universal and consistent 
practices in global refugee protection by providing a common definition of who can be a refugee and institutionalising standards that guide a state's response to refugee protection.

The majority of Southeast Asian nations are not signatories to the 1951 Convention and its 1967 Protocol (UNHCR, n.d.a.). Out of eleven states in the region, only two have signed both the Convention and Protocol: Cambodia and the Philippines. As of now, there is no attempt in Southeast Asia to develop regional instruments that would standardise the management of refugee crises (Davies 2008, 3). In contrast to Southeast Asia, other regional organisations such as the Organisation of African Unity, Organisation of American States and the European Union have made efforts to complement international refugee law with additional regional measures.

The closest thing to a refugee protection mechanism in Southeast Asia is the AsianAfrican Legal Consultative Organisation (AALCO), which includes the vast majority of Southeast Asian states as members. The AALCO instituted the 1966 Bangkok Principles on Status and Treatment of Refugees, formally adopted in 2001. The Bangkok Principles generally reiterate the core provisos of the 1951 Convention and its 1967 Protocol, where member states should provide asylum and guarantee the principle of non-refoulement. ${ }^{1}$ However, the most interesting feature of the Bangkok Principles can be found in Article V, which states that "save in the national or public interest or in order to safeguard the population, the State shall not expel a refugee" (AALCO 1966, 3). The implications of this caveat are important, for it places any consideration of refugee rights largely at the discretion of the receiving state. It is also necessary to note that the Bangkok Principles are only declaratory and non-binding, as the AALCO mostly serves as an advisory board to its member states in the field of international law (AALCO, n.d). Lacking appropriate monitoring and enforcement mechanisms, the Bangkok Principles have had little impact on states in managing refugee crises (Muntarbhorn 1992, 47).

In Southeast Asia, Thailand and Malaysia have the highest number of refugees seeking asylum at their UNHCR offices and Myanmar has produced the highest number of refugees currently assisted by UNHCR (UNHCR 2015b, 17). This does not take into account the number of asylum seekers who remain outside the auspices of UNHCR. There remain a large number of potential asylum seekers in Southeast Asia, who are often categorised as (i) illegal migrants, (ii) economic migrants, (iii) internally displaced persons and (iv) people living in refugee-like

\footnotetext{
${ }^{1}$ Non-refoulement refers to the practice of not sending refugees against their will to a country where they will be subjected to persecution.
} 
situations (UNHCR 2015b, 16-19). These people are categorised as such because the Southeast Asian states they are in do not recognise refugees and they fear being denied refugee status by UNHCR. It remains unclear as to what extent should UNHCR involve itself with the four categories of people described above. The first category refers to migrants who are not in the country legitimately, and these people are usually involved in the informal economies of the countries they are currently in. The second category refers to persons who move overseas for better economic opportunities, and they can be in the country by both legal and illegal means. The third category suggests that such individuals have not crossed national borders, and have not fulfilled the condition of seeking refuge outside their country of persecution (UNHCR $2015 \mathrm{~b}, 28)$. The final category is more imprecise, referring to people who are stateless or denied the protection of their government, but have not been recognised as refugees (Russell 2002). As there are no agreed procedures and administrative frameworks for dealing with these multiple categories, humanitarian assistance to refugees and its associated groups is usually provided on an ad-hoc basis.

This thesis will be using the terms 'refugees' and 'asylum seekers' interchangeably. It is understood that there are differences between these two terms, where the former refers to someone fleeing persecution while the latter refers to some whose request for asylum has yet to be processed (UNHCR, n.d.b.). However, as the treatment of both asylum seekers and refugees are often provided under the same legislative framework and domestic policies of the nations examined in this thesis, both terms are taken to imply the same meaning for individuals fleeing persecution.

Currently, Southeast Asia's most important regional group, the Association of Southeast Asian Nations (ASEAN) has not shown any inclination to develop a coherent regional refugee framework that would standardise procedures for handling refugee crises in the region. The need to treat refugees in accordance with international refugee law has however been referenced in the ASEAN Human Rights Declaration (AHRD). Point 16 of the AHRD reaffirms this point, by stating "every person has the right to seek and receive asylum in another State in accordance with the laws of such State and applicable international agreements" (ASEAN 2012, 6). Although ASEAN has recognised the right to seek asylum as indivisible from fundamental human rights, the clause that refers any asylum seeker to the 'laws of such state' means it would be premature to suggest that a full recognition of universal refugee rights is happening in Southeast Asia. 
Since the development of the 1951 Convention, there has been ongoing debate about Southeast Asia's attitudes towards non-traditional security, especially with a discernible change in Southeast Asia's point of view on humanitarian issues and how ASEAN approaches the universalism of human rights while maintaining the 'ASEAN way'. Attitudes towards refugee protection within Southeast Asia, undoubtedly, is still very perplexing for and within Southeast Asian states and most scholars. It is an area that remains understudied, given that Southeast Asia has only managed a vague discussion of rights in the AHRD without offering any specific prescriptions on refugee protection. Therefore, the nature of this study is timely as it seeks to investigate changes in refugee protection attitudes in Southeast Asia over two different historical periods, with a view to studying the causality behind such changes.

\section{Outline of the Study and Research Methodology}

\section{Structure of the Thesis}

This thesis is organised in four chapters. Chapter 2 utilises the case study of the Indochinese refugee crisis to establish why refugee protection levels at the time were low. The chapter is divided into 3 main parts. First, it provides a background to the refugee crisis. Second, it examines the response developed by selected Southeast Asian states such as Thailand and Malaysia to the Indochinese refugee crisis. Finally, the chapter ends by examining factors influencing refugee protection attitudes and assesses why they may or may not have varied in Thailand and Malaysia. Chapter 3 will then utilise the same approach on a more recent case study, the Rohingya refugee crisis. As the same analytical approach is adopted for Chapters 2 and 3, this allows us to assess for any changes in refugee protection attitudes in Chapter 4. Chapter 4 will then review the most important findings and contributions of this thesis. It concludes by arguing that while attitudes towards refugee protection may be shaped by socio-economic issues; regional dynamics; international influences; refugee definitions and the relevancy of refugee laws that vary over time and context, there has been no real change since refugee protection has remained poor across the two case studies studied.

\section{Statement of Methodology}

\section{Case Selection}

In studying the limits of refugee protection in Southeast Asia, which examples should we investigate? When it comes to refugee crises, two critical events are particularly pertinent 
to Southeast Asia: the 1975 Indochina conflict and the Rohingya refugee crisis. Their centrality to the Southeast Asian refugee literature cannot be understated. In relation to the Indochinese and Rohingya refugee crises, Thailand and Malaysia are among the most important actors in regional refugee protection due to their status as first asylum countries. These countries held their own convictions as to what each subsequent exodus of people from conflict zones meant and developed their own individual responses to the refugee crises.

The Indochina exodus came at the conclusion of the Vietnam War in 1975. The installation of communist governments in the former French colonies of Vietnam, Cambodia and Laos forced over three million people to seek refuge neighbouring countries, hoping to acquire permanent resettlement in third countries such as the United States, Australia and Canada (UNHCR 2000, 86). The Indochinese refugees consisted of the Vietnamese boat people, Cambodians, ethnic Hmong and Laotians. Their flight from persecution was often perilous, with up to a quarter of a million people estimated to have died at sea by drowning or at the hands of pirates (St Cartmail 1983, 12). Barely four years after the fall of Saigon, more than a quarter of a million "Vietnamese and Laotian refugees remained scattered in camps from Thailand to Hong Kong, and another half a million Cambodians were massed at the Thai border" (Robinson 2004, 319). As the Indochina refugee arrivals surged again in 1987 and 1988, a Comprehensive Plan of Action (CPA) was adopted to restore the principle of asylum and introduced "a repatriation option, including forced return" (UNHCR 2000, 92).

To be able to understand Thailand and Malaysia's stance on refugee protection, it is necessary to examine their motivations for participating in or rejecting refugee protection efforts, and see if there were any unique circumstances that encouraged them to adopt certain courses of action. The selection of the Indochinese refugee crisis as a case study allows us to trace any important developments in their respective policies that contributed to the protracted nature of refugee crises in Southeast Asia.

In the past few years leading up to the May 2015 Rohingya boat crisis, more than 120,000 Rohingya sought to flee Myanmar by boat due to intensifying repression and attacks under former Myanmar President Thein Sein's government (BBC News, 2015). This led to the unfolding of the Rohingya boat crisis in the Andaman Sea. Fomented by historical processes of persecution and exclusion from the citizenship debate in Myanmar, the number of Rohingya refugees have increased over the years, escaping to Thailand and Malaysia (Singh 2014, 9). Calls for a regional solution have been largely ineffective and mostly rhetorical in nature. Any 
discussion of the Rohingya often reveals sharp divisions among these countries on the best way to deal with them. Earlier attempts to organise a regional summit were rejected outright by Myanmar (Kassim 2012). On the other hand, Thailand refused to deal with the boat people alone, arguing that it was a problem for Malaysia and Indonesia as well (Royal Thai Government, 2009). Amidst such political intransigence, Thailand and Malaysia responded with boat pushbacks, justifying their actions with reasons ranging from the principle of noninterference to national security threats.

The Rohingya refugee crisis is a useful case study for the following reasons: First, it provides an opportunity to consider the current state of Thailand and Malaysia's commitment to refugee protection. Second, the utilisation of a recent refugee issue would also serve as a point of reference in assessing changes from the Indochina refugee crisis.

This thesis seeks to assess the degree of change in refugee attitudes and how Thailand and Malaysia have responded to refugee protection at two different historical periods. I have chosen to examine the responses of these countries to the two refugee crises because they are well documented, they are comparable both between and within the two states under examination, and because they provide variation in refugee protection attitudes. My aim is to determine if and how such countries have changed their attitudes towards refugee protection over time.

\section{Methods}

This thesis adopts the qualitative methodology of process tracing. Given that the goal of this thesis is to identify and assess data on the casual processes that might lead to differing approaches to refugee protection in Southeast Asia, it will help identify which causes pose a greater challenge to refugee protection. Process tracing is known as the "cause-effect link that connects independent variable and outcome, unwrapped and divided into smaller steps; then the investigator looks for observable evidence of each step" (Van Evera 1997, 64). The need to trace causal mechanisms allows the researcher to determine whether the hypothesised outcome is sufficient or not (George and Bennett 2005). Given that the research design of this thesis is based on examining the attitudes to refugee protection in Thailand and Malaysia, multiple causes are to be expected. Process tracing offers a highly relevant approach that allows one to follow changes in refugee protection, potentially helping us narrow the number of possible causes of differing refugee protection attitudes in Southeast Asia. In both refugee case studies, tracing the process of how Thailand and Malaysia developed their refugee protection 
policies will allow us to collect information on how factors such as Southeast Asian regional dynamics; domestic socio-political and economic considerations; legal aspects of refugee protection; states' understanding of refugee crises and international influences affected the protection of refugees. It generates insights as to what extent does each individual hypothesised causal mechanism has obfuscated attempts at refugee protection in Southeast Asia.

\section{Sources}

This thesis uses both primary and secondary sources of reference. Primary sources such as excerpts of interviews, fieldwork studies, UN statistical data and government publications will be used to complement the methods of this research. Secondary sources such as newspaper articles, journal articles and books on Southeast Asian refugee practices will be analysed in tandem to the primary sources used in this thesis. It is hoped that the sources used in this thesis will help provide some indication as to how approaches to refugee protection were developed by Thailand and Malaysia during the Indochina and Rohingya refugee crisis. The data will then explain how internal and external conditions such as domestic politics; conceptualisation of refugees; regional dynamics in Southeast Asia; international assistance and law contributed to their respective attitudes towards refugee protection in both refugee case studies.

\section{Literature Review}

\section{Competing Perspectives on Refugee Protection in Southeast Asia}

Scholars working on refugee protection in Southeast Asia have succeeded in identifying a number of important factors influencing state approaches to asylum seekers. These include the 'ASEAN way', how a commitment to international refugee law involves higher economic costs of accession, threats to social cohesion in Southeast Asian states and the discourse between universalism and Asian Values on refugee issues. These factors figure prominently in distinct approaches to refugee protection in Southeast Asia. Some of these studies aim to provide explanations for Southeast Asia's inadequate refugee protection by emphasising how non-interference often impedes the development regional solutions to refugee crises (Kneebone 2016, 154). Others provide an explanation of how social identities influence the unique policy choices of individual states (Vas Dev 2009, 33). Common in many of these approaches to refugee protection is the conviction that states are ultimately responsible for creating the obstacles that have prevented efforts to ameliorate refugee crises. These arguments place a lot 
of emphasis as to how principles of non-interference are institutionalised and presented as problematic to the refugee protection agenda in Southeast Asia. However, most have studied refugee issues such as non-interference in isolation without considering how alternative factors such as domestic political considerations and states' understanding of refugee crises interact together to influence refugee protection attitudes in Southeast Asia.

The case for setting out a refugee protection agenda is often informed by the principle of non-interference in Southeast Asia. The focus on non-interference thus sets out both general and/or specific context for refugee protection in Southeast Asia and the perspectives on Southeast Asian norm diffusion that often revolve around the dichotomous relationship between sovereignty and interference. Such an approach forms part of the 'ASEAN way', known for its "informality, preference for consensus over majority voting, avoidance of legalistic procedures, preference of non-binding resolutions and tendency to avoid contentious bilateral issues in multilateral discussions" (Acharya 2009, 79). Astri Surkhe (1993, 180) argues that refugees represent a "foreign policy complication", a conundrum in the ASEAN way. A cross comparison with the potential development of a refugee regime in South Asia illustrates the same principle, with Chowdhury Abrar $(2001,21)$ stating:

“(An) important hindrance towards developing a formal refugee regime in South Asia has been the adherence to the policy of working out political solutions through bilateral negotiation between the host country and the country of origin, with the emphasis on sovereign jurisdiction".

Such an argument suggests that the issue of refugee protection is often subordinate to sovereignty concerns encapsulated by the ASEAN way. This follows similar lines of argument in explaining that the practice of non-interference retains its primacy in mediating sociopolitical issues in Southeast Asia. Such an approach encourages the ignoring of transnational calls for support from the same ethnic groups or religious followers and limits political commentaries to what member states are doing within their sovereign borders (Bercowtch, Oishi and Askandar 2002, 32). As Vitit Muntarbhorn (1992, 33) explains, the reluctance by Southeast Asian states to institutionalise refugee protection by adopting international refugee law instruments is largely explained as being because of national interest concerns which are in turn, determined by many other reasons such as social cohesion and economic development.

However, the principle of non-interference has not always been absolute and is often subject to the fluid nature of political interests. Suhrke $(1993,180)$ notes that Asian states have often appropriated the refugee issue by settling refugees within their state as part of a broader 
political game. For example, the 1973 martial law imposed by President Marcos of the Philippines in Mindanao encouraged Filipino Muslims to leave the south due to religious differences and armed conflict. During this period, they were granted residence followed by citizenship by Malaysia (Muntarbhorn 1992, 115). Given that the nature of the conflict was one between Catholics and Muslims, Sara E. Davies (2008, 9) argues that Malaysia's acceptance of Muslim refugees could be seen as an implicit endorsement of the conflict in Mindanao. A more recent example touches on the plight of the Rohingya from Burma, where Former Malaysian Prime Minister Dr Mahathir Mohammad argued that the Rohingya crisis was not a boat problem and the "idea of not interfering should have a limitation" (Palansamy 2015). These examples show how the principle of non-interference has not remained absolute at times, creating varying responses to refugee protection that may be based on racial and religious grounds or just part of a state's geopolitical strategy. The inconsistencies around noninterference have been raised by Lee Jones $(2010,479)$, who argues that the norm has never been absolute but has rather been "upheld or ignored in line with the interests of the region's dominant social forces”. Brooke Coe's $(2015,290)$ study on varying trends of non-interference in the global South speaks to this as well.

There is an increasing consensus in the literature that focuses on the dilemma ASEAN is facing, if Southeast Asian states should continue to focus on a strict adherence or flexible interpretation of the ASEAN way. Matthew Davies $(2013,56)$ situates the debate within the context of the ASEAN Human Rights Declaration, stating that the discussion of rights only takes place within the traditional framework of non-interference and sovereign equality, terming it the "ASEAN synthesis". In the context of human rights protection, there has also been work done in assessing the level of treaty compliance among Southeast Asian states. Davies $(2014,415)$ postulates a future where some ASEAN member states would be more inclined to participate in the global human rights debate, aligning their human rights norms with global ones under international pressure while those who limit their exposure to human rights treaties will fall behind their neighbours.

However, despite some evidence that ASEAN is incorporating a human rights approach at regional level, poor enforcement mechanisms suggest that the practice of non-interference is still happening here. The adoption of the 2007 ASEAN Charter which reinforces the commitment to democracy and human rights was meant to increase the level of adherence to charter standards. However, despite the shift to a discourse of rights, the lack of enforcement mechanisms means it cannot qualify as interference (Davies 2013, 54). Inevitably, the norm of 
non-interference is immediately reasserted, undermining ASEAN's approach to human security.

On the other hand, while such developments in the ASEAN Charter may speak about human rights exclusively, their relevance to refugee protection cannot be understated, as refugee protection is still a "claim grounded in an assertion of right" (Dauvergne 2000, 56). The development of a rights discourse in ASEAN has implications for refugee protection, since the process of protecting refugees ultimately speaks about what kind of rights should be granted to asylum seekers. Therefore, the body of literature reviewed here suggests that there remains some way to go before refugee protection is properly integrated in this emerging discourse of human rights in Southeast Asia.

Another complication to approaches in refugee protection would be the debate between sovereignty and humanitarian concerns. Myanmar is a case in point. Abad Jr 2004 (cited in Loke 2004, 24) argues that ASEAN's response to Myanmar's human rights violations have been ineffectual, where "human security is a function of the interplay of the territoriality of the nation state and the non-territoriality of the human being". An example would be Myanmar's treatment of the Rohingya. In addition to subjecting them to human rights abuses such as rape, robbery and torture, they have also relocated communities and placed them under curfew. Jack Dunford $(2000,161)$ argues that it is unlikely that Myanmar would exercise its responsibility to protect the Rohingya while rejecting international assistance at the same time because the Myanmar state is the cause of the Rohingya refugee exodus and continues to deny their existence. The exercise of sovereign power by a state allows it to dictate what is to matter and what is not, effectively circumscribing any humanitarian concerns the international community may have.

Some other authors choose to express the tension between sovereignty and noninterference as one based on Asian values, that Southeast Asian states cannot be expected to recognise international refugee law as the concept is inherently Eurocentric and pays no attention to Asian cultural specificities. Former Malaysian Prime Minister Mahathir was a vocal opponent of humanitarian intervention by Western powers, and such views were generally accepted in Southeast Asia:

"Southeast Asians generally believe that humanitarian intervention could subvert the region's dominant non-intervention norm, weakening political and social cohesion and allowing the West to call into question the legitimacy of governments and regimes not of their liking" (Dupont 2000, 165). 
This statement has an important implication for the protection of refugees under the Asian values debate. A commitment to refugee protection may result in increased refugee inflows that may upset the racial and ethnic landscape of their nations. Shaun Narine $(2005,468)$ argues that the domestic politics of developing states, characterised by ethnic and religious differences determine how states respond to international issues. Ethnic conflict in Philippines, Southern Thailand and Myanmar that has produced large numbers of refugees are examples that demonstrate the challenges of nation building in these countries.

A final point of contention would be how the economic costs of accession to international refugee treaties inform states' reluctance to refugee protection. This argument implies that compliance with international refugee law imposes heavy financial burdens, and developing states lack the financial capacity to bear this burden (Surkhe and Zolberg 1999, 168). For example, when Asian states were invited to sign the 1951 Convention or 1967 Protocol, countries such as Laos, Malaysia, and Singapore stressed that the 1951 Convention created financial expectations that were higher than developing states could commit to (Davies 2008 , 10). However, the perceived costs of accession have not been viewed in the same way by other developing countries around the world. In fact, the majority of African states have acceded to the 1951 Convention and 1967 Protocol (Oucho 2002, 154). Therefore, there are certain limitations to how the economic cost of treaty accession argument can be utilised by Southeast Asian states.

A criticism of the economic cost argument focuses on how states have neglected to look at the function asylum seekers, often labelled as 'illegal migrants' fulfil. These 'illegal migrants' often work in informal economies, filling labour gaps in which the host country's nationals are often reluctant to do. A term used in Southeast Asia is 'SALEP' - Shunned by all except the very poor - which is another indication of the nature of these jobs (Bohning 1998, 367). Piyasiri Wickramasekera $(2002,3)$ argues that as a result of economic growth, employment conditions have improved expectations and 'SALEP' jobs are now unattractive to the local urban population. On a similar note, Karen Jacobsen $(2001,12)$ argues that the perception that "refugees create more economic costs than benefits does not correspond to the evidence provided by close analysis of a host state's market, where "refugees are often blamed for pre-existing...economic problems". Even though 'self-settled' refugees can compete with locals for resources, their presence can also lead to "expanding the capacity and productivity of the RHA (Refugee Hosting Area) economy" (Davies 2008, 12). Therefore, it appears that 
there is little evidence suggesting that granting refugee status would have any adverse impact on the economic well-being of the receiving state.

Using the above literature review as a point of entry, this thesis integrates those separate topics in a way that serves the research purposes, avoids any singular and reductionist approach in studying the phenomenon of refugee protection attitudes in Southeast Asia. Furthermore, this allows us to assess for changes in refugee protection attitudes and account for why certain explanations are more influential in accounting for such attitudes in Southeast Asia.

\section{How this Thesis differs from, and Adds to, the Existing Literature}

The issue of refugee rights protection in Southeast Asia is not a completely new topic. In fact, there have been workshops and research projects which, to some extent, broach and examine different aspects of this subject. The academic response to refugee protection in Southeast Asia has generally focused on investigating how non-interference norms have affected the practice of refugee protection. Such analysis often speaks to the sovereignty concerns of states and the interventionary nature of humanitarian assistance. They typically also only pay attention to singular causes of poor refugee protection in Southeast Asia. No substantial research has been done on assessing if refugee protection attitudes have evolved over time. More importantly, no work has been completed in assessing how alternative factors such as the legal aspects of refugee protection, domestic socio-political considerations and the securitisation of refugee issues function together to affect refugee protection in the region. As revealed by the above review of existing literature, there are few significant publications that examine this issue in a thorough and comprehensive manner.

In sum, this survey of literature reveals some gaps which point to a new and little explored territory for original research. Specifically, these gaps suggest a research direction for this thesis to examine a comprehensive approach in tracing the evolution of refugee protection attitudes in the two states selected. The ability to identify variations in refugee protection attitudes could also help policy makers in making choices on issues that offer the best possible outcome for refugees. This is where the thesis, once completed, differs from and adds to the existing literature on refugee protection attitudes in Southeast Asia. 


\section{Chapter 2: The Indochina Exodus of 1975 -1989}

The 1975 Indochina refugee crisis is arguably Southeast Asia's most prominent humanitarian crisis to date. The refugee crisis served as a litmus test for attitudes towards refugee protection in Southeast Asia, testing the capacity and will of many newly independent Southeast Asian states in offering humanitarian assistance. During this period, the paradoxes of refugee assistance became evident when regional powers strategically adjusted their refugee protection approaches with the national interest in mind. At the same time, political intransigence due to an unfamiliarity or non-ratification of the Refugee Convention and its Protocol; threats to social cohesiveness; and ways in which states interpreted the refugee crisis contributed to varying degrees of refugee protection. Together, these factors not only contributed to discordant approaches to refugee protection, but also created situations of insecurity for the Indochinese refugees.

This chapter examines the level of refugee protection during the Indochinese refugee crisis. The chapter is organised as follows. The first four sections begin by describing and examining the origins of the Indochinese refugee during the Indochina refugee crisis. It will also provide a brief introduction of the two key refugee resettlement programmes during the Indochina refugee crisis.

The fifth section will then examine the responses of Thailand and Malaysia to the Indochina refugee crisis from 1975 to 1989. An examination of their responses reveal that boat pushbacks and forced repatriations were commonly adopted to stem the flow of refugees into their countries. Overall, Thailand and Malaysia's response to the Indochina refugee crisis was framed around a process of arbitrary decision making, resulting in inconsistent approaches to refugee protection.

The final section focuses on an analysis of which factors were instrumental in influencing attitudes towards refugee protection in these countries. Domestic factors such as threats to the socio-economic order; Eurocentric claims of international refugee law and the selected nations' subsequent manipulation of refugee protection law; regional dynamics of refugee protection and the role of the international community will form the bulk of the analysis in this chapter. The purpose of this section is to clarify which attitudes and assumptions were 
crucial in developing Thailand and Malaysia's subsequent approach to refugee protection during the Indochinese Refugee Crisis.

This chapter concludes that these factors combined to explain why attitudes towards refugee protection during the Indochina refugee crisis remained inconsistent, where domestic and regional considerations, allied to the disingenuous engagement with the global refugee protection regime, resulted in a less than optimal outcome for the Indochinese refugees.

\section{Origins and Background of the Indochinese Refugee}

\section{Vietnam}

The Indochina refugee crisis had its origins in the colonial era, where Vietnam was part of the French Colonial Empire. The conclusion of the Second World War saw Ho Chi Minh, the leader of the Indochinese Communist Party (Viet Minh) declare Vietnamese independence in a ceremony attended by, among others, "American personnel, whose presence was seen by many as an acknowledgement of his claim to power" (Dalglish 1989, 16). However, only North Vietnam, proclaimed as the Democratic Republic of Vietnam was controlled by the Viet Minh while the South remained in the hands of the French. Attempts by the French to regain control over the North led to the First Indochina War in 1949. Eventually, the conflict became a proxy war between communist and capitalist forces. According to the 1954 French military budget, the United States (US) funded seventy eight percent of the war effort (St Cartmail 1983, 16). The French defeat at Dien Bien Phu led to the Geneva Agreements of 1954, terminating hostilities with guarantees of a free election for a Vietnamese government in 1956.

The Republic of Vietnam (South Vietnam) was established with Ngo Dinh Diem as its president, a nationalist supported by the US. In the years after the First Indochina War, some 890,000 refugees, the majority of them Catholics fearing persecution, arrived in South Vietnam from the Communist North (St Cartmail 1983, 17). At the same time, South Vietnam had to deal with increasing levels of communist guerrilla activity in their territory, instituting repressive measures against the communists and former Viet Minh nationalists. Together, these issues added to Diem's problems with socio-economic reconstruction during the post First

Indochina War period. In response to Diem's crackdown on Communist activity, the Communist movement in the South intensified and culminated in the formation of the National Front for the Liberation of South Vietnam (Viet Cong). 
The intensification of communist guerrilla activity in the South to overthrow the USDiem alliance, coupled with Buddhist opposition to Diem's pro-Catholic policy would later lead to the fall of the Diem regime (St Cartmail 1983, 18). In response, the United States demonstrated its military commitment to South Vietnam by bombing North Vietnam, partially in retaliation to the shelling of the US destroyer Maddox in the Gulf of Tonkin (St Cartmail $1983,18)$. The ensuing hostilities led to the creation of " 528,000 refugees, made homeless by the attacks" (St Cartmail 1983, 18). Another example of America's role in exacerbating the numbers of refugee can be found in the 1968 My Lai massacre of 500 Vietnamese civilians by American soldiers. The operation was conducted on the assumption that villagers were harbouring elements of the Viet Cong (Schell 1987, 252). The plight of the refugees during this period would foreshadow the events of the Indochina refugee crisis a decade later, where physical dislocation from their homes and inurement to protracted situations of conflict became the status quo. Such incidents encouraged many to leave their homes to seek shelter in other countries.

Arguably, the unprecedented number of Indochinese refugees can be attributed to Nixon's policy of Vietnamisation. Firstly, this policy involved a gradual withdrawal of American soldiers while building up the combat capabilities of the South Vietnamese military (Hunt 2015, 104). This was based on the presumption that American military aid would develop a South Vietnamese force with numerical and arms superiority. After the US military withdrawal in April 1975, South Vietnam collapsed and fell to the communists. The fall of major cities such as Saigon, Hue and Danang generated a massive displacement of Vietnamese people as the Viet Cong moved south to gain control. At this point, the new US President Gerald Ford ordered US Navy vessels and aircraft to assist in the evacuation of 176,000 refugees from South Vietnam (St Cartmail 1983, 20). Other Vietnamese escaped by means of small vessels to Hong Kong, Singapore, Malaysia, the Philippines and Thailand. During this period of uncertainty, the first signs of the Vietnamese boat people finally emerged, precipitating the larger number of boat refugees that would occur a few years later.

Furthermore, Nixon's policy of Vietnamisation had an indirect effect on Indochinese politics when Operation Menu was ordered in secret without the approval of the US Congress in 1969. The order was given to bomb Vietnamese sanctuaries in Cambodia (Shawcross 1979, 28). Apart from driving the Viet Cong deeper into Cambodia, the bombings would precipitate Pol Pot's coming into power and entering into a temporary mutually beneficial alliance with the US (Shawcross 1979, 95). Vietnam responded by invading Cambodia in 1979, in a move 
that would exacerbate the number of refugees, in addition to those fleeing Pol Pot's repressive rule.

The disenfranchisement of the Chinese minority in Vietnam, was another contributing factor to the number of Indochinese refugees. As part of the newly installed Communist government's new development policy in 1976, new economic zones (NEZ) were created to deurbanise populations and increase agricultural output in rural areas. This had huge ramifications for the ethnic Chinese (Hoa) in Vietnam. As most of the businesses in Saigon were owned by the Hoa, the state took over possession of their businesses under the new policy (Wain 1979, 164). If any Hoa refused to participate in the government's economic programme, they could either leave for China or Hong Kong after paying a hefty fee, the NEZs or be sent to a concentration camp. It is estimated that around 626,000 Hoa refugees left Vietnam since January 1975 (St Cartmail 1983, 79). While this lends support to the argument that the Hoa were discriminated against, there is no evidence the Vietnamese government was forcibly expelling them.

The involvement of global powers was also a contributing factor to the further displacement of Indochinese refugees. Beijing's interest in the Hoa propelled it to engage in a propaganda war with Vietnam. Eventually this led to China's invasion of Vietnam in 1979. China's move was seen by some as less to do with the fate of Hoa but more about restricting the Soviet Union's influence in the region and countering Vietnam's invasion of Cambodia (Wain 1979, 164). Eventually, China's invasion of Vietnam, coupled with her dire need for financial aid to continue the war in Cambodia, facilitated their decision to join the Soviet-led Council for Mutual Economic Assistance, also known as COMECON (Wain 1979, 164). The machinations of great power politics placed the Hoa in the middle of the Sino-Soviet rivalry. Ultimately, many chose to flee Vietnam in search of sanctuary. Geopolitical rivalry between China and the Soviet Union contributed to the worsening of the Indochina refugee crisis as Indochina's largest state (Vietnam) was now aligned with the Soviet Union. Furthermore, communist victories in Cambodia and Laos ensured that the Indochina refugee exodus was set on a course that would affect countries not only in Southeast Asia but globally as well.

\section{Cambodia}

Pol Pot's coming to power in Cambodia in 1975 was responsible for another source of refugees during the Indochinese refugee crisis. The US bombardment of Cambodia had already created hundreds of thousands of refugees seeking refuge in the capital Phnom Penh, but the 
imminent genocidal nihilism of the Khmer Rouge created an exodus that convoluted efforts to control increasing numbers of refugees in the Indochina.

Cambodia's refugee problem was less clearly defined as opposed to the ideological conflict between colonialism versus nationalism and the subsequent struggle between communists and US supported nationalists in Vietnam. This explanation arose because of Vietnamese involvement in Cambodian affairs. This began when Prince Norodom Sihanouk's compromised Cambodia's neutrality by allowing the North Vietnamese to settle bases in the border areas of his country. Subsequently, American displeasure with Cambodia's alignment with the Vietnamese communists created much disenchantment with Prince Sihanouk's government, culminating in the Lon Nol coup d'état in March 1970. Lon Nol's expulsion of the North Vietnamese in exchange for American support created conditions that encouraged the growth of the Khmer Rouge, a communist offshoot of the North Vietnamese (St Cartmail 1983, 42). As a result, internecine conflict between Lon Nol's government and the Khmer Rouge, continued bombing in Cambodia by the American air forces would lead to the social disintegration of Cambodia in 1975.

As the Khmer Rouge assumed power in April 1975, they envisioned a new form of political system that would result in the 'purification' of Cambodia. Central to this ideology was the fact that the cities of Cambodia, "long contaminated by the decadent bourgeoisie, would have to be emptied as a prerequisite to the return to the land" (St Cartmail 1983, 45). The absolutist nature of Khmer Rouge's political philosophy eschewed human weakness or mercy, such was its iron resolve to rid Cambodia of its colonial influences. Given the racial and religious diversity in Southeast Asia, the Khmer Rouge's targeting of urban populations; Buddhist monks; Muslim, Chinese and Vietnamese ethnic minorities ensured that other countries would have to deal with the Cambodian refugees at some point in time (Gatrell 2013, 213). Milton Osborne $(1980,44)$ argues that the fact ethnic Cambodians, traditionally seen as enemies by the Vietnamese, sought refuge in Vietnam, shows the enormity of Pol Pot's genocidal policies and the extent of dislocation of society in Cambodia. Eventually, Vietnamese troops invaded Cambodia and Phnom Penh fell in 1979 with Heng Samrin installed as the Vietnamese puppet for Cambodia (Kiernan 2008, 56).

However, the removal of Pol Pot's government did not mean that the refugee exodus stopped. The fragmented nature of Cambodian society sustained the fighting between Heng Samrin and the last pockets of Khmer Rouge resistance; Force Armme de Liberation du Cambodge, Khmer 
People's National Liberation Front and the 'Moulinaka Faction'. The protracted nature of conflict in Cambodia ensured that there was no respite in sight for the Indochinese refugees.

\section{Laos}

Laos was not immune to the transnational nature of revolutionary conflict in Indochina. In the early 1960s, the American military recruited guerrilla forces from the Hmong and Montagnard to fight against the communist Pathet Lao and the Viet Cong. Heavy US bombardment in Laos on the Vietcong who were using the country as a route of attack and escape inflicted heavy casualties on the Hmong people (Gatrell 2013, 212). In December 1975, the communist triumph in Laos "turned Hmong into targets and prompted their mass flight" (McCoy 2006, 285). During Vietnam's invasion of Cambodia, Hanoi intensified its support for the Pathet Lao in operations against the Hmong with the apparent aim of annihilating them in particular (Wain 1979, 163). Of the Hmong flight from Laos, a United Nations High Commissioner for Refugees (UNHCR) official in Laos and Thai said:

"The great majority of Hmong refugees fled because of a genuinely felt fear of reprisal or persecution from the new regime... (but) there were additional economic reasons for the Hmong to leave Laos" (Cooper 1986, 27).

Although there are no specific figures as to how many Hmong have escaped Laos since 1975, it is generally agreed that of the approximately " 250,000 persons who have left Laos since mid1975 half are ethnic Laotians while half are members of a range of upland minority groups...with probably more than seventy percent being Hmong people" (Osborne 1980, 45).

\section{Refugee Movement During the Indochina Refugee Crisis}

In 1975, displaced refugees were moving everywhere in Indochina. From this period onwards, it can be argued that five critical events were responsible for the huge surge in refugee numbers in Southeast Asia. In Vietnam, the fall of Saigon to communist North Vietnam and the Viet Cong in 1975 and the subsequent purging of ethnic Chinese. In Cambodia, Pol Pot's rise to power in 1975 and Vietnam's invasion in 1979 sustained the mass exodus of refugees from the region. The persecution of the Hmong in 1975 by the new Laotian communist government contributed to the refugee numbers as well. Together, these events created a situation that was highly complex because it did not just invoke ideological tensions, but also ethnic strife that tested the limits of territorial sovereignty. This resulted in a refugee crisis that 
could not be contained within national borders, greatly accelerating the dispersal of Indochina's population.

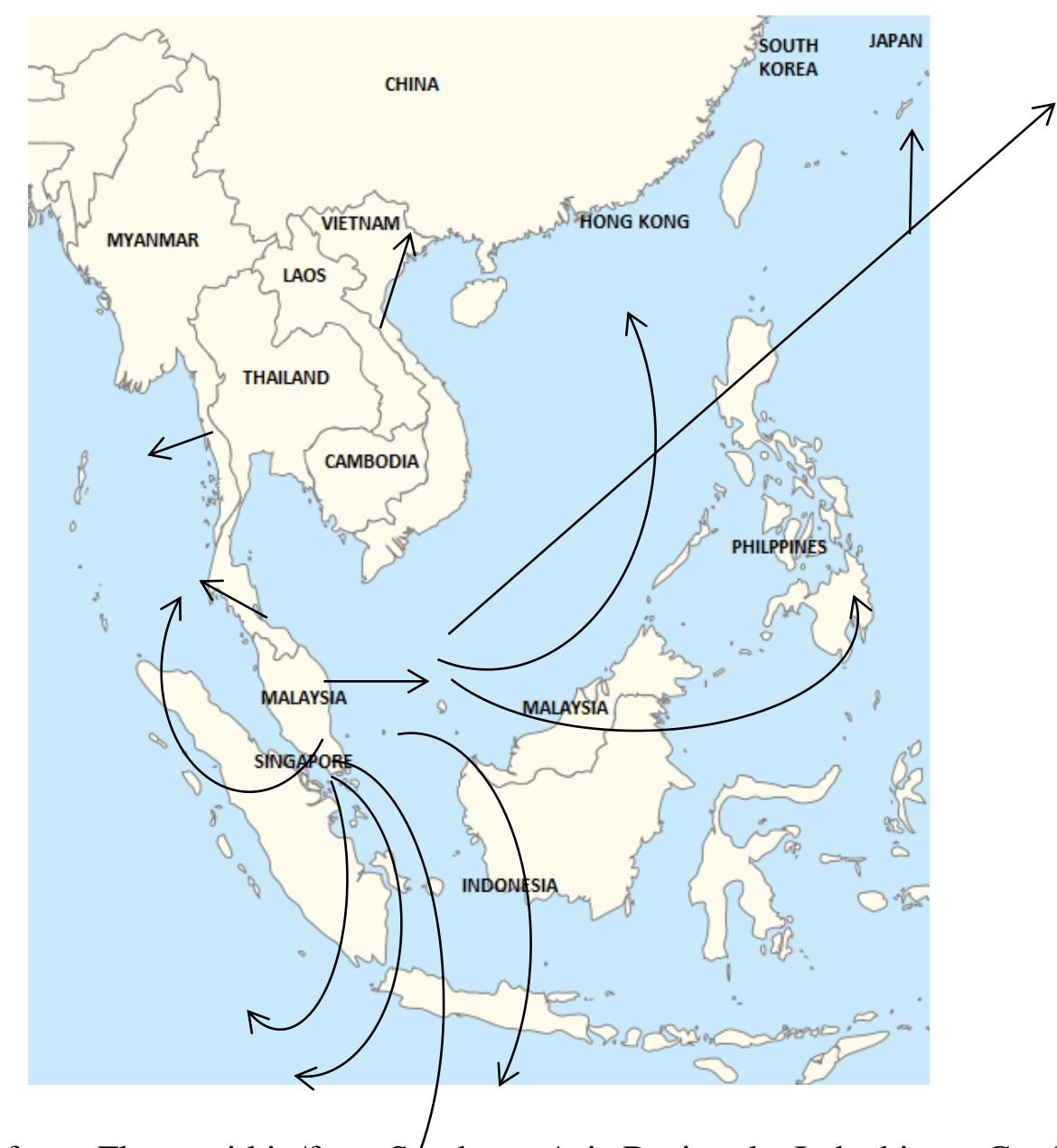

Map 1: Refugee Flows within/from Southeast Asia During the Indochinese Conflict

The exodus of the Vietnamese refugees can be characterised in three different stages.

The first significant flight of refugees from Vietnam began as the South Vietnamese administration led by Nguyen Van Thieu neared its end in 1975. A US Special Interagency Task Force for Indochina Refugees was charged to evacuate the refugees, offering them temporary relief from the ongoing civil war in Vietnam and resettling them either in the United States or other countries. Gradually, the Task Force's 'Operation New Life' began to "register the more than 140,000 who had been brought to Guam" (Robinson 1998, 18). Second, due to increasing levels of discrimination and the Sino-Vietnamese conflict, the Hoa sought to escape Vietnam into China. By the end of 1979, it is estimated that around 250,000 Hoa fled into China by land (Miller 2015). 
Finally, as the socialist system gradually took hold of Vietnam, about 15,000 Vietnamese sought refuge in Southeast Asia in 1977 (UNHCR 2000, 82). By the end of 1978, the numbers fleeing by boat had "quadrupled and 70 percent of these asylum seekers were Vietnamese of Chinese origin" (UNHCR 2000, 82). These refugees escaping by boat did not just travel by small wooden fishing boats on their own, but also sought the assistance of people smugglers who transported them on steel-hulled freighters (UNHCR 2000, 82). In September 1978, a tramp steamer, the Southern Cross beached itself on a reef off the Indonesian island of Pengibu claiming that the refugees were rescued from smaller vessels. However, investigations showed that the "900-ton, Honduras-registered, uninsured rust bucket was... the first large foreign vessel explicitly chartered to go to Vietnam and pick up refugees" (Wain 1979, 28). On 8 November, 1978, another freighter, the Hai Long, docked at Port Klang, Malaysia seeking to unload its human cargo of 2500 Vietnamese (Wain 1979, 28).

In Cambodia, the expulsion of foreign ethnicities formed part of the Khmer Rouge purge. Part of Pol Pot's directive to his assembled cadres was to "expel the entire Vietnamese minority population" (Kiernan 2004, 415). The government expelled more than half of the 400,000 ethnic Vietnamese living in Cambodia (Ninh 2015, 109). Apart from the ethnic Cambodian-Vietnamese, several Cambodian Muslims, Indians, Pakistanis and ethnic Thais crossed the borders into Thailand as well. Most of these refugees were settled in camps along the Thai-Cambodia border. UNHCR estimates that only "34,000 Cambodians managed to escape into Thailand from 1975-1978 and another 20,000 going to Laos" (Robinson 1996, 74).

The exodus of Laotians may not be comparable to the figures in Vietnam and Cambodia. However, the refugee influx from Laos remained significant for the fact that it contributed the highest number of overland asylum seekers among the three countries affected by the Indochina conflict (see Table 1). The movement of Laotian refugees were divided into two main groups: the highland minority (Hmong) and the lowland Lao. These people were settled in camps along the Laotian-Thai border. 


\begin{tabular}{|l|r|r|r|r|r|}
\hline Country/territory of first asylum & $1975-79$ & $1980-84$ & $1985-89$ & $1990-95$ & Cumulative 1975-95 \\
\hline Vietnamese boat people & & & & & \\
\hline Hong Kong & 79906 & 28975 & 59518 & 27434 & 195833 \\
\hline Indonesia & 51156 & 36208 & 19070 & 15274 & 121708 \\
\hline Japan & 3073 & 4635 & 1834 & 1529 & 11071 \\
\hline Republic of Korea & 409 & 318 & 621 & 0 & 1348 \\
\hline Macau & 4333 & 2777 & 17 & 1 & 7128 \\
\hline Malaysia & 124103 & 76205 & 52860 & 1327 & 254495 \\
\hline Philippines & 12299 & 20201 & 17829 & 1393 & 51722 \\
\hline Singapore & 7858 & 19868 & 4578 & 153 & 32457 \\
\hline Thailand & 25723 & 52468 & 29850 & 9280 & 117321 \\
\hline Other & 2566 & 340 & 321 & 0 & 3227 \\
\hline Sub-total (boat people) & 311426 & 241995 & 186498 & 56391 & 796310 \\
\hline & & & & & 640246 \\
\hline Thailand (overland) & 397943 & 155325 & 66073 & 20905 & 237398 \\
\hline Cambodians & 171933 & 47984 & 12811 & 4670 & 359930 \\
\hline Laotians & 211344 & 96224 & 42795 & 9567 & 42918 \\
\hline Vietnamese & 14666 & 11117 & 10467 & 6668 & 1436556 \\
\hline Total (boat and land) & 709369 & 397320 & 252571 & 77296 & \\
\hline
\end{tabular}

Table 1: Distribution of Indochinese Refugees in Country/Territory of First Asylum (UNHCR 2000, 98).

Population displacement in Southeast Asia from 1975 to 1989 evokes similarities with other historical refugee crises that were often caused by revolution and sectarian strife. Table 1 only reflects the number of refugees that sought refuge in territories in predominantly Southeast Asian countries of first asylum and does not include concurrent Western efforts that brought them directly to a country of resettlement. If one were to include Western resettlement efforts, the total number of refugees would amount to more than three million people that fled Indochina in the two decades after the 1975 socio-political uprisings in Vietnam, Cambodia and Laos (UNHCR 2000, 79). The large numbers of refugees seen in the Indochina refugee crisis can be attributed to the transnational nature of ethnicities in Southeast Asia, and subsequently, the spill over effect of insurrectionary social structures that led to the first concerted attempt to seek a solution to the diaspora of refugees from Southeast Asia. 


\section{The Ordinary Departure Programme}

In response to the increased number of boat arrivals in Southeast Asian countries, the July 1979 Geneva Conference on Indochina was convened. Just barely a month earlier, the then five members of the Association of Southeast Nations (ASEAN) - Indonesia, Malaysia, Singapore, Philippines and Thailand issued a statement that they had "reached the limit of their endurance and decided that they would not accept any new arrivals" (ASEAN 1979, 5). For example, the Thai government started repatriating Cambodian refugees who had crossed into Thailand to escape the civil war (Das 1979, 17). Therefore, urgent action was required by the international community to control an escalating situation that could get out of hand in light of ASEAN nations' refusal to accept any more refugees. The purpose of the 1979 Conference was to mobilise collective action into committing resources and establishing numbers for resettlement opportunities in the international community. In his speech at the Conference, former US Vice President Walter F. Mondale said:

"There must be an immediate moratorium on the further expulsion of people from Vietnam. We must stop the drownings and establish a humane emigration program... It must be replaced by a policy which enables those who wish to leave their homes to do so - in safety and by choice and in an orderly manner" (United States Office of the Vice President's Press Secretary 1979, 3).

This led to the establishment of the Ordinary Departure Programme (ODP), based on UNHCR and Vietnam's Memorandum of Understanding signed earlier in May 1979. First, the programme was developed as a response to the exodus of boat people in Southeast Asia. UNHCR thought that the tragedy of the boat people could be further prevented if the neighbouring states would allow them to land for temporary refuge, pending resettlement in other countries. Second, it was also a vehicle for family reunification from Vietnam, where the US government's desire to bring out individuals left behind in 1975 would provide an avenue from which they could engage with socialist Vietnam and China during the Cold War era (Kumin 2008, 105).

Under the auspices of the ODP, Vietnam agreed to authorise the exit "of family reunion and other humanitarian cases wishing to leave Vietnam if other countries were prepared to accept them" (Kumin 2008, 112). It gave assurances that for a period of time, "it would make every effort to stop illegal departures" (UNGA 1979). Despite human rights concerns that 'stopping illegal departures' represented an erosion of the right to travel freely and choose 
one's place of residence, the ODP was relatively successful when it came to reducing the number of refugees in Southeast Asia.

Despite the positive impact of the ODP, the consistently high number of refugees is correlated to two issues: formal restrictions on first asylum Vietnamese seekers combined with signs that America was going to restrict its intake from first asylum seekers, and the subsequent ASEAN countries' position to the revised American policy. Firstly, the Thai government announced in August 1981 that "future arrivals would not be resettled into the resettlement stream but would be detained in Thailand for an indefinite period of time in austerity camps" (Kumin 2008, 105). Secondly, the Reagan administration's decision to resettle only new arrivals who had been political prisoners, whose lives were in danger, or had familial ties to the United States (Kumin 2008, 105) in 1982 created concerns among ASEAN countries over the possibility of a residual camp population. This encouraged the reluctance of first asylum countries to permit further resettlement opportunities to new Indochinese refugees and they reinstituted their old policy of boat push-backs. Eventually, the surge of Indochinese arrivals in 1987 and 1988 rendered the old consensus of first country asylum that was followed by permanent resettlement in a third country broken.

\section{Comprehensive Plan of Action}

A decade after the first Geneva Indochinese refugee conference, a second one was held in June 1989. Despite the large numbers resettled by the ODP, there had been no real decline in the number of refugees that remained in temporary camps in Southeast Asia. There was a need to revise existing resettlement strategies that would bring an end to the Indochina refugee crisis. As the former Special Envoy for the UNHCR in Cambodia, Sergio Vieira de Mello argued that there was a need for a "new solutions-oriented consensus involving the cooperations of countries of origin, first asylum and resettlement" (cited in Betts 2006, 32). Therefore, at the second Geneva conference, the Comprehensive Plan of Action for Indochinese Refugees (CPA) was adopted by the 70 governments in attendance.

The CPA was similar to the 1979 ODP in the sense that it sought to preserve rights of first asylum, reducing clandestine departures and resettle refugees in third countries. It was however, different in the sense that it introduced screening and repatriation (UNGA 1989, 15). 
It also depended more on the commitments of the countries of first asylum and origin, as they were now properly included in the programme.

One of the more qualified successes of the CPA was that it restored principles of asylum to Southeast Asian countries. In Thailand, there were generally "no reports of pushbacks after 1989 ... and the rest of the region by and large held to the CPA commitments" (Robinson 2004, 323). Figures for asylum seekers also fell, where in 1989, an estimated number of 70,000 Vietnamese along with 3,300 Laotians sought refuge in Southeast Asian camps but by 1992, it fell to 41 and 10 respectively (Robinson 2004, 323). From this period onwards, the decline in new refugee arrivals was accompanied by an increase in the rate of voluntary returns. Central to the decline in refugee numbers was UNHCR's increase of reintegration grants for returnees, sustaining Vietnam's interest in supporting the voluntary return of refugees and reducing clandestine departures (Betts 2006, 36). The CPA was effective in dealing with the clandestine departures, providing a comprehensive approach to protecting 'genuine' refugees and finding solutions for 'non-genuine' ones (Feller 2001, 133).

However, refugee statistics can only paint a partial picture of how the CPA was operationalised. Courtland Robinson $(2004,323)$ argues that the CPA was designed not so much as to preserve asylum as to obviate the need for it. A key tenet of the CPA emphasised an approach that sought to combat smugglers from transporting refugees (UNGA 1989, 11). In other words, this could be understood as a tacit sanction to stop the flow of refugees while failing to address the root causes of the Indochinese exodus. There were also issues with the individual screening policies of the participating states who were not signatories to the 1951 Refugee Convention. Due to a lack of guidelines for establishing refugee status, states could arbitrarily categorise a refugee as 'genuine' or 'non-genuine' (Davies 2008, 193). Towards the end of the CPA, the level of involuntary repatriations increased as funding and support for the programme declined. On 30 June 1996, the UNHCR ceased funding for the Vietnamese boat people in Southeast Asia. Involuntary repatriations in countries such as Thailand increased immediately, deporting 2,000 refugees back to their countries of origin (Robinson 1998, 221).

This section has focused on addressing the origins of the refugee crisis in Indochina. It has also provided an overview of policies that were implemented to stem the flow of refugees. Overall, the ODP and CPA achieved their overarching goal of resettlement and reducing the number of refugees. Such successes were varied in terms of impact and in fact, the only consistency in Southeast Asia was that "each country did things differently, some better than 
others and none perfectly" (Robinson 1998, 202). Having established the context in which the Indochinese refugee crisis occurred, subsequent sections will look at the responses of Thailand and Malaysia and assess which factors contributed to attitudes that ensured that refugee protection remained low.

\section{Responses to the Indochinese Refugee Crisis}

\section{Malaysia}

The widespread dislocation of individuals after the installation of communist regimes in Vietnam, Cambodia and Laos created one of the largest refugee movements that tested the world's capacity to deal with asylum seekers. Unlike the Cambodian and Laotian refugees who sought to escape overland into Thailand, large numbers of Vietnamese asylum seekers arrived in Malaysia by boat. Before 1975, Malaysia "maintained a creditable record of generosity, granting temporary asylum to more than 250,000 Vietnamese" (Robinson 2004, 322). Most of the refugees were settled on the east coast of Peninsular Malaysia. This was due to the Malaysian east coast being in the direct path of boats departing Vietnam.

With the east coast offering an attractive destination for Vietnamese refugees, the number of boat arrivals increased. The numbers picked up greatly in 1978, where the Hai Long incident was symptomatic of the broader boat arrival trend affecting the region. Faced with the increased number of boat arrivals, overcrowding and socio-political issues became problematic for the Malaysian government. In May 1978, former Malaysian Prime Minister Hussein Onn stated:

"We are very concerned because more and more are coming. They are creating social, political, economic and security problems. We don't know exactly who is coming in, and local people are starting to complain. I can see a situation... when we will have to turn them away" (Frost 1980, 355).

Furthermore, the pace of resettlement efforts were unable to keep up with the number of boat arrivals. In October 1978, only 6,600 out of 20,000 refugees who arrived were accepted for resettlement in third countries (cited in Davies 2008, 96).

Despite the relocation of the Vietnamese refugees to the islands off the east coast, boat arrivals continued en-masse. By July 1979, it is estimated that some 120,000 refugees reached the east coast of Malaysia (Osborne 1980, 48). Not long after, the Malaysian authorities 
adopted a harder stance towards boat arrivals and began a 'shoo-off' policy where boats would be turned back. Deputy Prime Minister at that time, Dr Mahathir bin Mohammad announced that "refugees in Malaysia would be expelled and those seeking to enter in the future would be shot if they ignored warnings to go away" (Osborne 1980, 49). In an attempt to defuse the tension, Hussein Onn denied that refugees would be shot but said Malaysia would turn away boats attempting to land refugees (Osborne 1980, 49). This led to the convening of the first 1979 Geneva Convention and the implementation of the ODP in an attempt to restore the principle of first asylum.

As noted in the previous section, the ODP failed due to tightening resettlement criteria imposed by Western countries. By 1989, the refugee caseload had "climbed past 20,000 for the first time in ten years" (Robinson 2004, 322). Thus, the Second Geneva Conference was convened in 1989, with former Malaysian Foreign Minister Abu Hassan Omar as the chair. At this conference, he sought to guarantee temporary refuge for asylum seekers (Helton 1990, 111). The CPA was developed as an alternative to the ODP, where a cut-off date was to be established at the discretion of the first asylum countries for third country resettlement.

As long as refugees arrived before the Malaysian cut-off date of 14 March, 1989, they would be considered as prima-facie refugees and granted third country resettlement. However, this was accompanied by a policy of boat pushbacks. Two US-based refugee lobby groups Refugees International and the US Committee for Refugees and Inmmigrants- claimed Malaysia had pushed off more than 5,600 boat people between May 1989 and March 1990 (Azam and Vatikiotis 1990, 18). Malaysia has denied that what they did amounted to boat pushbacks. Of this, Suahaini Azam and Michael Vatikiotis (1990, 18) notes:

"The issue is fraught with semantics as there is no hard and fast definition of first asylum as stipulating shelter until screening and resettlement or repatriation takes place. Malaysia appears to have taken the shortest interpretation - a brief stay for fuel and provisions before heading off elsewhere".

The revision of Malaysia's position over the policy of first asylum resulted not only in deaths at sea but more importantly, directed the flow of refugee boats to Indonesia. Prior to Malaysia's redirection policy, Indonesia was not a major destination for Indochina refugees. After June 1989, over 218 boats carrying over 10,000 Vietnamese refugees were redirected by the Malaysian authorities (Helton 1991a, 1204). In the end, the Vietnamese refugees stopped coming due to the pushbacks and sought sanctuary in Thailand and Indonesia instead. 


\section{Thailand}

Surrounded by Cambodia, Laos and Vietnam in cross proximity, the effects of the Indochina conflict were felt most acutely in Thailand. Refugees who entered Thailand came either from Cambodia or Laos. At the beginning of 1977, the refugee population in Thailand increased from 25,000 to 113,300 in June 1978 (Davies 2006, 13). Since 1975, the UNHCR had been able to resettle only "63,300 asylum seekers from Thailand to third countries" (Davies 2006, 13). This influenced Thailand's reluctance towards hosting more refugees, where:

"While it is easy to suggest all displaced persons be permitted to resettle in Thailand, even if funding were on hand, political and national security matters coupled with the shortage of arable land makes it impossible for us to consider this alternative" (Robinson 1998, 25).

Given that the rate of resettlement outpacing the rate of refugee arrivals mirrored Malaysia's situation, Thailand considered that it had no choice but to implement policies to restrict the number of refugees arriving into the country.

The matter of Cambodian asylum seekers figured prominently in Thailand's response to refugee protection. As conflict between Cambodia and Vietnam escalated into a full scale war, the number of Cambodian refugees increased. The Cambodian policy of relocating Chinese Cambodians was similar to Vietnam's NEZ policy, and resulted in an increase of refugees fleeing to the Thai border (Agence France-Presse 1979). The increase in the number of Cambodian refugees influenced Thailand's decision to forcibly repatriate 42,000 of them back into Cambodia in June 1979 (cited in Davies 2008, 105). Due to international criticism of Thailand's policies, Prime Minister General Kriangsak reversed his earlier position on repatriating refugees in 1979. In October 1979, Cambodian refugees were allowed to remain in Thailand in "holding centres set up under the general control of the Thai Military Supreme Command but administered by UNHCR" (Osborne 1981, 11).

The decision to re-admit Cambodian refugees in late 1979 saw a dramatic increase to their numbers. In January 1980, more than 150,000 Cambodians entered Thailand in search of sanctuary (Osborne 1981, 13). These arrivals were placed in three temporary camps in Sa Kaeo, Kamput and Surin before being moved to a refugee centre at Mairut, capable of holding 300,000 people (Robinson 1998, 69). Eventually, a new camp, Khao I Dang was built in November 1979 and became the biggest Cambodian refugee camp. The huge surge in the number of refugees into Cambodia provoked an almost immediate response from the Thai 
authorities - the open policy was cancelled on 24 January 1980 and preparations were made to repatriate them five months later in June.

In stemming the flow of Vietnamese and Laotian arrivals, Thailand instituted 'humane deterrence' policies by reducing camp services to basic levels and halted resettlement interviews for new arrivals. As the rate of Laotian arrivals fell, the Thai government continued to implement other forms of refugee influx control by pushbacks and border screening. For example, in 1987, Thai officials "removed 38 Hmong from Ban Vinai and, charging them with illegal entry, turned them over to the Laotian authorities" (Robinson 1998, 119). It was reported to be the first forced repatriation from a UNHCR-supported camp in Thailand. The influx of Vietnamese boat refugees into Thailand also reached a record high in November 1987, with almost 6,000 new arrivals. It was said that these refugees came via a "sophisticated smuggling network through Cambodia by land and then on a short boat trip to the coast of Trat" (Brown 1988, 38). In response, Thai authorities turned back boats who attempted to enter Thai waters from Cambodia. As for Vietnamese who were already "ashore, but not yet in a refugee camp...determined to have come to Thailand via a short trip from Cambodia would be heretofore treated as 'land Vietnamese' and sent to the Site Two displaced persons camp" (Brown 1988, 38). The deaths arising from boat pushbacks and the lack of genuine first asylum opportunities in Thailand was another contributing factor to the development of a Comprehensive Plan of Action in June 1989.

\section{Factors Affecting Attitudes Towards Refugee Protection}

This section intends to examine which factors were most influential in affecting refugee protection attitudes in Southeast Asia during the Indochina refugee crisis. This study analyses the factors that influence the varied conditions of refugee protection across the two countries used in the study of the Indochina refugee crisis. This section consists of five separate but related analyses. At the international level, this chapter examines the level of geopolitical influence and refugee aid commitment that affected the degree of refugee rights protection among the two selected Southeast Asian states. At the regional level, a study is conducted to analyse how regional dynamics in Southeast Asia shaped Thailand and Malaysia's attitudes towards refugee protection. At the domestic level, the analytical focus is put on the conditions that affect the actual level of refugee rights protection in Thailand and Malaysia. This section will also seek to analyse the legal aspects of refugee protection and its impact on regulating attitudes towards refugee protection in Thailand and Malaysia. 


\section{Domestic Socio-Political Issues}

The Indochinese refugees posed a variety of challenges to Thailand and Malaysia. The refugee influx imposed severed economic and political burdens upon these states and challenged their capacity to respond in an effective and humanitarian way. Due to reasons such as economic costs, an upsetting of the delicate ethnic balances and political reasons, these countries have been at best reticent, and often unwilling to provide asylum to the Indochinese refugees. Therefore, a comprehensive understanding of the implications of the refugee movement for these Southeast Asian nations emerges from a study of their socio-political circumstances.

Attitudes towards refugee protection were often subjected to socio-economic considerations in Thailand. Amara Raksasataya $(1974,24)$ claims that as early as 1974 , Thailand was not well suited for immigration due to limited resources, heavy reliance on foreign aid for economic development and overpopulation. Similarly, Peter Tripp $(1979,253)$ notes that the local populations of many regions where refugees arrived in huge numbers were already living in impoverished conditions, suffering from frequent food shortages even before the refugees came. The presence of the refugees also led to black marketeering, price rises and corruption that caused the local populace to resent them and also accuse the Thai government for not doing more to help its citizens.

Similarly, the economic argument was also used in Malaysia. The provision of aid to Vietnamese refugees created the perception that the Malaysian government was doing more to help the refugees than its own people who were poor. It is worth reiterating the point that the boat arrivals settled off the east coast of Peninsular Malaysia, which was generally an underdeveloped and impoverished region. The influx of refugees were also seen as threats to public health, a contributing factor to price rises in basic food and necessities while reports of them bribing Malaysian officials created much discontent (Frost 1980, 355). This placed additional pressure on the government to take a firmer stand on the boat arrivals.

In assessing the motivations of the Thai decision to deny protection to the Cambodian refugees, the social composition of the refugee camps helps shed light on their attitudes towards refugee protection. The previous section outlined Thailand's decision to reopen and subsequently close the borders to fleeing Cambodian refugees in 1979. Many of the refugees in the border camps were believed to be Pol Pot's soldiers, and in comparison to the pre-1975 bourgeois who had a genuine desire to be resettled in a third country, many of them were 
believed to express a desire to return to Cambodia to fight against the Vietnamese. For example, in Sa Kaeo, it was estimated that "upwards of two-thirds of the 25,000 Cambodians were either Khmer Rouge soldiers or their supporters" (Osborne 1981, 14). Milton Osborne's study of the Thai-Cambodia refugee conundrum showed that Thailand's status as a host country for substantial numbers of Cambodian refugees was ultimately undesirable (Osborne 1981, 16). On another note, Keith St Cartmail's $(1983,208)$ interview with a local businessman exposed concerns over how the refugee influx impact on the ethnic makeup of Thai society could result in a violent response with xenophobic and retaliatory overtones. Therefore, the issue of ethnicity not only informed Thailand's attitudes towards refugee protection in terms of maintaining social cohesion, but was also expressed through national security concerns as well.

Issues of ethnicity were also of major concern to the Malaysian government. The number of boat arrivals were also interpreted as threats to national security in addition to the upsetting of the racial balance in a Malay-dominated nation. First, the Vietnamese boat arrivals were characterised as an invasion force from Communist Vietnam. For example, the New Straits Times, a pro-govt Malaysian daily newspaper commented: "The crux of the issue is that the flow from Vietnam is no longer a humanitarian problem. It has become as much a weapon of war as a softening-up raid by waves of bombers" (Wain 1979, 168). Second, the high percentage of ethnic Chinese (mostly non-Muslims) from Vietnam had the effect of upsetting the delicate internal ethnic balance between Malays and Chinese. As the former Prime Minister of Singapore, Lee Kuan Yew $(1979,6)$ said:

"The more pressures are placed on these countries, the more the balance is upset and the more anti-Chinese and anti-China they become".

In response, locals resorted to turning boats away on their own and harassed refugee camps (Rachagan 1987, 261). These circumstances propelled the government to relocate the refugees to Pulau Bidong and Pulau Besar, in an attempt to alleviate the tensions created by the refugees by placing them in isolated areas.

Therefore, socio-political explanations such as the economic burden of hosting refugees; the arrival of the Indochinese refugees couched as a national security threat and ethnic disturbances characterised Thailand and Malaysia attitudes towards refugee protection during the Indochina refugee crisis. Issues of ethnicity and race figured importantly in both countries' attitudes towards refugee protection. In addition, the presence of refugees in Thailand and Malaysia also created economic tensions between them and the local population. Together, 
these two factors informed how Thailand and Malaysia developed their approaches to refugee protection during the Indochinese refugee crisis.

\section{Legal Aspects of Refugee Protection and its Impact on the Indochinese Refugees}

Given the fact that most Southeast Asian states were not signatories to international refugee law, the non-existent levels of treaty ratification arguably resulted in lower levels of refugee protection in Southeast Asia. During the Indochinese refugee crisis, only the Philippines became a signatory to the Refugee Convention in 1981 (UNHCR, n.d.a.). As the introductory chapter of this thesis has outlined, reasons for non-accession to international refugee law were due to the Eurocentric nature of the 1951 Convention and the associated economic costs with ratifying it. However, this section will argue that a non-ratification of international law does not necessarily result in poorer refugee protection attitudes. Rather, Southeast Asian nations' inconsistent attitudes towards refugee protection through the medium of international refugee law had more to do with securing their own interests, creating a range of responses that eroded levels of protection for the Indochinese refugees. In return, this raises questions over the influence of international refugee law over Thailand and Malaysia's attitudes towards refugee protection.

Before we can examine how a lack of treaty participation legitimises the non-protection of refugees, some attention needs to be paid to the reasons surrounding Southeast Asian states' reservations over international refugee law. Firstly, the 1951 Convention was often criticised as being Eurocentric. Even the UNHCR had to admit that African and Asian experiences were quite different from the European experiences that shaped the 1951 Convention (Davies 2006, 5). When international refugee law was being drawn in 1951 and 1967, African and Asian involvement in the drafting of refugee legal instruments was limited, since most of the countries were dealing with processes of decolonisation. This meant that the Convention and its Protocol remained insensitive to the context-specific demands of refugee crises in Southeast Asia.

The high economic costs of treaty accession and perceived threats to social cohesion informed many Southeast Asian states' attitudes to the 1951 Refugee Convention. For example, countries such as the Philippines and Laos refused to sign either instrument because of the financial commitment that would be damaging to their development (cited in Davies 2006, 56). Another example would be Singapore and Malaysia's claim to being unaware of the 
Convention and its Protocol, and upon being informed of their content, expressed concern that "signing onto such instruments would impede these states' ability to address specific national problems such as racial balance and unemployment" (Davies 2006, 6).

These arguments demonstrate an emerging consensus among Southeast Asian states that international refugee law was flawed. First, the Eurocentric nature of the 1951 Convention and its 1967 Protocol was not a good fit for the socio-political realities of Southeast Asia. Second, the financial burden for developing states was too much and encouraged them to remain ignorant of the Convention's provisions. Third, a ratification of the Refugee Convention would require them to open their borders to refugees of different ethnicities, undermining their attempts at nation building. Therefore, these sentiments encouraged increasing levels of resistance to refugee protection among Southeast Asian nations.

Despite the perceived issues with the Refugee Convention, Southeast Asian countries did not completely reject the application of international refugee law. Countries such as Thailand and Malaysia did engage with international refugee law, but on its own terms. At the end of the Second Indochinese War in 1975, UNHCR sought an agreement with Southeast Asian states for provisions to provide temporary assistance to the people fleeing conflict. Broadly speaking, the agreement is outlined as follows:

"The High Commissioner and the Government (of Thailand) have agreed to collaborate in a program for the purpose of providing humanitarian aid to Displaced Persons from Cambodia, Laos and South Vietnam...(T)he two parties have also agreed to collaborate in seeking durable solutions, including in particular voluntary repatriation and resettlement in other countries" (cited in Robinson 1998, 20).

In this agreement, all references to refugees were omitted. The omission of the term 'refugee' enabled Thailand to adopt a laissez faire approach in determining who was a refugee and also heavily emphasised the focus towards on refugee resettlement in third countries. Such agreements would characterise many Southeast Asian nations' attitudes towards asylum seekers during the Indochinese refugee crisis. Countries such as Indonesia and the Philippines agreed with Thailand's insistence on international assistance in the form of financial aid and resettling refugees to third countries in return for guaranteeing temporary asylum (cited in Davies 2006, 13).

By entering into agreements for refugee protection with UNHCR, attitudes towards refugee protection in Southeast Asia can be broadly characterised as positive at this stage. However, such attitudes worsened as the number of refugees showed no signs of abating. 
Countries such as Thailand and Malaysia responded with boat pushbacks, forced repatriation and responding with force to new refugee arrivals. For example, Thailand reversed its open door policy to Cambodian refugees and started repatriating them back to Cambodia. In fact, UNHCR was often unable to track the population that was forcibly repatriated back to Cambodia, and that the majority was now under the control of Vietnamese forces and their status unknown (Unger 2003, 25). It was also reported that the Thai military also opened fire on asylum seekers when they refused to cross areas known to be strewn with mines (Robinson 1998, 476). Subsequently, this led to the foreign ministers of ASEAN issuing a joint communique which stated that all new arrivals were to be denied entry into their countries, while maintaining the right to return all refuges to their countries of origins unless they were resettled within a "reasonable time" (cited in Davies 2006, 19).

At the 1979 UN Meeting on Refugees and Displaced Persons, UN Secretary-General Waldheim stressed that:

"it was essential that the rest of the world should act in a decisive way to ease this tremendous burden imposed upon (Southeast Asian) countries and if the rest of the world did this it would enable those States to adhere to the principle of first asylum and to contribute within the limit of their possibilities to an overall action that would lead to desirable solutions for the refugees" (cited in Davies 2006, 19).

The conference was a success, as it resulted in Western nations pledging 260,000 resettlement places and US $\$ 160$ million in financial aid (McConnachie 2014, 48). After the meeting, Thailand and Malaysia's attitudes towards refugee protection was reversed and the practice of first asylum continued.

Although the non-signatory status of most Southeast Asian states meant that they were not accountable for any violations of the Refugee Convention, their poor behaviour often put them in violation of general international law as well. According to Article 33(1) of the 1951 UN Convention Relating to the Status of Refugees, the principle of non-refoulement states that: "No Contracting State shall expel or return ('refouler') a refugee in any manner whatsoever to the frontiers of territories where his life or freedom would be threatened" (UN Refugee Convention 1951). Arthur C. Helton (1991a, 1205) offers a legalist argument that nonrefoulement is generally thought to have "crystallised as a peremptory norm of customary international law, jus cogens, binding on all states irrespective of accession to treaty regime". He then argues that even if non-refoulement was to be disregarded as a principle of general customary law, it could at the very least qualify as a principle of regional customary 
international law (Helton 1991a, 1205). Such international laws were legally binding on these countries as the regional CPA adopted by Southeast Asian countries incorporated many of the procedural norms found in the 1951 Convention and its Protocol. Therefore, the question of whether accession to international refugee treaties guarantees higher levels of refugee protection again becomes irrelevant here. Levels of refugee protection are not determined by whether a state is signatory to the Convention and its Protocol because when non-refoulement is expressed as a principle of general international law, Thailand and Malaysia's practice of repatriation and boat pushbacks demonstrates the continued violation of this legal norm. In this context, the question of whether ratification status would have a more positive impact on refugee protection attitudes becomes irrelevant.

A key point of contention on how non-signatory states refuse to ratify the Refugee Convention revolves around the argument about how most states of first asylum lack the bureaucratic infrastructure to deal with refugees in the manner prescribed by the Convention (Chatelard 2006, 9). The refugee status determination (RSD) process under the CPA illustrates how the non-accession to the Refugee Convention often resulted in lower levels of refugee protection. Not being signatories to the 1951 Convention and 1967 Protocol meant that national authorities in Thailand and Malaysia lacked the know-how in introducing refugee protection legislation and conduct refugee status determination. The CPA's provision for determining refugee status was based largely on Western legal principles that were to be transplanted onto the respective legal systems of Southeast nations, with no analogous provisions (Helton 1991b, 263). As Richard Towle $(2006,549)$ notes in an interview with Erika Feller:

"It should be remembered that most officials had virtually no experience with RSD prior to the start of the CPA... There were regional differences: Indonesia and the Philippines felt that it was better to screen in and get people resettled. Malaysia was fairly balanced. Thailand was fairly tough".

It is not surprising that differing approaches to the screening process resulted in varying rates of refugee recognition. At the national level, rates varied between "Indonesia (43.3 percent), Malaysia (39 percent) and Thailand (22.5 percent)" (Towle 2006, 549). Such results would suggest that a non-accession to international refugee law can create diverging approaches to refugee protection due to a lack of understanding on how refugees should be processed.

A closer examination of Thailand and Malaysia's screening process reveals inconsistencies and an ad-hoc approach that failed to conform to the legal principles set out by the CPA. For example, the Thai Ministry of the Interior often did not allow UNHCR officials 
to be present at the main interviews with asylum seekers (Davies 2008, 203). This contravened UNHCR policy that its officials had to be present at such interviews (cited in Davies 2008, 203). In these two countries, an applicant denied refugee status was often given cursory reasons (Helton 1993, 548). Malaysia fared better when it came to screening, as it allowed the UNHCR to be present for all interviews with asylum seekers and also followed the screening procedures outlined in the CPA agreement (Davies 2008, 205). However, it must be noted that the Malaysian government's policy of implementing boat pushbacks in 1989 put it in violation of the CPA's non-refoulement policy, breaching the condition of providing first asylum. The implementation of refugee status determination in these countries thus indicates significant discrepancies in refugee protection. Thailand and Malaysia's approach to refugee protection demonstrates a reluctance to conform to internationally defined legal obligations and the selective engagement with international law created inconsistent results in refugee protection.

In analysing what influenced the change in refugee protection attitudes, a few issues come to mind. First, the notion that a non-ratification of the Refugee Convention results in poor attitudes towards refugee protection is not entirely valid. Thailand and Malaysia already had existing agreements with UNHCR to process the Indochinese refugees as first asylum countries. At the very least, it indicates an engagement with the 1951 Refugee Convention, notably through the offering of first asylum to refugees. Second, attitudes towards refugee protection turned poor when Thailand and Malaysia forcibly expelled refugees from their territory. Understanding that their attitudes changed with the international community's promise of aid, the main factor that shaped Southeast Asian countries' attitudes towards refugee protection can be arguably attributed to the promise of international refugee aid. The behaviour of Thailand and Malaysia also illustrates the paradox of refugee aid, where poor refugee protection practices had the contradictory effect of improving refugee protection behaviour after the promise of aid. International aid was desperately needed because of their socioeconomic circumstances.

Therefore, the explanation of whether a ratification of the Refugee Convention results in more positive/negative attitudes towards refugee protection becomes less pronounced. Rather, the legal elements of international refugee law were manipulated through Southeast Asia nations' selective engagement with them, resulting in refugee protection attitudes that may vary over time and context. Any argument that the ratification of international refugee law could have positively impacted upon refugee protection attitude became irrelevant through Thailand and Malaysia's selective engagement with the Refugee Convention and its associated 
international laws. At best, the lack of treaty ratification would only affect the operationalisation of refugee protection, as demonstrated the different results achieved in the RSD.

\section{Conceptualisation of the Refugee}

The problem of what is a refugee is a vexing question, since the framing of the term often affects the kind of solutions implemented. The Indochinese refugees created heavy burdens on Southeast Asian states' ability to grant them temporary asylum within their borders. In order to restrict refugee flows, a common strategy involved manipulating the definition of 'refugee' in justifying their policies of forced repatriation and boat pushbacks. Therefore the labelling of the Indochinese refugees influenced refugee protection attitudes in Thailand and Malaysia during the Indochina refugee crisis.

In Thailand's move to forcibly repatriate half of the more than 80,000 new Cambodian arrivals in 1979, these refugees were termed as 'illegal immigrants' (Wain 1979, 163). Subsequently, Neptnapis Nakavachara and John Rogge (1987, 279) have observed that Thailand's treatment of refugees approximated definitions of de facto and de jure (officially sanctioned) illegal immigrants by the transformation of refugee camps into prison-like holding centres.

In Malaysia, the question of who is a refugee is often determined by how these refugees escaped from their countries. Malaysia felt that for refugees to escape by boat in such large numbers, such departures must have been officially sanctioned and organised, leading to their classification as 'illegal immigrants' (Ahmad 1979, 67). Furthermore, the Vietnamese boat arrivals in Malaysia were predominantly ethnic Chinese and were generally middle class and well to do. The general definition of a 'refugee' did not generally apply to them. On the other hand, Cambodian Muslim refugees arriving in Malaysia by boat were generally accepted, given that they made the correct choice on their part in that they selected a Muslim country which made assimilation easier for them (Ahmad 1979, 68).

Additionally, the Indochinese refugees were also labelled as 'economic migrants', as Thailand and Malaysia hoped to dissuade new boat arrivals since the general response to such migrants would be repatriation (McGurn 1988, 1). As such, an analysis of who is an 'economic migrant' cannot be divorced from an association with political refugees since they often go hand in hand during this period. 
Alternative categorisations of the refugee during the Indochina refugee crisis were employed by both Thailand and Malaysia. Through the use of labels such as illegal immigrants and economic migrants, they were able to justify heavy handed attitudes towards refugee protection. In addition to allowing states leeway in determining who was to be refused first asylum privileges, the process of categorisation also affected the operationalisation of the CPA during the screening process, excluding many refugees from consideration. Therefore, the way in which refugees were viewed contributed to poor refugee protection attitudes during the Indochina refugee crisis.

\section{Regional Dynamics in Southeast Asia}

In refugee crises of any scale, a transnational response to the need for humanitarian assistance is often required. The magnitude of the Indochinese refugee crisis, and the resulting flow of asylum seekers filtering into countries across Southeast Asia, often created a variety of responses in line with the specific interests of the nations involved. Attitudes toward refugee protection was often influenced by competing regional interests. Under a climate of strategic considerations, the principle of non-interference actually shaped the level of refugee protection given to those fleeing conflict in Indochina.

The strategic relationship between Thailand and Vietnam is complex, raising many issues related to the encroaching influence of communism in Indochina. This relationship was further placed under strain when Vietnam invaded Cambodia in 1979. The consensus of noninterference is not one that is easily set in stone, as this section will show how multiple attempts at interfering in other countries' affairs created conditions that were hostile to refugees. The need for intervention was driven by the possibility of communism spreading into their territory. Jones argues that patterns of non-interference were guided by the 'domino theory' that, "if one society fell to communism, this would strategically advantage fellow travellers in neighbouring countries whilst demoralising defenders of the status quo, making communist victory more likely there also" (Jones 2013, 1163). In other words, the principle of non-interference was violated not only to manage stability in the target states of Vietnam and Cambodia, but also shored up domestic resistance to perceived negative influences such as Communism which threatened their national security. During the Vietnam War, Thailand sent military forces to fight the Viet Cong in South Vietnam. Malaysia also transferred surplus military equipment to shore up South Vietnam's defence against the North (Jones 2013, 1163). In 1971, Thailand 
also covertly deployed over 20,000 soldiers masquerading as Laotians while training the Hmong to fight as proxy forces against Pathet Laos (Osornprasop 2012, 167).

During the Indochinese refugee crisis, Thailand increasingly implemented coercive policies against the ethnic Meo, Laotians and Vietnamese seeking to enter Thai territory. The Thai were also suspicious that ten percent of all refugees entering Thailand were agents planted by Hanoi to subvert Thai politics (Wain 1979, 167). Such fears contributed to the production of the perception of a Vietnamese 'fifth column', avenues from which communism could spread and undermine the stability of the state. Sharing similar sentiments on the influx of Vietnamese refugees, Malaysia also had fears of the "Chinese peril" (Lavoie and Knock 1990, 48). The reality of poor refugee protection attitudes during this period reflected the competition between communism and capitalism. In addition, ethnic considerations also dictated how Malaysia implemented its refugee protection policies.

When assessing the motivations of the Thai decision to close the borders and re-engage in the repatriation of Cambodians, the Thai government had misgivings about hosting them. The Thai government believed the refugee influx was "seeded with subversive agents by Hanoi" (Wain 1979, 167). Thailand also feared the presence of clashes between the Vietnamese and Pol Pot's forces near Thailand could destabilise the bordering regions (Frost 1980, 364). This had an important effect on shaping Thailand's attitudes towards refugee protection that was poor at this stage. In response to the repatriations of refugees to the border, the Cambodian Foreign Minister sent a letter to the UN High Commissioner for Refugees, Poul Hartling, terming the move as "an attempt to introduce into Kampuchean territory armed bands of the Pol Pot-Ieng Sary and Sereika clique, supplied and trained in Thailand by the Peking expansionists in collusion with the American imperialists" (Terry 2002, 126). In this manner, Thailand's poor attitudes towards refugee protection was shaped by its manipulation of its refugee border population in an attempt to weaken the Cambodian government.

The fear of subversive elements in Thailand's border refugee camps drove Thailand to interfere in Cambodia. A clear violation of the principle of non-interference can be found in border clashes between Thailand and Cambodia. To counter the Vietnamese threat in Cambodia, the Thais supported the Khmer Rouge with arms, food and jungle equipment (Kramer 1980, 48). This shored up the Khmer Rouge resistance, allowing them to launch attacks in September 1982, on Vietnamese installations and military encampments along the north-western Cambodian border town on Poipet (Van der Kroef 1983, 20). As with previous 
border clashes, artillery and mortar shells often landed in Thai territory. In response the Vietnamese and the People's Republic of Kampuchea (PRK) coalition started to construct 'self-defence villages' in the refugee Thai-Cambodian border zone, in order to counter the Khmer Rouge units in the refugee border population (Van der Kroef 1983, 21). On 22 January, 1983, before the attack on Nong Chan, the Secretary General of Thailand's National Security Council, Prasong Sunsiri said that there were about 60,000 Cambodian people in the country, and any more new arrivals would be kept at the border so they could return home easily (Van der Kroef 1983, 22). However, Thailand's decision to keep the Cambodian refugees was less to do with their ease of mobility but rather, to keep the fighting further from home. As Thailand explained, "having lost Cambodia as a buffer, the best Thailand could do was to sustain the fighting that in itself constituted a border" (Jones 2013, 1165).

It is worth revisiting Thailand and Malaysia's refugee attitudes at this point of time. Thailand and Malaysia's policy of keeping out refugees sought to ward against the influence of communism spreading into their countries. Bangkok has argued that some of them were Hanoi spies while Malaysia has described the influx of refugees as a Communist invasion. Yet, there is more than meets the eye when the "strategic value of the refugees as a buffer along the border and as a source of support for the re-emerging resistance movement" (Jones 2007, 529) was recognised. Thailand's reluctance to classify them as refugees while hosting them in refugee camps is illuminating in this regard. This would significantly alter approaches to refugee norms in three crucial ways.

First, the establishment of refugee border camps provided a base from which support could be mobilised by the Khmer Rouge and other resistance factions. The Thai Task Force 80 was employed to keep civilians captive in these border camps, to which tens of thousands of refugees were forcibly transferred from temporary UNHCR facilities (Jones 2007, 529). The UN Border Relief Organisation reported that by 1987 the guerrillas controlled all of the refugee camps and over 260,000 civilians (Jones 2007, 529). Second, the presence of refugees in the border camps were used to 'shame' Vietnam, as propaganda tools that demonstrated the unpopularity of the PRK. It is argued that the UNHCR camp at Khao I dang was established deliberately to attract refugees across the border to assist in these efforts, only to be closed in 1987 when civilians began fleeing the resistance camps en-masse (Jones 2007, 530). Third, the strategic value of the refugees lay in the fact they could be used as a buffer. 
As Vietnam and Cambodia have been traditionally seen as states being on the receiving end of different forms of intervention used by their neighbours such as Thailand and Malaysia, it is argued that Vietnam sought to manipulate the refugee agenda to interfere in other countries. The Vietnamese position on the refugee exodus was initially quite reticent. At the 1979 Conference for Indochina Refugees, the Australian representative, Immigration Minister J.R. Mackellar declared that Hanoi had been "encouraging the Chinese refugee flow" (Van der Kroef 1979, 4). It is understood that Vietnam's new economic policy was highly discriminatory against the ethnic Hoa. Vietnamese Prime Minster Dong attempted to clarify Vietnam's position on employing refugees as a tool of interference:

"We have on many occasions expressed our regret about this. We are doing our utmost to avoid whatever can create difficulties to other countries in the region" (Frost 1980, $352)$.

To a large extent, the only problem that Vietnam was complicit in generating refugee flows outwards came in the form of its conniving behaviour over the refugees' departure. There have been reports that the Vietnamese government had "established a special department to supervise the would-be refugees' departure, but that payments to senior SRV government officials have been required just to obtain the necessary travel documents to go to a port where a refugee vessel might be waiting" (Van der Kroef 1979, 11). To this end, this does not settle the argument that Vietnam was employing refugees as a tool to undermine the security of her neighbours. At best, it shows Vietnam's overall lack of control and managing the mass outflow of people due to corrupt officials.

While it is important not to over read the tenuous links between Vietnam's forced displacement of refugees as a tool of socio-political subversion against Thailand and Malaysia, such considerations are in no doubt worth understanding. The nature of threat perceptions attitudes towards refugee protection in Southeast Asia. Through the lens of Thailand and Malaysia, the refugee issue became securitised where it was understood as a product of an anticommunist struggle, ethnic incompatibility or at times, a mixture of the two. Ultimately, this made it possible for refugees be understood as a tool of interference, allowing these states to invoke arguments of sovereignty in maintaining a social order that was either anti-communist or ethnically homogenous. Therefore, during the Indochina Refugee Crisis, attitudes towards refugee protection was influenced by the perceived interventionary nature of refugee movement. 


\section{International Influences}

With the involvement of great superpowers such as the Soviet Union and China, the Indochina refugee crisis took on an international dimension which influenced Southeast Asian states' attitudes towards refugee protection. The Soviet Union, Vietnam's political backer showed no inclination in offering restraint to Vietnam's political overtures in Cambodia. China's fractious relationship with Vietnam also indirectly led to higher numbers of Hoa refugees seeking to leave Vietnam. Indirectly, the influence of great powers such as China and the Soviet Union contributed to the protracted nature of the Indochina refugee crisis.

Wary of foreign influences in Southeast Asia, ASEAN established the Zone of Peace, Freedom and Neutrality (ZOFPAN) Declaration ${ }^{2}$. However, Laotian and Vietnamese delegates attacked the ZOFPAN proposal, claiming it was designed to "resuscitate the past by camouflaging an intensifying American war of aggression in Indochina" (Huxley 1987, 198). In April 1978, China's suggestion that ASEAN should join with it in a united front against unnamed big power encroachments in Southeast Asia - aimed against Moscow - was not warmly embraced by Southeast Asian nations (Van der Kroef 1980, 488). The presence of super-power rivalry did not lead to any significant outcomes as evidenced by Southeast Asian states' interest in preserving the key tenets of ZOFPAN. However, this political stalemate sustained Vietnam's impervious attitude to diplomatic pressure over its invasion of Cambodia. The uncertainty created by the impasse between both regional and international states was inevitably counter-productive, especially for the refugees.

On the other hand, international refugee assistance also contributed to more positive attitudes towards refugee protection in Southeast Asia, most notably through the offering of resettlement places. Although, the relative success of the ODP and CPA can be debated, it is not the purpose of this thesis to address the limitations of the international burden sharing programme. Guarantees of international resettlement, fuelled primarily by commitments by the United States, ensured that the system of first asylum remained viable in Southeast Asian countries. For example, the CPA instigated the shift from dangerous and illicit modes of departures to legal migration channels, allowing refugees to take safer routes to asylum. At the

\footnotetext{
${ }^{2}$ ZOFPAN was a declaration to keep Southeast Asia free from any outside interference, and to broaden areas of cooperation. However, Vietnam and Laos saw ASEAN as a US proxy that sought to contain the spread of communism. See ASEAN, "1971 Zone of Peace, Freedom and Neutrality Declaration,” Accessed July 28, 2016. http://www.icnl.org/research/library/files/Transnational/zone.pdf and Tim Huxley, "ASEAN's Prospective Security Role: Moving Beyond the Indochina Fixation,” Contemporary Southeast Asia, 9/3 (1987): 198.
} 
end of the 1979 Geneva Conference, the international community committed to 260,000 plus resettlement places, with the United States, France, Australia and Canada accounting for most of them (Stein 1979, 721). At this point, it is worth recalling how Southeast Asian nations such as Thailand and Malaysia acted in concert to draw international attention to the refugee problem. The refusal to accept any more refugees had the paradoxical effect of increasing the number of resettlement places, and this subsequently influenced Thailand and Malaysia's decision to continue the practice of first asylum.

The most significant development in refugee protection that developed during the Indochinese refugee crisis was how prima facie refugee recognition for the Indochinese refugees led to a situation where non-signatory states of the 1951 Convention and its 1967 Protocol were allowed to dictate who could be given refugee status. The international community and UNHCR were complicit in permitting the transition into a highly arbitrary process of RSD, allowing Southeast Asian nations to adopt unrestrained attitudes towards refugee protection.

As the CPA had made constant references to the 1951 Convention in terms of operationalising refugee protection practices, Helton's analysis of status procedures in Southeast Asia argues that such actions "never embraced screening-in the name of refugee protection but only as a deterrent measure to the Indochinese refugees" (Helton 1993, 556). This facilitated a process where refugees could be expelled according to political considerations. The only way the UNHCR and resettlement states such as the United States had agreed to the repatriation of these people was that they were individually screened (Davies 2008, 213). Therefore, there was little commitment made to ensuring fair outcomes for the Indochinese refugees in a region that was not well acquainted with the 1951 Convention. Rather, the screening was just another process to end the problem of protracted refugee influx, regardless of whether genuine refugees were accepted for resettlement or repatriated. Eventually, this led to the international community accepting forced repatriations in the 1990s. Although the CPA led to more than 507,000 Indochinese refugees being resettled, it also led to a large number of asylum seekers being forcibly repatriated to their home countries (Towle 2006, 545). The failure of the international community to regulate the screening process fairly allowed Southeast Asian countries to adopt refugee protection approaches. These approaches often demonstrated a poor regard for the safety of the Indochinese refugees and political expediency was a major influence on refugee protection attitudes during the Indochinese refugee crisis. 
This section underscores how the refugee crisis became conflated with the political and military campaign between Vietnamese forces and an anti-Vietnamese coalition consisting of Cambodian rebels funded by China and Thailand. Ideological contests played by global superpowers often undermined attempts to seek relief for the protracted refugee situation in Southeast Asia. In addition, while the role of the international community was instrumental in ensuring that the asylum seeking process remained open, political expediencies often informed the process of refugee protection in Southeast Asian countries and influenced poor outcomes for the Indochinese refugees.

\section{Conclusion}

In this chapter, I examined the impacts of a variety of factors on the level of refugee protection attitudes in Southeast Asia during the Indochinese refugee crisis. The results of the findings constitute a complicated portrait.

The generic assumption that the non-ratification of the 1951 Refugee Convention and its Protocol automatically results in lower levels of refugee protection is not evident, as Southeast Asian states demonstrated a selective engagement with international refugee protection norms only when it was aligned with their interests. This suggests that the lack of ratification cannot be argued as an obstacle to refugee protection, where other international legally binding practices are in place, the continued violation of refugee protection practices renders such a perspective irrelevant.

With regard to the other factors such as domestic socio-political factors, conceptualisation of the refugee, international factors and regional norms, the results were not very encouraging in the context of refugee protection in Southeast Asia during the Indochinese refugee crisis. All of these factors are significant but they also varied in terms of their impact. Socio-economic issues and conceptualisation of the refugee often demonstrated a propensity to view the refugee problem through the lens of securitisation, whether as illegal immigrants or 'agents of subversion' that sought to undermine the social fabric of their populations. Regional and international issues factored more strongly in the provision of refugee protection among Thailand and Malaysia. First, possible solutions to the Indochinese refugee crisis were based on the understanding that the system of first asylum was only guaranteed when a commitment to resettling them by the international community was clear. Second, the violation of the principle of non-interference also contributed much to the political impasse and conflict that exacerbated the refugee crisis. Ruling elites in Thailand and Malaysia were less sensitised 
to refugee protection but chose to strategically manoeuvre its control over the refugee situation by interfering in the affairs of Vietnam and Cambodia. This chapter argues that violation of the cherished principle of non-interference and the ability to secure international commitment to refugee settlement were crucial influences on Southeast Asian states' attitudes towards refugee protection. Despite the varied nature of influences on refugee protection attitudes, the only consistency was to be found in the levels of insecurity faced by the Indochinese refugees. 


\section{Chapter 3: The Rohingya Refugee Crisis}

The process of determining attitudes towards refugee protection has remained largely unchanged since the Indochina refugee crisis. Domestic sentiment, international opinion, strength of international legal norms and geopolitical considerations continue to serve as indicators of whether a refugee protection regime will succeed or fail. As Leon Gordenker explains, the possibility of any refugee protection framework owes its existence to the political will of governments to act and also cooperate with each other (Gordenker 1987, 11). The higher the degree of positive attitudes towards refugee protection in each state are, the more likely states will participate in the refugee protection regime. The more positive the attitude of regional countries towards cooperation in humanitarian crises, the more effective humanitarian efforts will operate.

This chapter seeks to examine the level of refugee protection with the Rohingya as a case study. The chapter is organised as follows. The first section begins by providing a historical and contemporary overview of the Rohingya refugees from the $19^{\text {th }}$ century to 2017 .

The second section makes a short review of Thailand and Malaysia's response to the flight of the Rohingya for the last 26 years. Attention is paid to official government responses and subsequent refugee policies developed to deal with the influx of Rohingya refugees. The review shows that both countries examined demonstrated similarly inconsistent attempts at refugee protection.

Section three will examine the attitudes towards refugee protection as five separate but related issues. Domestic factors such as socio-economic explanations; regional political factors; influence of international refugee law; conceptualisation of the refugee and the international response to the Rohingya refugee crisis will be analysed in depth to provide insight as to why refugee protection levels in the two selected countries have remained low.

The overall picture, as concluded in the final section, is mixed and complex. The region appears to have differing levels of policy approaches and attitudes towards refugee protection. The levels of refugee protection continue to remain low not just because of the non-ratification of the 1951 Refugee Convention and its Protocol, but also because of domestic socio-economic explanations. The increasing tendency to securitise the refugee issue through the Bali Process has also created additional obstacles to refugee protection. 


\section{Origins and Background of the Rohingya Refugees in Southeast Asia}

The history of the Rohingya in Myanmar is in itself a controversial topic. The United Nations has often described the Rohingya as the most persecuted ethnic minority in the world. The term 'Rohingya' commonly refers to Muslims from Northern Rakhine (formerly Arakan) who speak a language closer to Bengali spoken in Bangladesh's Chittagonian district. In the $17^{\text {th }}$ Century, Arakan was an independent kingdom that forced tens of thousands of Bengali Muslims to settle in Arakan through incursions into Bengali territory (The Economist 2015). Later, the Arakan kingdom was conquered by the Burmese. At this time, there was little tension between the Muslims and the Arakanese (The Economist 2015). However, this would change with the British conquest of Arakan.

During the British Raj, the Rakhine region was managed from Chittagong and this allowed the Rohingya to move freely between these two regions. However, it also facilitated the influx of Bengali Muslims into Arakan for work. They were seen as a threat to the Arakanese, taking away their jobs and land (The Economist 2015). Furthermore, the Bengali Muslims were armed by the British to fight against the Japanese, who had the backing of the mainly Buddhist Arakanese (The Economist 2015). This would set the tone for an acrimonious relationship between the Rohingya and the Rakhine in the future. After Myanmar's independence from the British in 1948, the Myanmar government identified the Rohingya as Bangladeshis, labelling them as 'illegal migrants' and forced them out on several occasions (Human Rights Watch 2000a). Given that they had a long-standing association with Arakan, Bangladesh also did not consider them to be Bangladeshis. As a result, the Rohingya found themselves stateless.

The level of persecution of the Rohingya gradually increased over time, where the Myanmar government intensified its efforts to strip the Rohingya of all basic citizenship rights through legislation. In 1974, the Myanmar Emergency Immigration Act was signed into law. All citizens were required to carry National Registration Certificates (NRC), but the Rohingya were forced to carry Foreign Registration Cards, having earlier held NRCs (Human Rights Watch 1996). A revision to the 1982 Myanmar Citizenship Law excluded the Rohingya from the list of national ethnic groups. ${ }^{3}$ Although the law allows foreigners to become naturalised citizens, they must either "have one parent who already holds Myanmar citizenship or they must provide conclusive evidence that they or their parents entered and resided in Myanmar

\footnotetext{
3 The eight primary races in Myanmar are Arakanese, Burman, Chin, Kachin, Karen, Karenni, Mon and Shan
} 
prior to independence in 1948" (Kingston 2015, 1168). Of particular interest found in the 1982 Citizenship Law is the requirement to speak one of the national languages (Kingston 2015, 1168). This has two implications for the Rohingya's citizenship prospects. First, the exclusion of the Rohingya as an ethnicity from national census meant that Rohingya (language) was not recognised. Second, the requirement for ancestral evidence made the process of acquiring citizenship harder for the Rohingya, given their earlier history of moving between Arakan and Bangladesh. Therefore, the Rohingya were discriminated and excluded by the Myanmar government's move to introduce legislation that legimitised their current 'stateless' status.

In addition to discrimination that came in the form of restrictive nationality laws, the Rohingya were also subjected to physical violence that contributed to the refugee exodus that continues till today. In 1984, 'Operation King Dragon' was put into force, “taking action against foreigners who have filtered into the country illegally" (Smith 1999, 37). The operation was marked by reports that local army units were attacking the Rohingya. Seven years later, Myanmar military forces commenced a campaign called Pyi Thaya (Operation Clean and Beautiful Nation), seeking to contain the civil unrest that arose from the military junta's rejection of Aung San Suu Kyi's win in the national election. Aware of the anti-Muslim sentiments among Rakhine Buddhists, the military junta leveraged the ill feelings created from the election and directed violence against the Rohingya (Linter 1991).

In recent years, the June 2012 clashes between Buddhists and Muslims in Rakhine created a new wave of Rohingya refugees fleeing to neighbouring countries. It began with the rape and murder of a Rakhine woman on 28 May. This was followed by the retaliatory killing of 10 Muslims by the Rakhine people on 3 June (Kipgen 2014, 236). While the government stated that it "exercised maximum restraint in order to restore law and order" (Petty 2012), Myanmar military forces tasked to re-establish order have been accused of ignoring atrocities, committing acts of rape and ethnic cleansing. Human Rights Watch (2013) has suggested that political and religious leaders "planned, organised and incited attacks against the Rohingya with the intent to drive them from the state or at least relocate them from areas in which they have been sharing with the majority Buddhist population". Some Buddhist monk organisations called for the deportation of all Rohingya and attempted to block the delivery of humanitarian assistance to displacement camps (Global Centre for the Responsibility to Protect 2015, 3).

In response to the events in Rakhine, the former President of Myanmar Thein Sein said in July 2012 that the only solution to the troubles in Rakhine were to send the stateless 
Rohingya to third countries or contain them within United Nations High Commissioner for Refugees (UNHCR) -administered camps (May 2012). Subsequently, the Rakhine Investigation Commission was established to investigate the communal violence. The Commission concluded that the violence was due to mutual distrust and religious differences between the Rohingya Muslims and Rakhine Buddhists (Kipgen 2014, 237). In response to the Commission's findings, the government developed the Rakhine State Action Plan that promised a path towards development and post-conflict reconstruction.

However, the Rakhine State Action Plan continued to refer to the 1982 Citizenship Law as the basis for citizenship assessment. At a speech at the United Nations (UN) General Assembly in 2013, former Myanmar Foreign Affairs Minister Wunna Maung Lwin stated that the population in Rakhine would be divided into three categories: Those previously recorded or registered, the unrecorded who are willing to undergo registration in accordance with Burmese national laws, and those who refuse to be categorised as 'Bengali'; the third category would be denied the right to be considered for citizenship (Human Rights Watch 2014). As Myanmar continues to refer to the Rohingya as Bengalis, Phil Robertson argues that those who agree to be called Bengali are basically admitting to being undocumented immigrants, resulting in the denial of citizenship and deportation (Human Rights Watch 2014). This proposal could reinforce efforts to discriminate against Rohingya by forcing them to repudiate their ethnic identity, and accept being labelled as a Bengali that may not necessarily offer them a better chance of securing citizenship.

The attempt to pacify violence in the July 2012 riots had limited impact and sporadic incidents of anti-Rohingya violence continued to occur. On 13 January, 2014, "Buddhist mobs attacked and killed at least 40 Rohingya in Du Chee Yar Tan village" (Global Centre for the Responsibility to Protect 2015,3). The government's human rights commission called the news "unverifiable and unconfirmed" (Perlez 2014). As recently as November 2016, two Myanmar soldiers were killed by Rohingya, leading the Myanmar military to retaliate with helicopter attacks (Perlez and Moe 2016). The violent situation show no signs of letting up, as the level of government persecution increases due to the protracted nature of conflict in Myanmar, the Rohingya will continue to leave Myanmar for sanctuary in other countries.

At the time of current writing, Myanmar has not ratified the 1951 Refugee Convention and its 1967 Protocol. Myanmar's current position on the Rohingya refugees has remained unchanged from a position articulated decades ago: 
“The 'refugees' are in fact illegal immigrants or fugitives from law. The so-called refugees, it is contended, are Bangladesh nationals, who had illegally settled along the border inside Burma. According to the official Burma News Agency (NAB) the Bengalis' had fled because they lacked proper entry registration papers and also because of instigation by "unscrupulous persons"' (Anand 1978, 1101).

Myanmar's position on the status of the Rohingya as refugees continues to inform their approach in denying them citizenship. The attempt to characterise the Rohingya as Bengalis also indicates the Myanmar position on how the Rohingya are not their responsibility. Former Myanmar Foreign Minister Wunna Maung Lwin also completely rejects the claim that the maltreatment of the Rohingya in Myanmar is the leading cause of the crisis (Hookaway 2015). His successor, Aung San Suu Kyi remains extremely reticent about on the Rohingya issue, torn between the need to maintain legitimacy with the Rakhine Buddhist majority and the pressing need to deliver a humanitarian solution to the Rohingya. Against this background, it is plausible that the Rohingya refugee situation will continue for some time.

\section{Refugee Movement During the Rohingya Refugee Crisis}

Amidst the hostile and discriminatory climate in Myanmar, many Rohingya were forced to flee to Bangladesh; others fled to Thailand, Malaysia, India, Pakistan and the Middle East (Chimni 1998, 362). The first notable wave was in 1978, where approximately 250,000 Rohingya fled during 'Operation King Dragon' to neighbouring Bangladesh (Banglapedia 2015). Initially, the Rohingya were accepted by the Bangladeshi government. However, as the numbers grew, Bangladesh decided they could not host the Rohingya refugees indefinitely and appealed to the United Nations for assistance (Rahman 2010, 234). Towards the end of 1979, more than 180,000 Rohingya were repatriated to Myanmar through a bilateral agreement signed by Bangladesh and Myanmar (UNHCR 2000, 75). During 'Operation Pyi Thaya', similar numbers of Rohingya again sought refuge in southern Bangladesh, primarily around Teknaf and Cox's Bazaar (Blitz 2010, 30). In April 1993, an agreement was signed between the Bangladeshi and Myanmar governments on the repatriation of refugees. The agreement was made based on the understanding that all refugees who could prove the right of abode or citizenship in Myanmar would be allowed to return. However, Myanmar claimed that most of the refugees were illegal immigrants, turning the repatriation agreement into a controversial one (Tran 1996, 29). By 1999, about 20,000 Rohingya had been repatriated with some of them 
forced (Rahman 2010, 235). Figures as recent as 2009 show that around 200,000 to 400,000 Rohingya are still awaiting repatriation in Bangladesh (Moni 2009).

In 2012, widespread violence in Rakhine left approximately 280 dead and another 140,000 internally displaced, leaving the Rohingya to live under 'apartheid-like conditions' in camps and villages (Al Jazeera 2014). In addition, UNHCR estimated that more than 86,000 left by boat since June 2012, with more than 16,000 in the middle of 2012, some 55,000 in 2013 and nearly 15,000 in the first four months of 2014 (Tan 2014). In the first three months of 2015, a UNHCR report states that 25,000 Rohingya left Myanmar (Kalra 2013, 39). These refugees are often smuggled by transnational trafficking syndicates, often enticing them with the promise of a better life overseas. Interviews with rescued Rohingya boat people reveal that they paid around USD 90-370 to get a one way ride on the boat and as most of them cannot afford the fee; they are often forced into indentured labour as means of paying off their debts (Kalra 2013, 39). 


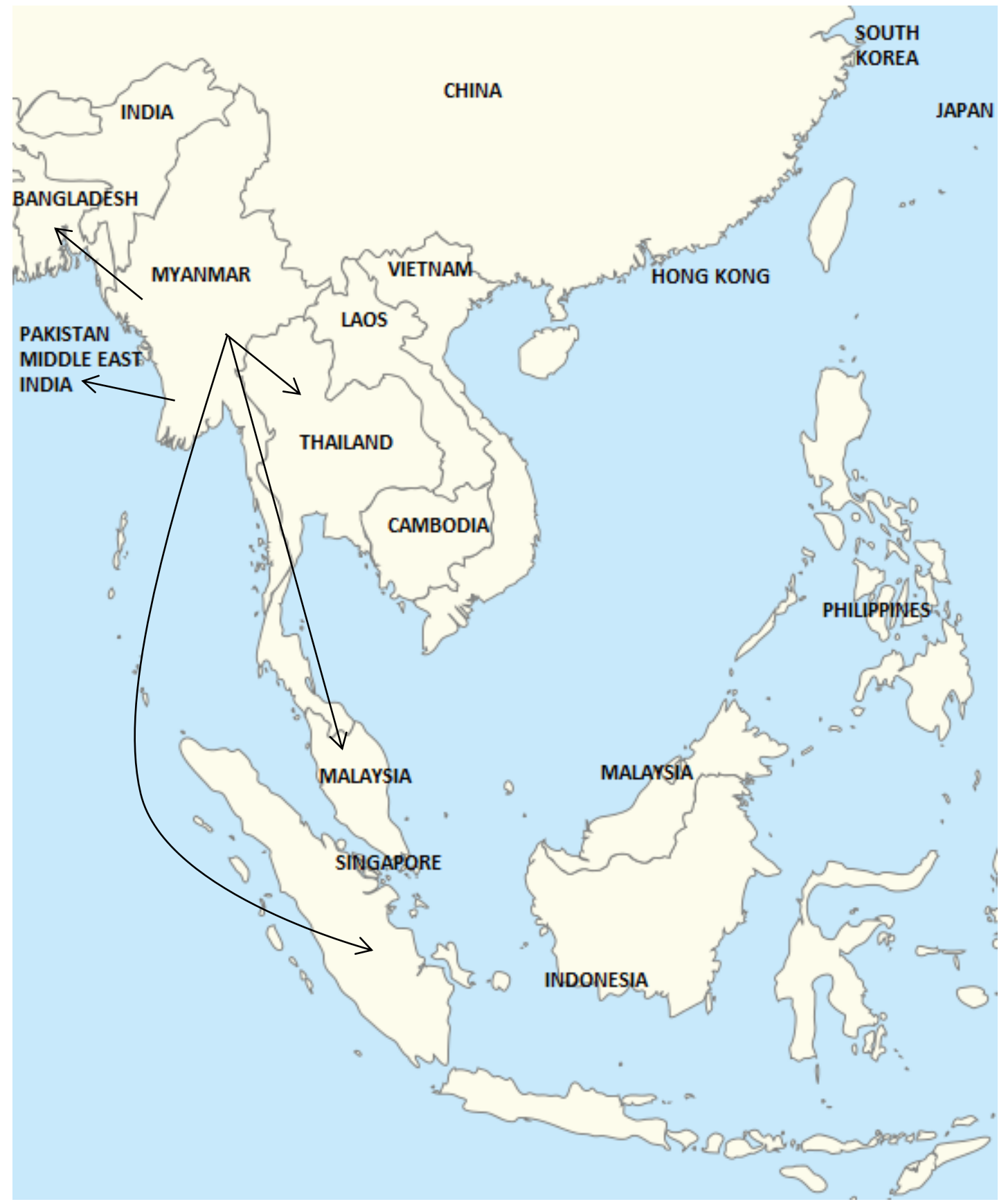

Map 2: Rohingya Refugee Flows within/from Southeast Asia

The boat exodus reached its peak in the period January to March 2015, with thousands seeking to reach Thailand, Malaysia and Indonesia. News reports suggest that 200 died during the boat journey to Malaysia (Lamb 2015), and another 10 en-route to Thailand (Head 2015a). For those who avoided dying at sea, they often found themselves abandoned at sea or held ransom in smuggler camps at the Thai-Malaysian border (Tan 2014). On the other hand, the boat refugees who managed to break free of the smugglers' grasp were often detained in temporary refugee camps in Thailand and Malaysia. 


\section{Responses to the Rohingya Refugee Crisis}

\section{Malaysia}

Malaysia has hosted refugees since the 1970s, with influxes from Aceh and Burma following the Indochinese refugee crisis of the 1970s and 1980s. There is presently a continuous flow of refugees into Malaysia, where it hosts about 150,200 refugees as of August 2016 (UNHCR 2016a). The vast majority are from Myanmar, comprising of some 53,900 Rohingya. This does not take into account the number of people who are not registered by the UNHCR, where figures could easily push the total up to 271,973 persons of concern (UNHCR 2015, 17). Malaysia is not a party to the Refugee Convention or the 1967 Protocol and therefore does not recognise the status of refugees.

Ethnic conflict in Rakhine has forced tens of thousands of Rohingya refugees to seek safety outside of Myanmar. By virtue of geographical proximity, Malaysia is often an attractive location because it is near and also is an Islamic country. In the early 1990s, Rohingya who arrived in Malaysia were issued limited documentation in the form of protection and attestation letters by UNHCR. This allowed them to achieve a level of unofficial integration that granted them entry into the informal labour market and limited access to health and education services (Cheung 2011, 54). However, this period of relative shelter and safety ended when Malaysia introduced the Immigration Act in 2002, subjecting the Rohingya to arrest, detention and refoulement. After negotiating with the UNHCR, the government decided to grant temporary residence permits to 10,000 Rohingya residing in Malaysia, allowing them to work and attend school. The current Prime Minister Najib Razak has hailed it as a "way to resolve a human rights issue and resolve the labour crunch in the country" (Agence France-Presse 2005). However, due to allegations of corruption where permits were being granted to non-Rohingya, the programme was halted (Abdul Aziz 2015). Malaysia's position on the refugee status of the Rohingya took a turn for the worse when former Prime Minister Abdullah Ahmad Badawi affirmed that Malaysia had to be firm in turning back Rohingya refugees as the "problem has been about people who come without permits" (Agence France-Presse 2009).

In March 2010, the Ministry of Home Affairs announced plans to issue government identification cards to refugees, regularising their temporary stay but without the right to work (Amnesty International 2010, 12). However, such plans were eventually abandoned when a Home Ministry spokesman said "no law allows us to issue a card to an illegal" (Zappei 2010). Unaware of the policy change and attracted by the promise of securing safe residency in 
Malaysia, many Rohingya continued to arrive in Malaysia by boat or an overland journey, subject to the exploitation of human traffickers (US Committee on Foreign Relations 2009).

Asylum seekers who attempt to enter Malaysia illegally are often arrested and denied their rights as asylum seekers. Suara Rakyat Malaysia (SUARAM), a Malaysian civil and political rights group has said that trafficking victims are often sent to detention centres, in violation of the Anti-Trafficking in Persons Act 2007 which stipulates that such individuals be placed in shelters as opposed to detention centres (Mizzima 2010). Such developments actually contradicts the Malaysian government's position on how they were 'most humane' to the Rohingya refugees (Ghazali 2014).

During the 2015 Southeast Asian Boat Crisis, Malaysia often responded to asylum seekers arriving by boat with punitive measures. On 11 May, 2015, 1,018 Bangladeshi and Rohingya refugees were arrested after arriving at Langkawi Island (Head 2015b). Two days later, Malaysia turned away a boat with more than 500 Rohingya Muslims and Bangladeshis off the coast of Penang. The United Nations High Commissioner for Human Rights urged governments in Southeast Asia to respond to the crisis from the premise that "migrants, regardless of their legal status, how they arrive at borders, or where they come from, are people with rights that must be upheld" (OHCHR 2015). On 19 May, 2015, local Malaysian makers said that there was a legal obligation under international maritime law to rescue people in distress at sea, if the rescuing country does not put itself in imminent danger by doing so (Santiago 2015). In response to the accusations of boat pushbacks, the Malaysian Foreign Ministry stated that they would offer "temporary shelter provided that the resettlement and repatriation process will be done in one year by the international community" (Al-Mahmood and Rachman 2015).

Malaysia's position on the Rohingya refugees has been largely inconsistent. Previous attempts to offer protection to the Rohingya were often retracted. Up to May 2015, it appears there is no genuine inclination to engage with the Rohingya refugee situation from a humanitarian perspective, despite the presence of a few dissenting voices criticising Malaysia's abrogation of both domestic and international legal obligations. The motivations that inform Malaysia's attitudes towards refugee protection will be examined in greater depth in the next section. 


\section{Thailand}

Like Malaysia, Thailand is also not a party to the Refugee Convention. Thailand shares similar concerns over how ratifying the treaty will result in higher number of refugees seeking refuge. In 2015, Thailand hosted around 109,800 verified Myanmar refugees (UNHCR 2016).

In the last fifty years, over a million refugees have sought refuge in Thailand, by far the largest refugee burden of any Southeast Asian state (Loescher and Milner 2005, 56). It is possible that Thailand's position towards refugees might have been shaped by its previous experience with refugees, commonly referred as 'compassion fatigue'.

Generally, the Rohingya are not welcome in Thailand. In July 2007, 40 Rohingya Muslims were deported back to Myanmar, where Supreme Commander Boonsang Niampradit was concerned that the large numbers of illegal immigrants might undermine national security (Kasem 2007). A year later, former Prime Minister Samak Sundaravej said Thailand would relocate Rohingya refugees to an immigration facility on a deserted island (Chambers 2015). Phuketwan journalists and the Arakan Project, a Bangkok-based monitoring organisation, reported that Thai military forces were detaining Rohingya refugees on the remote Ko Sai Deang Island, before towing them out to shark infested waters and abandoning them (Head 2009). In another example, Rohingya refugees found by Indonesian fishermen said that they spent three weeks adrift at sea after the Thais beat them and dumped as many as ten wooden boats far out to sea with no motors and engines in 2009 (Agence France-Presse 2009). Such moves accurately reflect the position of the ruling government where the Thai National Security Council of Thailand has stated that they should not accept the Rohingya as long term refugees as this would encourage a flood of refugees (Bangkok Post 2013a).

After a significant reduction in boat arrivals between 2009 and 2011, boats began to arrive in Thailand again in 2012. Due to the increased violence in Myanmar's Rakhine state, Rohingya refugees starting entering Thailand's waters in greater numbers. The responsibility to offer protection to the Rohingya has not been forthcoming. Thailand has generally attempted to push the burden to others. In 2015, Thai Deputy Prime Minister Prawit Wongsuwon stated that if refugees decided to enter Thai waters, they will be prosecuted by law as illegal immigrants. If they decide to continue to a third country, the Thai authorities will provide engine maintenance, fuel, foods, drinks and medicine required to the refugees (Sangiam 2015). This was part of their 'Help On Policy' which officially involved escorting boats onwards to Malaysia (Mathew and Harley 2014, 9). The policy is inherently restrictive in nature, its logic 
resting on a blanket assumption that all boat people are illegal immigrants without assessing if they have grounds for asylum. In addition, there have been reports of Thai authorities collaborating with human traffickers, selling Rohingya refugees to the traffickers (Szep and Marshall 2013).

In summing up Thailand's response to the Rohingya refugee crisis, Thailand appears to be more resolute in their refugee protection attitudes towards the Rohingya, often responding with punitive measures that creates situations of greater insecurity for the Rohingya. Although Malaysia's practice of refugee protection in the Rohingya case study is inconsistent, it has made sporadic attempts to engage with the international refugee protection regime. The reasons accounting for Thailand's refugee protection attitudes in the Rohingya case study will now be assessed in the following section.

\section{Factors affecting refugee protection}

This section analyses the factors influencing the varied conditions of refugee protection across the two countries used in the study of the Rohingya refugee crisis. This section consists of five separate but related analyses. At the international level, this chapter examines how international leadership and aid to refugees shape attitudes towards refugee rights protection in Southeast Asia. At the regional level, a study is conducted to analyse how Thailand and Malaysia engage with/within multilateral organisations such as the Bali Process and ASEAN on matters of refugee protection. It will also examine how the principle of non-interference regulates attitudes towards refugee protection in Southeast Asia. Domestically, the analytical focus is put on the conditions that affect the actual level of refugee rights protection among regional countries. Subsequent socio-political constructions of the refugee have shifted the refugee protection discourse into one that is highly securitised. The widely-noted economic arguments are not particularly relevant here, given the marginal negative economic impact it has had on first asylum countries. The question of whether treaty participation serves to enhance levels of refugee protection is undermined by inconsistent approaches employed by Southeast Asian states. In addition, governments have been turning to national immigration laws instead of referring to international refugee law to deal with the Rohingya refugees. Together, these factors interact to produce an outcome that is highly undesirable for the Rohingya refugees. 


\section{Domestic Socio-Political Issues}

As with any refugee crisis, there are often considerable economic costs to the host state in providing humanitarian assistance. A protracted refugee situation may also impose social costs on the receiving society, with the presence of refugees generating discontent among the local populace. The Rohingya refugee crisis is no exception to this. Therefore, the level of refugee protection afforded often depends on the economic ability of the target asylum states, and the socio-political orientation of the country that often determines whether refugees are welcome in the host country.

The incomes of the countries of Southeast Asia have increased rapidly in the last quarter century. Since the 1970s, rises in Southeast Asia's Gross Domestic Product per capita have outpaced the rest of the world (Vinayak, Thompson and Tonby, 2014). Thailand and Malaysia are considered to be upper middle income economies (World Bank 2016). Naturally, it would be logical to assume that the level of refugee protection for the Rohingya should be higher as compared to Indochinese refugee crisis. However, the economic costs argument continues to be used by Thailand and Malaysia in dealing with the Rohingya refugees. Penelope Mathew and Tristan Harley $(2014,12)$ report that the Malaysia's government refusal to ratify the 1951 Convention is "due to the heavy financial burden it will impose upon Malaysia and "that the huge presence of 'refugees' or 'asylum-seekers' may be a threat to national security". To support this claim, the Malaysia deputy home minister Nur Jazlan Mohammad said the government spends nearly $\$ 10$ a day for each illegal immigrant detained in the country (AlMahmood and Rachman 2015). If medical expenses are included, it can go up to an average of about \$20 a person (Al-Mahmood and Rachman 2015). Thailand also concurs with Malaysia on the economic cost argument where refugees are seen as "competitors for jobs (and) resources" (Loescher and Milner 2005, 59).

The economic cost argument loses its pertinency when the economic role of the Rohingya is considered. Under the restrictive asylum and immigration policies of these countries, the Rohingya do not have the legal right to work. Therefore, the Rohingya can only seek economic support by participating in informal labour markets. In fact, the Rohingya often find work associated with the nature of 'SALEP' (Shunned by All Except the Very Poor) (Bohning 1998, 367). These refugees often work in jobs that the local population is unwilling to do. They also fill up the demand for low cost labour, filling up labour shortages in service industries. For example, the Rohingya in Malaysia are often employed in hypermarkets, 
supermarkets and wet markets. In Thailand, Sebastien Moretti $(2015,74)$ argues that the jobs performed by refugees are often too low or considered too badly paid by Thai workers. Considering Thailand's well documented need for foreign labour, the economic argument does not stand up to scrutiny here. In 2006 Thai employers made an official request to the government to register 1,333,703 foreign workers (MAP Foundation 2014). Many refugees often work in construction, tourism and levels in these sectors, and their total contribution to economic output has been calculated at around US \$11 billion, or 6.2 percent of Thailand's Gross Domestic Product (Martin 2007, 8). Therefore, there is a lack of definitive links between hosting refugees and increasing economic costs on the receiving state. If any, they make a significant contribution to these countries' economy through their participation in informal labour markets.

The foreign nature of the Rohingya refugees has allowed Thailand and Malaysia to portray them as security threats to public health and order, increasing the level of resistance in offering them asylum. Malaysia argues that the Rohingya contributed to increasing crime rates in the country. For example, Malaysian police in 2003 arrested "30 Burmese nationals during a drug bust in the southern Malaysian city, Johor Bahru, including a 13 year old girl who was found in possession of 415 grams of heroin" (Yap 2004). In 2014, there was a clash involving 18 Burmese nationals. Reports did not specify if they were Burmese Buddhist or Muslim (Agence France-Presse 2014). In 2015, two Malaysian states, Northern Penang and Kedah rejected the federal government's plan to host refugees, citing that high crime rates among the Rohingya and other Myanmar people (Kumar 2016). Together, these issues form the basis of how Malaysia sees the "the huge presence of 'refugees' or 'asylum-seekers' (as) a threat to national security" (Mathew and Harley 2014, 12).

Similarly, Thailand generally articulates the same security concerns as Malaysia, where refugees are deemed as health and criminal threats to the country. It is estimated that $80 \%$ of the sex workers in Thailand are from Myanmar and this leads to increased crime and health risks (Loescher and Milner 2005, 59). However, the Rohingya are also viewed as national security threats, where the presence of the Rohingya may increase the level of Islamic insurgency in Thailand's southern provinces. In 2009, around 1,000 Thai protested against the government's potential decision to allow the UNHCR to set up a Rohingya refugee centre in Ranong, Southern Thailand. They expressed concern about the presence of large numbers of Rohingya, "fearing that it would lead to problems similar to those in Thailand's southernmost provinces, where Islamic extremists have been waging a violent struggle for independence for 
years" (Weng 2009). The Rohingya have also been accused of assisting a Muslim-led insurgency in Southern Thailand. While there has been a lack of attacks in the area in recent years, it is arguable that Thailand's attitude towards refugee protection has been shaped by their experience with the Islamic insurgency in a country that is overwhelmingly Buddhist.

Additionally, Thailand's position on the Rohingya refugees as threats to national security feature more prominently than Malaysia. In 2009, Thailand came under international scrutiny when it was reported that the Thai navy had forced the Rohingya back into international waters (The Nation 2009a). Former Thai Prime Minister Abhisit Vejjajiva articulated Thailand's position on the status of the Rohingya refugees:

"The policy of course is to make sure that the issue of illegal migration is to be based on two principles - one is of course the individual's status and rights and the other one of course is national security and the rights of the Thai people... The policy, of course, is aiming to balance the two" (Corben 2009).

In 2013, the then Thai army chief General Prayuth Chan-ocha echoed the same concern that too many Rohingya refugees would affect the national security of Thailand (The Nation 2013). A senior naval officer also concurred that it was the Thai navy's duty to "curb smuggling of contraband goods, drugs and illegal migrants" (Bangkok Post 2013b). The chronology clearly shows that Thailand's attitude towards the Rohingya refugees is significantly shaped by its understanding of them as national security threats.

Attitudes towards refugee protection have also been shaped by religious considerations in Thailand and Malaysia. The question of refugees is well documented in Islam, and certain groups in Malaysia have tended to follow such teachings in guiding their calls for greater protection to the Rohingya. The Quran mentions, "If one amongst the pagans ask thee for asylum, grant it to him, so that he may hear the word of Allah, and then escort him to where he can be secure". ${ }^{4}$ If such teachings were extended to non-Muslims, it is then necessary to appreciate the urgency and centrality of such religious beliefs that call for greater protection of the Rohingya Muslims in Islamic Malaysia. The Malaysian Muslim Youth Movement (ABIM) has been influential in assisting with the protection of Rohingya in Malaysia. Malaysia has also sought to organise Muslim governments in applying pressure to Myanmar through the Organisation of Islamic Cooperation, also known as OIC (Reuters 2017).

\footnotetext{
${ }^{4}$ The Quran 9:6 (Surah Al-Tawbah).
} 
On the other hand, Buddhism has had a negative effect on the positive refugee protection attitudes in Thailand. The Rohingya have not been received with warm welcome once the Thai people realised that they were Muslims. Eakpant Pindavanija argues that when Buddhists believe their "values to be paramount, they disregard other religions, or even fear that their own is under threat...suddenly...the hate speech comes: 'Oh! They are here because they want to destroy this country, they want to destroy our Buddhist society... So the feeling of sympathy has done" (Ng 2017). In fact, Thai Senator Jate Sirataranont argued that Thai authorities must send the Rohingya refugees to a third, Muslim country as fast as possible in 2013 (The Nation 2013). In both countries, the role of religion is shown to have an important role in deciding whether attitudes towards refugee protection are positive or negative. Therefore, to a certain extent, the religious composition of the host country can offer indications as to whether refugee protection efforts will be successful or not.

Despite the significance of religion in mediating successful outcomes for refugees, Malaysia remains intransigent on the issue of the Rohingya as refugees. The only previous instance when Malaysia granted asylum was to the Minadanao Muslims in Sabah. The acceptance of the Minadanao refugees was a calculated political move to alter the demographic of Sabah while funding the Muslim insurgency in Southern Philippines (Thalang 2017). Even now, Malaysia's agreement to allow 300 Rohingya the legal right to work through a UNHCR programme does not offer any promise that the Rohingya will be resettled as refugees in Malaysia (Jha 2017). While religion has had an impact on how states operationalise refugee protection, their influence on getting the country to accept the Rohingya on basis of faith remains limited. It remains to be seen if levels of refugee protection for the Rohingya will actually increase.

\section{Legal Aspects of Refugee Protection and its Impact on the Rohingya}

Four decades after the Indochina refugee crisis, the level of treaty ratification remains low in Southeast Asia. As of March 2017, only Cambodia and the Philippines have ratified the 1951 Convention and its 1967 Protocol. While most countries in Southeast Asia do not ratify the Refugee Convention, they do engage with it on an ad-hoc basis. As the previous chapter has indicated, reasons for non-ratification generally revolve around the Eurocentric nature of international refugee law and the high costs of refugee upkeep during the Indochinese refugee crisis. Although the current discourse on refugee protection pertaining to the Rohingya situation have not invoked the Eurocentric argument so far, Thailand and Malaysia's 
engagement with international refugee law remains inconsistent. The selective application of Thailand and Malaysia's obligations to international law does not only result in inconsistent approaches to refugee protection, but also contributes to the conceptualisation of refugees as illegal migrants in the absence of international refugee law.

Not being signatories to the Refugee Convention allows states to employ policies that do not result in the recognition of refugee rights. Arguably, the most critical issue surrounding non-signatories to such legal instruments is that it permits an arbitrary decision making process on how refugees are afforded protection. On the other hand, this may not always hold true since countries such as Australia have refused to accept new refugee arrivals, despite having ratified the 1951 Refugee Convention. Malaysia has argued that any ratification of the Convention and its Protocol is unnecessary, because there are states party to the Convention who shirk away from their responsibilities of protection, while Malaysia has managed to host refugees without signing the legal instruments (Mathew and Harley 2014, 12). However, at its very basic level of operation, the non-adherence to international refugee law creates a highly subjective space from which states can wilfully apply any arguments to justify the non-protection of refugees.

Malaysia's approach to Rohingya holding UNHCR refugee cards illustrates its inconsistent engagement with international refugee law. As of April 2016, there are 53,410 Rohingya refugees registered with UNHCR Malaysia (S. Bedi 2016). Any asylum seekers in Malaysia granted refugee status are issued a refugee card once the determination process is completed (Phung 2016). The refugee card grants refugee protection from detention and judicial caning which is a punishment that could be ordered against any asylum seeker who does not have lawful migration status in Malaysia (Sivanandam 2012). However, Human Rights Watch (2000b) has reported that some Rohingya were detained by the authorities despite having proper UNHCR documentation.

The issuing and status of refugees holding UNHCR documentation in Malaysia is often controversial, where the government has continued to articulate an inconsistent position on the status of the Rohingya. Previously, the Malaysian Home Ministry recognised the Rohingya refugees in 2003 (Beh 2004). However, despite the Rohingya holding UNHCR certification, Malaysia refused to use the term refugee, but referred to them as "UNHCR cardholders in Malaysia" (Mathew and Harley 2014, 13). The situation took a turn for the worse when UNHCR responsibility for refugee status determination (RSD) was taken away by the Malaysian government in July 2016. On the government's move to reclaim responsibility for 
RSD, Minister in the Prime Minister's Department Datuk Seri Shahidan Kassim stated that it was "the prerogative of the government to determine if an immigrant should be granted refugee status, a decision that should not solely be made by UNHCR" (Lin 2016). It is understood that the government's move was developed in response to the proliferation of counterfeit UNHCR cards being sold by syndicates to illegal immigrants seeking to pose as refugees. In such circumstances, one might argue that there was a genuine intention to curb criminal activity but the shift of responsibility over RSD from UNHCR to the Malaysian state reduces the scope for accountability according to international refugee law.

Although Rohingya holding UNHCR certification have not been recognised as refugees and subjected to detention, the treatment of non-documented Rohingya refugees is considerably worse compared to UNHCR cardholders as Malaysia does not appear to have accorded them with any rights at all. It is estimated that in excess of 40,000 unregistered Rohingya refugees live in Malaysia (Towle 2017). In 2008, a Human Rights Watch report stated that Malaysian officials apprehended a group of undocumented Rohingya refugees during raids and kept them in detention centres before dumping them at the Thai border, often directly in the hands of human traffickers (The Nation 2009b). The collusion of Malaysian immigration authorities with human traffickers often results in Rohingya refugees being sent to work on fishing boats or rubber plantations, while those attempting to escape are often shot and killed (The Nation 2009b). In another example, SUARAM reported that an estimated 500 Burmese detainees at Lenggeng Immigration Detention Centre went on hunger strike... to protest against the lack of waste supply which was subsequently denied by the Immigration department (Mizzima 2010). It is worth recalling in the previous section that SUARAM has argued that Malaysia holding victims of trafficking in detention centres rather than shelters puts it in violation of the Anti-Trafficking in Persons Act 2007. Under such conditions, it is arguable that Malaysia's violation of its domestic legislation exhibits a poor understanding of refugee protection approaches in the absence of international refugee law. Former Prime Minister Abdullah Ahmad Badawi puts this conundrum quite succinctly:

"If they come as workers with permits which have been approved, then we can regulate them. But the problem is those Rohingya who just turn up. So what do we do with them?" (Bangkok Post 2009).

In the absence of international and domestic refugee law regulating the protection of refugees, the level of protection offered is understandably low. However, the non-ratification of the Refugee Convention also opens up an amorphous space where refugee rights can be interpreted 
in a subjective manner. A look at one side of a coin tells us that Malaysia has inconsistently engaged with international refugee law through its dealings with UNHCR, resulting in situations of insecurity for the refugees. On the other hand, the perplexing manner in which it violates its own domestic legislation, demonstrates that Malaysia's disinterest in ratifying the Refugee Convention, results in the lack of a framework where the rights of the Rohingya can be protected and regulated consistently.

The policy of boat pushbacks during the May 2015 Rohingya boat crisis offers another perspective on Malaysia's attitudes towards refugee protection. During the Rohingya boat crisis, Malaysia often turned away boats in the hope that they would turn up in a third country. Despite not being a signatory to the Refugee Convention, Malaysia's boat pushback policy put it in violation of general international law. Klang Member of Parliament Charles Santiago argued that Malaysia was also in breach of international maritime law to "rescue people in distress at sea, if the rescuing country does not put itself in imminent danger by doing so" (Santiago 2015). In response to international and domestic criticism, Malaysia agreed to offer temporary shelter to the 7,000 Rohingya refugees stranded at sea, with the understanding the resettlement and repatriation would be done in a year (Borneo Post 2015). Malaysia's response to the Rohingya refugee crisis is reminiscent of Southeast Asia's boat pushback policies during the Indochinese refugee crisis that led to the 1979 Conference on Indochinese Refugees. Attitudes towards refugee protection during the Rohingya boat crisis was shaped by the rejection and subsequent reengagement with refugee protection practices consistent with international refugee law.

Thailand's poor engagement with international law shaped the level of protection afforded to the Rohingya refugees. In January 2013, The Thai National Security Council (NSC) said that it "would not set up permanent refugee camps, though it could still build temporary detention centres" (Bangkok Post 2013a). NSC Secretary General Lt Gen Paradon Pattanathaboot said that the Rohingya should not be accepted as long term refugees, fearing an influx of Rohingya and asked the UNHCR to take care of them after the 6 month period. In the same month, 73 Rohingya migrants were intercepted at Phuket, en-route to Malaysia. It was reported that they were arrested and ordered to return to Burma by land (VOA News 2013). 


\begin{tabular}{|l|l|l|}
\hline Relevant Protections Related to Refugees under International Law & Thailand & Malaysia \\
\hline Principle of Non-Refoulement & Yes & Yes \\
\hline Refugee Convention / Protocol & No & No \\
\hline Domestic Framework for Refugee Status Determination & No & No \\
\hline Convention against Torture (CAT) & Yes & No \\
\hline International Covenant on Civil and Political Rights (ICCPR) & Yes & No \\
\hline Rights of the Child & Yes & Yes \\
\hline International Convention on the Elimination of All Forms of Racial Discrimination (CERD) & Yes & No \\
\hline
\end{tabular}

Table 2: Ratification Status on Refugee-related International Legal Provisions in Thailand and Malaysia

In assessing Thailand and Malaysia's response to the Rohingya refugees, the examples of boat pushbacks and forced repatriation provide evidence how the principle of non-refoulement has been violated. Although both states are not signatories to the Refugee Convention and its Protocol, some of its provisions such as the principle of non-refoulement are principles of customary international law.

Despite such obligations, Thailand's response to the Rohingya refugees has been largely conducted on an ad-hoc basis. This has led to differing approaches in how Thailand treats its refugees. For example, the persecution of politically active dissidents from the National League for Democracy by the Myanmar government resulted in thousands of them fleeing to Thailand. Recognising that there was a fear of persecution, the Thai authorities called them 'students', allowing UNHCR to register them and provide assistance (Loescher and Milner 2005, 58). On the other hand, ethnic minorities such as the Rohingya were termed as 'temporarily displaced people' and UNHCR access to them was limited. Compared to the Myanmar 'students', such conditions did not apply to the Rohingya coming from the ethnic minority regions of Myanmar despite their clear links to political persecution.(Human Rights Watch 2012, 20). Considering Thailand's discriminatory approach towards the Rohingya, it is clear that international legal instruments such as the CERD and ICCPR have been violated in the ways it approached the Rohingya refugee issue.

A common feature of states that have not acceded to international refugee treaties is the lack of a domestic asylum framework. In the absence of such a framework, domestic immigration laws are often employed when dealing with asylum seekers. Thailand and Malaysia have used their respective immigration laws to deal with the influx of asylum seekers. Of particular interest is Malaysia's tendency to convolute categories of statelessness, refugees and asylum seekers. Their 1959/1963 Immigration Act classifies all three categories as "illegal migrants" (Immigration Act 1959/1963, Act 53). Similarly, Thailand's Immigration Act of 
1979 requires all foreigners to enter the country with legal documentation, where those without will be considered as illegal migrants (Immigration Act 1979, Chap 2). Here, the statelessness of the Rohingya becomes more pronounced. It leads to a catch-22 situation where the opportunity to seek asylum is automatically precluded because the Rohingya hold no legal documentation. In both cases, the automatic application of an illegal migrant status to the Rohingya excludes them from the possibility of seeking asylum while subjecting them to imprisonment and deportation. Instead, domestic immigration law becomes the main reference point where the national refugee 'protection' agenda is articulated.

Overall, the legal aspects of refugee protection and its impact on the Rohingya provide a complicated picture of refugee protection attitudes in Thailand and Malaysia. Inconsistencies between domestic laws and international obligations have contributed to poor protection practices, placing the Rohingya in situations of insecurity. First, countries such as Malaysia have identified that ratification of the Refugee Convention is not necessarily associated with higher levels of protection. Minister in the Prime Minister's Department Datuk Seri Shahidan Kassim maintained that the "Government was 'most humane' to Rohingya refugees although it has not signed the United Nation Refugee Convention" (Ghazali 2014). In light of this claim coming from a source that is placed at the highest level of the Malaysian Government, Malaysia's attitudes towards the Rohingya prove that its claim remains unfounded based on evidence provided in this section. Second, failure to ratify the Refugee Convention often leads to inconsistent approaches to refugee protection and allows the state to arbitrary exercise its power over the regulation of refugees within its sovereign borders through national immigration legislation. This arises because the lack of an accompanying domestic refugee protection framework to the Refugee Convention permits such a situation to happen. Third, when the status of refugees are considered under national immigration laws, there is a tendency to shift the conceptualisation of the Rohingya from 'refugee' to 'illegal migrant'. In these two countries where refugee protection remains scarce, the shift to categorising them as 'illegal migrants' further erodes whatever level of protection they have left. Finally, despite not being signatories to the Refugee Convention, both Thailand and Malaysia have engaged in refugee protection practices that disregard the refugee status of the Rohingya in violation of customary international laws, most notably the principle of non-refoulement. Therefore, the convoluted nature of legal protection for refugees continues to inform Thailand and Malaysia's attitude towards refugee protection in the Rohingya refugee crisis. 


\section{Conceptualisation of the Refugee}

The conceptualisation of the Rohingya as refugees is important as it informs the level of refugee protection granted to them in Thailand and Malaysia. The framing of an individual as a refugee is inherently political, since a state's response is dictated by its understanding and subsequent perception of these individuals. For example, the Rohingya have been classified as illegal migrants, economic migrants, victims of human smuggling, security threats, stateless people in addition to the usual UNHCR lexicon of refugees and asylum seekers. This section seeks to focus on how the Malaysian and Thai governments have described the Rohingya asylum seekers in the public realm, depicted as 'illegal migrants' through their undocumented mobility. Within this discourse, the conceptualisation of the Rohingya refugee as a threat to national security or dubious asylum seekers have been used to justify trajectories specific to their own national agenda and also validate their arguments.

The state of statelessness has a significant impact on human security and the enjoyment of human rights. This has affected the Rohingya's experience with asylum seeking in countries such as Thailand and Malaysia. They are often labelled as stateless persons, ethnic minority and an 'outsider' in the host country. This makes them vulnerable to states' practices of restricting basic rights such as education, health care and employment. Consequently, asylum seekers have also been viewed with animosity by the Malaysian public and local political parties because of their 'foreign status' (Vas Dev 2009, 35). In this migratory context, the legal ambiguity regarding their statelessness becomes clearer as states are granted discretionary power over their lives. The stateless Rohingya often find themselves in "the revolving door of 'informal' deportations" (Lewa 2009, 13). As Myanmar continues to deny its responsibility for the Rohingya, 'Thailand has occasionally deported Rohingya boat people unofficially into border areas of Burma ... (while) Malaysia usually deports them over the border in Thailand" (Lewa 2009, 13). Therefore, they are often subjected to multiple patterns of exclusion and discrimination in Southeast Asia.

A crucial pre-requisite of acquiring immigration status would be proof of legal identity. Therefore, the stateless nature of the Rohingya means that they are unable to rely on any legal forms of migration. As the previous section has outlined, Thailand's Immigration Act of 1979 automatically classifies the Rohingya as illegal migrants, given their lack of documentation. Malaysia's national immigration law is more unrelenting on the Rohingya, as refugees, stateless persons and asylum seekers fall under the blanket category of illegal migrants. 
Therefore, the conceptualisation of the Rohingya through national legislation reduces the level of protection for them and offers no possibility that they will receive protection in Thailand and Malaysia.

Finally, the conceptualisation of the refugee as 'victims of trafficking' securitises the refugee agenda. In a bilateral security dialogue between Thai and Malaysian defence officials, both parties have discussed "possible solutions for the human trafficking issue, especially the Rohingya refugee issue, which Malaysia is also involved" (Royal Thai Government 2015). Matters of human security then become a matter of national security, as the discourse generally revolves around combating human traffickers and stopping the boat people. This allows states to avoid their obligations to asylum seekers by referring to them as victims of trafficking.

\section{Regional Dynamics in Southeast Asia}

The transnational nature of the Rohingya refugee exodus has had a differential impact on states in the region, which, in turn predispose states to adopt and sustain varying policies in controlling refugee arrivals in their territory. In a region where most governments are denoted by quasi-democratic forms of governance, the principle of non-interference is a defining feature of ASEAN solidarity. For the most part, any efforts at coordinating a regional solution to the Rohingya refugee crisis have often been rhetorical, often failing to translate into action that suggests that Southeast Asian countries are more inclined towards refugee protection.

There is evidence that ASEAN is gradually mainstreaming human security concerns at the regional level. Central to a discussion of human security and rights would be the ASEAN Charter. In Article I of the ASEAN Charter, such an approach is outlined where the purposes of ASEAN are to "strengthen democracy, enhance good governance and the rule of law, and to promote and protect human rights and fundamental freedoms" (ASEAN 2008). Such developments indicate a consensus that a notable shift towards non-traditional security concerns is occurring. However, inconsistencies remain over the way ASEAN articulates matters of human security. On 21 November, 2015, the ASEAN Plan of Action Against Trafficking in Persons, Especially Women and Children was established. The Plan of Action mainly referred to the ASEAN Convention Against Trafficking in Persons, Especially Women and Children as the framework for regulating human trafficking (ASEAN 2015). Interestingly, the Regional Plan of Action made references to multiple UN and ASEAN treaties but the 1951 Convention and its Protocol was omitted (ASEAN 2015). Therefore, the depth and extent in which human security concerns such as refugees have been mainstreamed into ASEAN's 
agenda remains unclear. On one hand, the omission of the Refugee Convention could indicate a balancing of a controversial humanitarian issue and ASEAN's cherished principle of noninterference. On the other, the lack of references to international refugee law could also indicate that the phenomenon of unregulated human migration is being securitised through the framework of transnational trafficking crime.

The Rohingya refugee crisis is the most recent event to challenge this shaky compromise in ASEAN. There are two aspects of the Rohingya crisis that confronts any prospective attempts to reach a consensus in a regional solution to the refugee situation. First, it is well established that the Rohingya are defined as 'stateless' by Myanmar. To tackle the refugee problem, countries need to define if the Rohingya are bona fide Southeast Asians and thus covered by the ASEAN Charter. Sarinna Areethamsirikul (2009) argues that ASEAN could end up siding with traditional principles of non-interference, where the Rohingya issue can be dismissed if the Rohingya are interpreted as non-ASEAN people because they are not recognised by the Myanmar government. Second, the roots of the Rohingya influx in Thailand and Malaysia originate from Myanmar's refusal to accord the Rohingya citizenship rights accompanied by human rights abuses. What appears to be an 'internal affair' is now transnational in nature. These two factors pose challenges to the new ASEAN way that appears to have embraced human security concerns while safeguarding its traditional adherence to noninterference.

Countries in Southeast Asia have consistently expressed their preference for a regional solution to the Rohingya refugee crisis, notably through the Bali Process ${ }^{5}$. In 2009, a bilateral meeting between Indonesia and Thailand agreed to refer the Rohingya issue to the Bali Process. Former Thailand Prime Minister Abhisit Vejjajiva also insisted that the Rohingya issue should be jointly solved between Indonesia, Malaysia, Thailand and Myanmar, adding it was the common problem between these nations, and not Thailand's alone (Royal Thai Government 2009). Former Thai Foreign Minister Kasit Piromya stated that they were going to "renew the Bali process... (picking) up from where (they) left off and tackle this problem in a very coordinated manner" (Osman 2009). However, at the Third Bali Regional Ministerial Conference, it was noted that the Rohingya issue was not "discussed at the plenary session, nor

\footnotetext{
${ }^{5}$ The Bali Process provides a consultative function where dialogue and information could be shared among member nations on the issue of people smuggling, trafficking and related transnational crimes Such conferences are only conducted on an ad-hoc basis. See Bali Process. n.d "About the Bali Process." Accessed November 11, 2016. http://www.baliprocess.net/.
} 
was it explicitly mentioned in the concluding statement" (IRIN 2009). Rather, regional leaders continued to refer to the Rohingya as illegal migrants. The Bali Process meeting did not arrive at any specific solutions, only to agree on retasking Ad Hoc Group (AHG) mechanisms to address "comprehensively particular situations on a case-by-case basis upon the request of affected countries" (Bali Process 2009).

While the plight of the Rohingya has not been dismissed entirely in Southeast Asia, there remains a lot of intransigence at official level to formally introduce the Rohingya refugees into the regional agenda. The then Secretary-General Surin Pitsuwan acknowledged that ASEAN cannot press the Myanmar government to grant citizenship to the Rohingyas (Hindstrom 2012). Understanding ASEAN's reluctance to press for the Rohingya issue to be discussed at meetings, Myanmar successfully kept the Rohingya off the agenda of the $24^{\text {th }}$ ASEAN Summit and its Foreign Ministers' meeting (McLaughlin and Aung 2014). This pattern is consistent with Myanmar's earlier attempts in 2012 to keep the Rohingya out of the regional spotlight, where efforts to organise an ASEAN meeting on the Rohingya refugees at sea collapsed in August 2012 after being rejected outright by Myanmar's Foreign Ministry (Kassim 2012). At the May 2015 'Special Meeting on Irregular Migration in the Indian Ocean' in Bangkok, Zaw Htay, a member of former President Thein Sein's office mentioned that any Myanmar participation in the meeting was conditional on the omission of the name 'Rohingya' in discussions (Mahtani and Myo 2015). ASEAN's position towards including the Rohingya in official discussions remained unchanged at the July 2015 Emergency ASEAN Ministerial Meeting on Transnational Crime Concerning Irregular Movement of Persons in Southeast Asia. At this meeting, ASEAN ministers emphasised that "the meeting is not about politics. It is about transnational crime. We shouldn't be involved in their domestic matter" (Goh 2015).

In addition to Myanmar's refusal to allow the Rohingya be included in regional discussions, calls for attention to be given to the Rohingya refugee crisis has failed to translate into concrete action, affecting the level of refugee protection in Southeast Asia. In 2014, The ASEAN Interparliamentary Caucus has made several statements condemning discrimination and violence against Rohingya (Global Centre for the Responsibility to Protect 2015, 5). Also, the ASEAN Parliamentarians for Human Rights (2014) have released numerous statements criticising the "dangerous, discriminatory and unnecessary" draft law proposing restrictions on interfaith marriage in Myanmar. In March 2016, at the Sixth Ministerial Conference of the Bali Process, countries came together and pledged to establish a mechanism to "facilitate timely and proactive consultation to respond to emergency situations" (Bali Process 2016). Barring 
the development of tangible solutions, the rhetoric espoused by regional leaders suggests that the Rohingya refugee situation is more of an issue about semantics than action.

However, this would change with Myanmar's renewed hostilities with the Rohingya in October 2016. It is reported that in response to the Rohingya militant attacks on Myanmar police border posts, the Myanmar government initiated a crackdown that resulted in the deaths of more than 1000 Rohingya, prompting some 70,000 Rohingya to flee to Bangladesh (Reuters 2017). Malaysia was the only Southeast Asian nation to break away from the tepid state of regional 'solutions' that offered no concrete action in resolving the Rohingya refugee crisis. At a protest against the crackdown on the Rohingya, Malaysian Prime Minister Najib Razak said:

"I want to tell Aung San Suu Kyi: Enough is enough! Two days ago, I received a statement from the Myanmar government telling me if I attend today's rally, it shows that I'm interfering in their internal affairs... But I don't care, because I'm not here just as Najib Razak, I am here in the name of the Ummah" (Yunus 2016).

He explained that the Myanmar government cited the non-interference principle under the ASEAN Charter in their response to his participation at the rally, but responded by saying that they were just using one article and questioned if they only "just read one article, (and) what about articles on human rights" (Yunus 2016). Most significantly, Malaysia sent a ship with aid for the Rohingya Muslims on 10 February, 2017 (Al-Jazeera 2017). Not long after, Malaysia implemented a pilot programme with UNHCR, allowing 300 Rohingya refugees to legally work in the country on 1 March, 2017 (Palansamy 2017). Malaysia's new position contrasts with Thailand's, since the latter has remained resolutely quiet on the new wave of attacks on the Rohingya. Prime Minister Najib Razak's use of the word, 'Ummah'6, also suggests that the role of religion has facilitated Malaysia's change of attitude towards the Rohingya refugees.

Regional influences on refugee protection attitudes can be understood from two perspectives. First, ASEAN nations' continued preference for dealing with the Rohingya refugees through the Bali Process suggests that the refugee issue is being securitised here. The Bali Process primarily deals with human trafficking, therefore, it does not adequately cover situations where some Rohingya may not have been trafficked. The conceptualisation of the Rohingya as 'illegal migrants' also strips away the humanitarian impetus for seeking a regional solution, placing it under transnational framework of crime and trafficking. Second, ASEAN's

\footnotetext{
${ }^{6}$ Ummah generally refers to the global Muslim community bound by religious ties.
} 
indulgence of Myanmar's refusal to allow any inclusion of the Rohingya officially in the regional agenda suggests that non-interference is being practiced here. Therefore, the principle of non-interference has retained much influence over refugee protection attitudes at the regional level. Amnesty International has said that it is “truly in ASEAN's self-interest to scrap its non-interference policy and to ensure that it is able to deal with human rights problems in individual member states including Myanmar" (Mizzima 2009). Occasionally, a departure from the regional non-interference consensus may occur, demonstrating continuity with the practice of interference during the Indochinese refugee crisis. Malaysia's response to the October 2016 clashes between the Rohingya and Myanmar security forces is a case in point. Malaysia's position on the Rohingya refugee situation in Myanmar demonstrates the possibility of divergent attitudes towards refugee protection in ASEAN. Therefore, it remains to be seen how effective ASEAN's embrace of human security concerns will result in a tangible and effective consensus on resolving the Rohingya refugee crisis in Southeast Asia.

\section{International Influences}

The protracted nature of the Rohingya refugee crisis is symptomatic of Southeast Asia's reliance on international aid. This behaviour was evident during the Indochinese Refugee Crisis, and continues till today. The previous chapter indicated that one of the primary purposes of the CPA was to manage the resettlement of refugees from first asylum countries. Robinson $(2004,325)$ has suggested that due to the lack of local integration solutions, the resettlement approach created in some Asian states an historical precedent for relying on Western supported permanent solutions. Similarly, Malaysia has also echoed calls for international assistance, arguing that "the world cannot sit by and watch genocide taking place" (Ponniah 2017). Thailand concurs with Malaysia's position, where former Thai Prime Minister Abhisit Vejjajiva insisted that the Rohingya refugee crisis was not Thailand's alone (Vejjajiva 2009). Together these calls for the involvement of the international community provide insights as to how Southeast Asian countries such as Thailand and Malaysia understand practices of refugee protection - that is, an unwillingness to shoulder the burden alone. If the international community fails to intervene, this may harden Thailand and Malaysia's attitudes towards protecting the Rohingya refugees. The possibility of such a scenario is not dissimilar to the events that led to the 1979 Indochinese Refugee Conference, where Thailand and Malaysia decided no more refugees would be accepted unless the international community offered resettlement places. 
The reasons Southeast Asian regional intake of refugees are so low are often complex - ranging from principle of non-interference to socio-economically weak states unable to offer first asylum. However, given Southeast Asia's propensity to look to Western countries for matters of refugee protection, deteriorating protection standards in countries such as Australia may contribute to the notion that boat-push backs and refusal to accept refugees are acceptable. Australia's shift to punitive unilateralism is reflective of the Southeast Asian reality. Regarding the matter of resettling Rohingya refugees in Australia, former Prime Minister Tony Abbott said, "Australia will do absolutely nothing that gives any encouragement to anyone to think that they can get on a boat, that they can work with people smugglers to start a new life" (Cooke 2015). Australia has also sought to extend the reach of its refugee deterrence policy by funding immigration detention facilities in Indonesia (Crock 2014, 267). By employing measures such as boat-push backs and detention, Australia has not only shown that such bad behaviour is permissible, but it has also aligned itself with the kind of approaches to refugee protection seen as acceptable in Southeast Asia. Given Australia's close relationship with Southeast Asia, it is arguable that its poor leadership in refugee norms may contribute to hardening attitudes over refugee protection in Southeast Asia.

Globally, the discourse on the Rohingya refugees generally revolves around holding the Myanmar government accountable for its violation of human rights against the Rohingya Muslims. Reports of human rights violations in international news agencies have often framed the conflict in religious terms, where the Rohingya refugees represent an Islamic threat to Buddhism, seeking to supplant Buddhism in Myanmar (Schissler, Walton and Thi 2015). Jasmine Chia (2016) argues that this has increased Myanmar's opposition to international assistance. In the period after the May 2015 Boat Crisis, there were large protests in Sittwe, carrying signs like "no UN, no INGOS” (Chia 2016). The Myanmar Permanent Representative to the UN, Maung Wai responded that "the notion of human rights of Muslims in Myanmar are violated upon is totally wrong. It is only a false perception, not a reality. If you put a spin on the false story turning it to a human rights issue then you are making a very serious mistake" (PTI News 2015). The influence of the international community sheds light on Southeast Asian countries' attitudes towards refugee protection in an indirect way. Due to the framing of human rights violations in a religious context, Myanmar's does not appear to be receptive to international assistance and has asserted that the human rights of the Rohingya in Myanmar are not violated upon. Myanmar's position on its role in human rights violations may then subsequently influence regional Muslim states that may interpret Myanmar's denial in a 
negative way. This raises the possibility of Malaysia altering its attitudes towards refugee protection on religious grounds. At the same time, Thailand as a Buddhist nation may also decide to harden its stance on the Rohingya refugees. As evidenced by Malaysian Prime Minister Najib Razak's statement in December 2016, it is likely that the framing of the conflict in Myanmar in religious terms contributed to Myanmar's response which in turn, led to Malaysia criticising Myanmar, a break from the principle of non-interference.

The role of the international community in influencing Southeast Asian nations' attitudes towards refugee protection is clear. From the perspective of refugee norm adherence, the possibility of international assistance provided to affected first asylum countries, to the global framing of conflict in religious terms, it would not be unreasonable to expect that Thailand and Malaysia shift their attitudes depending on the context. The influence of the international community on refugee protection attitudes remains understated, and it should be taken into account in a consideration of refugee protection attitudes in Southeast Asia.

\section{Conclusion}

In this chapter, I examined the impacts of a variety of factors on the level of refugee protection in Southeast Asia pertaining to the Rohingya refugee situation. The results of the findings are not very promising for the Rohingya refugees.

The inconsistent nature of refugee protection in Southeast Asia is supported by the results of the analysis looking at Southeast Asia's response to the Rohingya refugee crisis. The issue of treaty ratification seems to be irrelevant here. Countries such as Thailand and Malaysia have often argued that despite a lack of treaty ratification, they have fulfilled their duties in accordance with international refugee protection norms.

With regard to the other factors such as domestic socio-economic factors, conceptualisation of the refugee, international factors and regional norms, the results were not very encouraging in the context of refugee protection in Southeast Asia during the Indochinese refugee crisis. These factors are significant but also varied in terms of impact. Questions of the negative economic impact on first asylum countries are often insufficient to sustain such arguments, given that the Rohingya's effect on jobs and economic growth has been marginal. The social perception of the Rohingya as Muslims, or criminal and health threats to the public also affected how much protection should be given to the Rohingya. Regional dynamics also retain significant influence over the level of refugee protection in Thailand and Malaysia. The 
principle of non-interference remains highly influential in mediating norms of refugee protection in Southeast Asia. This has encouraged Myanmar's reluctance in engaging with the issue at regional and international levels. While Malaysia has broken away from the ASEAN consensus of non-interference, Thailand has offered no assistance thus far. Furthermore, the securitisation of the refugee problem as one that is illegal in nature and approached from a nexus between regular and irregular migration takes away the impetus of resolving this through international refugee law. 


\section{Chapter 4: Conclusion}

This thesis set out to investigate if attitudes towards refugee protection have changed in Southeast Asia over the last fifty years. The changes can be measured by the factors influencing the policy responses of governments to mass refugee influxes from the Indochina and Rohingya refugee crisis. The purpose of this Chapter is to summarise the main findings of the thesis and propose some avenues for future research in this broad area of regional refugee protection.

\section{Causality of changes in refugee protection attitudes in Southeast Asia}

\section{Domestic Socio-Political Issues}

During the Indochina refugee crisis, governments in Southeast Asia had difficulties dealing with the huge influx of refugees because most of them were in the early stages of socioeconomic development. As the Indochinese refugee crisis occurred during the Cold War, Thailand and Malaysia's attitudes towards refugee protection was marked heavily by xenophobic overtones. However, there were slight differences in the ways they understood the Indochina refugee crisis. In Thailand, the perceived threat of ethnic disturbances arose from its geographical proximity to Vietnam, Cambodia and Laos. As a result, the influx of Indochinese refugees generated fears over the possibility of these refugees could be Khmer Rouge and Pathet Laos soldiers, undermining the security situation in Thailand's border provinces. In addition, the Vietnam's invasion of Cambodia also raised Thai concerns that it would soon be enveloped by Communist states, and the need to contain the spread of Communism in Southeast Asia informed its discriminatory policies towards refugee protection during the Indochinese refugee crisis.

Malaysia concurred with Thailand in seeing the Indochinese refugees as a communist threat, most notably with its assertion that the refugee situation was no longer a humanitarian problem but represented an invasion from Communist Vietnam. Traditionally, Malaysia has had issues with its more economically affluent minority Chinese. As a result, Malaysia's opposition to the Indochinese refugees was diametrical in response, informed by its experience of nation building and ended up being organised along racial lines, creating issues between the 
majority Malays and the ethnically Chinese Vietnamese. Therefore, racial considerations in Malaysia's refugee attitudes were more straightforward as opposed to Thailand's juggling of ethnic Vietnamese, Cambodians and Laotians.

The economic argument featured heavily in Thailand and Malaysia's attitudes towards refugee protection. Because Thailand and Malaysia resettled them in impoverished regions, any assistance provided to the Indochinese refugees created economic tensions between the local population and the refugees in these nascent nations. Subsequently, these tensions informed both countries' attitudes in developing an increasingly harder stance on future refugee arrivals.

In the more recent Rohingya refugee crisis, financial arguments continue to hold great currency in justifying an approach that has no regard for refugee protection. Despite the level of economic progress made in Thailand and Malaysia over the last fifty years, both countries have maintained that the Rohingya refugees only impose economic costs and do not offer any benefits to the country. Given that the Rohingya in these countries are only able to find work, often illegally, in the informal labour markets where they work in jobs shunned by all except the very poor (SALEP), the argument that they make no economic contributions and drain the nation's economy simply does not stand up to scrutiny. Despite costs associated with refugee processing and settlement, most of the Rohingya have maintained their agency to work and sustain themselves, albeit in squalid conditions.

With regards to the social impact of the Rohingya on issues of national security, there are slight differences in Thailand and Malaysia's attitudes towards the Rohingya refugees. In Malaysia, the Rohingya are often seen as contributing to levels of crime in different cities. It is widely believed that some Rohingya are involved in the drug trade and this has accounted for certain Malaysian states' refusal to host refugees in their territory. Any spillover effects from the religious and ethnic conflict in Myanmar have been quite limited, confined to the Myanmar community in Malaysia. Furthermore, Malaysia's status as an Islamic country suggests that the presence of the Rohingya will be tolerated, at least on grounds of religious solidarity.

In comparison with Malaysia, Thailand's concern over the Rohingya stems from religious differences between the Thai Buddhists and the Rohingya Muslims. Thailand is particularly apprehensive about how religious strife threatens its national security, especially in its Southern provinces where there is an ongoing Muslim insurgency. Notably, Thailand's religious composition is similar to Myanmar, where one of the root causes of the Rohingya 
refugee crisis is religious conflict between Buddhists and Muslims. From a religious perspective, this is where Thailand can be differentiated from Malaysia's attitude towards the Rohingya refugees. Threats to public health are also a notable feature in defining Thai sentiments towards the Rohingya refugees. Given that Myanmar nationals constitute a substantial proportion of the Thai sex industry, threats to public health is a factor in determining the level of protection afforded to the Rohingya refugees.

An appraisal of the two cases studies demonstrate that while the strategic nature of security threats has evolved, any consideration of protection afforded to the refugees continues to be subordinate to the national interest. If old fears were about ideological conflict, they have been replaced by public health and concerns about crime. The countries studied in this thesis remain highly sensitive to ethnic and religious disturbances that vary in context, and that will continue to inform the level of refugee protection in the region. The continued use of the financial costs argument for hosting refugees is debatable as the vast improvements in their economies and the linkages between refugees and their threats to the domestic economy remain unclear.

\section{Legal Aspects of Refugee Protection and its Impact on Refugees}

Any calls for Southeast Asian states to ratify the 1951 Convention and its 1967 Protocol have generally been met with the response that international refugee law is Eurocentric. None of the Southeast Asian states were signatories to the Convention during the First and Second Indochinese War. First, the status of non-ratification permitted Thailand and Malaysia to engage in policies of boat pushbacks and forced repatriation. For example, Thailand's policy on the Cambodian refugees was characterised by an initial acceptance and subsequent rejection while Malaysia continued to turn away boats, even going so far to suggest that these boats were to be fired upon as they reached Malaysian waters. These attitudes resulted in the 1979 Meeting on Refugees and Displaced Persons which then mobilised greater international assistance. This helped to cultivate the perception that not only was refugee protection conditional on international assistance, but it also clearly demonstrated the benefits of breaching the 1951 Convention even though the countries studied here were not signatories. Only when the commitment to resettlement was secured did Thailand and Malaysia continue to exercise its responsibilities as first asylum countries consistent with the practices outlined by international refugee law. 
Second, the lack of law and practice regarding refugee protection in Southeast Asia contributed to different ways in which refugee protection was conducted. Despite being bound by the Comprehensive Plan of Action (CPA), Thailand often limited the presence of UNHCR during the refugee status determination (RSD) process. On other hand, Malaysia allowed UNHCR to participate in the screening process, demonstrating a higher level of conformity with the guiding principles outlined by the CPA. However, it continued to turn away boats in 1989, breaching the condition of first asylum enshrined in the CPA. These examples indicate clearly that engagement with international refugee law was inconsistent and such attitudes contributed to different levels of protection for the Indochinese refugees.

Four decades later, only Cambodia and the Philippines have ratified the 1951 Convention and its 1967 Protocol. While the Eurocentric nature of international refugee law has become less central to Southeast Asian nations' arguments against hosting refugees, refugee protection in the region remains marked by inconsistency. The most interesting thing to note during this time period is how states such as Malaysia have articulated that nonratification of international refugee law is not necessarily correlated with poor protection standards. As this thesis has demonstrated, this is actually not the case. Malaysia's attitudes towards the Rohingya refugees have been inconsistent, characterised by policy 'backflips'. Where the Rohingya were recognised as refugees in 2003, Malaysia continued to periodically detain Rohingya on the basis of being unlawfully in the country, despite them having UNHCR documentation. As recent in July 2016, Malaysia decided to regain control of the RSD process, saying it was the sovereign right of Malaysia to determine who should be given asylum status rather than UNHCR. More importantly, Malaysia's insistence that any provisions of first asylum to the Rohingya refugees during the 2015 boat crisis would be made if resettlement was done within a year illustrates continuity with the approach taken during the Indochinese refugee crisis. The inconsistent engagement with UNHCR and the refugee protection practices in accordance with international refugee law indicates that such engagement is selective, where concerns over national sovereignty have influenced Malaysia's attitude towards refugee protection in Southeast Asia.

Thailand's has also mirrored Malaysia's recent move to regain control of the RSD process from UNHCR, and did so earlier in 2005. Central to Thailand's decision was the fact that any further acceptance of the Rohingya refugees had to take into account national security concerns and the rights of the Thai people. Therefore, both countries share similar attitudes on 
the importance of sovereignty that mediates the relationship between their obligations to international refugee law under the RSD process and refugee protection.

As Malaysia and Thailand are not signatories to the 1951 Convention, there is a lack of a domestic asylum framework that contains prescription for the treatment of refugees in these countries. The lack of a domestic asylum framework has remained consistent across the two refugee crises studied in this thesis. However, there is a significant shift to handle asylum seekers under the framework of domestic immigration laws. Malaysia's 1959/1963 Immigration Act and Thailand's Immigration Act of 1979 have featured prominently in the refugee protection discourse during the Rohingya refugee crisis. The tendency to describe and treat the Rohingya as illegal migrants instead of refugees provides evidence that such attitudes have become more common. Although Malaysia has shown more restraint in describing the Rohingya as illegal migrants in the public domain, their immigration law makes no distinction between statelessness, refugees and asylum seekers. Therefore, as the lack of a domestic asylum framework is mainly associated with non-ratification of the Convention, any attitudes towards refugee protection are often informed by Thailand and Malaysia's national immigration laws. This also allows for a process of arbitrary decision making, where most refugees are often treated as illegal immigrants and given treatment as befits a criminal.

In evaluating the changes of how a ratification of international refugee law affects levels of refugee protection over time, this thesis would argue that as Southeast Asian states continue to remain indifferent towards international refugee law, the level of refugee protection remains low. Firstly, attitudes towards refugee protection in the region continue to be determined by the level of resettlement to third countries and has not changed substantially from the Indochinese refugee crisis. Secondly, failure in ratifying the 1951 Convention can be linked to how there is a lack of a domestic refugee framework in Malaysia and Thailand. Despite this condition remaining constant over both refugee crises, there is a substantial move to consider the manner in which refugees are protected in these two countries under domestic immigration law. This indicates the continued significance of sovereignty norms that inform attitudes towards refugee protection in Southeast Asia.

However, there is an alternative proposition to consider. Both case studies have shown that countries such as Thailand and Malaysia do not completely reject the application of the Refugee Convention. If the hypothesised scenario that conformity with international refugee law does result in positive refugee attitudes and vice-versa, then it can be argued that the 
Refugee Convention does affect refugee attitudes in Thailand and Malaysia. However, this thesis has demonstrated that these states have chosen to selectively engage with international refugee law when it aligns with their own interests, disregarding it when it no longer suits them. It is unquestionable that the lack of ratification has created much uncertainty and ambiguity over their refugee policies. Instead of international law shaping attitudes towards refugee protection, socio-political interests shape the level of interaction with international law, which then results in poorer attitudes towards refugee protection. Therefore, to engage with these states from the perspective of international law and humanitarian aspirations may not be helpful as socio-political interests, both domestic, regional and international might be informing Southeast Asian nations' engagement with international refugee law.

\section{Conceptualisation of the Refugee}

The move to describe refugees as 'illegal immigrants' started during the Second Indochinese War. This shift is significant, for it determines the subsequent level of response given to them by the host governments. During the Indochinese Refugee Crisis, Thailand often labelled the Indochinese refugees as illegal immigrants, placing them into detention centres instead of refugee camps. In Malaysia, the large and organised arrivals of the Hoa by boat created the perception that they were illegal immigrants because of the way they left Vietnam. More importantly, the Hoa being ethnically Chinese and generally well to do created an image that did not conform to the stereotype of a suffering refugee in Malaysia. However, Malaysia was more sympathetic towards Cambodian Muslims and accepted them for asylum during the Indochinese refugee crisis. While Malaysia adopted a perspective that revolved around racial identities and the mode of departure in characterising the Indochinese refugees, it was similar to Thailand's approach in depicting the refugee arrivals as illegal immigrants.

During the Rohingya Boat Crisis, such practices of labelling became even more prominent. The constant references to the Rohingya as 'illegal immigrants' often places them under the purview of domestic immigration laws, and excludes them from the refugee determination process. For example, Thailand has continued to emphasise how any Rohingya refugees would be prosecuted by law as illegal immigrants upon entering Thai waters. Malaysia's treatment of the Rohingya in Lenggeng Immigration Detention Centre lends credence to the theory that they are being treated as illegal migrants in direct violation of the Anti-Trafficking in Persons Act 2007. In addition, the stateless nature of the Rohingya has also complicated attempts to situate them within the refugee protection agenda. Finally, the move 
to describe them as 'victims of trafficking' tends to securitise the refugee issue which is in essence, a humanitarian one. Human security then becomes a matter of national security, which does not put the well-being of the refugees ahead of other considerations.

Both case studies have demonstrated that attitudes towards refugee protection have remained unchanged and low because of Southeast Asian states' tendencies to avoid engaging the refugee issue as a refugee one, but rather using other labels such as economic migrants, illegal migrants, stateless and victims of trafficking so as to make the problem more manageable for them. It also allows them to avoid any humanitarian obligation they might have.

\section{Regional Dynamics in Southeast Asia}

Due to the tense geopolitical situation during the Indochinese refugee crisis, countries in Southeast Asia tended to interfere in each other's domestic affairs to secure their own strategic interests. This had implications for the refugee situation. Practices of interference were structured along ideological tensions between communism and capitalism. Thailand's indirect support for the Khmer Rouge after Vietnam's invasion of Cambodia and engaging in proxy wars against the Pathet Laos increased the number of refugees through the destruction of towns and villages. Refugees at the Thai-Cambodian border camp were also seen to have strategic value, providing as a buffer against the fighting. While Thailand's activities in Cambodia and Laos were quite interventionist, it cannot really be said to reflect regional norms as Vietnam, Cambodia and Laos were not members of ASEAN at that time. Malaysia did not face the same sort of political upheavals as it was relatively isolated from the revolutions in Indochina. However, Malaysia's attitude to refugee protection also converged with Thailand's position on how refugees were to be denied sanctuary on the basis that they were suspected communists. Due to Thailand's geographical position in Indochina, the level of interference was considerably higher than Malaysia, which came in the form of pressuring Vietnam to withdraw from Cambodia through ASEAN.

During the Rohingya Boat Crisis, the principle of non-interference has often been enforced by ASEAN's deference to Myanmar's refusal to allow any mentioning of the Rohingya at regional meetings. ASEAN has remained largely silent on the issue of citizenship for the Rohingya in Myanmar. However, recent developments in the Rohingya Crisis show that the practice of non-interference is being challenged. For example, Malaysia's denunciation of Myanmar's continued discrimination of the Rohingya in December 2016 clearly illustrates a 
departure from principles of non-interference. Malaysian Prime Minister Najib Razak proclaimed that he was not bothered if he was seen as interfering in Myanmar's internal affairs through his involvement at a political rally, saying he had a responsibility to show solidarity as a fellow Muslim to express his concern for the Rohingya. In February 2017, Malaysia's decision to send aid to the Rohingya could also be construed as an act of interference. In contrast with Thailand which has remained relatively quiet on the issue of non-interference, Malaysia's actions demonstrate divergence in terms of how practices of non-interference are exercised in Southeast Asia. Furthermore, this may indicate a gradual erosion of noninterference that may vary over time, subject to competing interests of race, religion and politics.

At regional forums, any discussion of the Rohingya is often linked to the Bali Process, a transnational mechanism that approaches the refugee issue from the nexus of people trafficking. This has led to the securitisation of the Rohingya as a matter of transnational crime, one that does not deal with the offering of asylum to the refugees, but rather, focuses on stemming the illegal departure of Rohingya from Myanmar.

The examples studied in the above two case studies clearly indicate that attitudes towards refugee protection at a regional level remains low. Despite Southeast Asian countries' commitment to the principle of non-interference, this commitment is not absolute as demonstrated in the Indochinese and Rohingya refugee crisis. What has changed over time, is the basis for interference. Where interference was justified on the basis of combatting communist insurgency during the Indochinese Refugee Crisis, Malaysia's practice of interference is aligned on religious grounds and humanitarian claims. This thesis has shown that the principle of non-interference is not necessarily set in stone and often changes when it is politically expedient to do so. Also, any prospective chances for regional cooperation also remain poor as discussion remains untranslated to concrete action. The most important change arising from both case studies shows that refugee issues are now being placed under the framework of transnational crime, and this has great implications for the refugee protection agenda in Southeast Asia. 


\section{International Influences}

The Indochinese Refugee Crisis was unique for the fact that it involved superpowers competing for influence in Southeast Asia. Southeast Asian countries' reluctance to align themselves with China or the Soviet Union influenced the level of interventionary practices in Indochina and created higher refugee numbers. On the other hand, the success of the first asylum policy was also driven by the international commitment to resettle them. Based on quantitative evidence on figures of first asylum and resettlement, it can be argued that refugee policies in Southeast Asia were generally successful.

Fifty years later, the Rohingya Boat Crisis has not seen any success in terms of guaranteeing first asylum and resettling refugees. International support for the Rohingya has been expressed in rhetorical terms, but any major commitment to resettling those in Thailand and Malaysia has not been forthcoming. This continues the trend of Southeast Asian countries depending on Western solutions to refugee crises since the Second Indochinese War. Furthermore, weak international leadership in refugee protection, as seen by the evidence of Australia promoting dubious practices in refugee protection may encourage Southeast Asian nations to do the same as well. At the same time, the ongoing Syrian refugee crisis that is affecting both countries in Europe and North America also diverts much of the focus on humanitarian aid from the Rohingya situation as well. International coverage of the Rohingya conflict in Rakhine state as a religious one has also increased the level of resistance Myanmar has over discussing the Rohingya at international forums.

The influence of the international community is clear and has implications for attitudes towards refugee protection in Southeast Asia. The tendency to call for greater international involvement by Southeast Asia remains unchanged across the two case studies examined, suggesting that the region remains reliant on international aid to resolve humanitarian crises. At the same time, good norm leadership in refugee protection is crucial in encouraging Southeast Asian countries to follow suit as well.

\section{Whither Refugee Protection in Southeast Asia?}

There are five key factors that explain why attitudes towards refugees in Southeast Asia have not changed for the better. First, despite the change of security threats from the Indochinese refugee crisis to the Rohingya boat crisis, attitudes towards refugee protection in 
Southeast Asia continue to be determined by ethnic and economic considerations. Despite slight variations in how Thailand and Malaysia constructed the refugee narrative during the Indochinese refugee crisis, both countries' attitudes towards refugee protection centred on how the ethnically diverse nature of refugees shared a common feature - the communist threat. In the Rohingya case study, racial considerations no longer had any strategic implications in shaping Thailand and Malaysia's attitudes, but became delineated along religious lines of Buddhism and Islam. Economic considerations continue to shape the level of refugee protection in the region. However, such arguments hold less relevancy when considering the economic roles of the Rohingya in recent years.

Second, the status of most Southeast Asian states as non-signatories to the Refugee Convention continue to impede efforts at refugee protection. Despite the levels of nonratification of the Refugee Convention during the Indochinese Refugee Crisis, there was a higher level of engagement with international refugee law due to the ODP and CPA. However, such engagement was performed on a selective basis, and Thailand and Malaysia's participation as first asylum countries continued on the condition that the international community would resettle them in the near future. The ad-hoc nature of refugee protection continues till today, as Malaysia has continued to express its doubts over the utility of the 1951 Convention, arguing that it has fulfilled its obligations better than other states who have ratified the Convention.

A significant difference between the two case studies is the prominence of national immigration laws to deal with the Rohingya refugee crisis - this approach was notably absent during the Indochinese refugee crisis. This development can be explained by a few key issues. First, there was a closer engagement with the Refugee Convention because the ODP and CPA played key roles in fostering Southeast Asia's attitudes towards refugee protection. Principles of first asylum and non-repatriation, key tenets of the Refugee Convention were found in these programmes. Compared with the Rohingya Refugee Crisis, the lack of such programmes allowed Thailand and Malaysia to develop their own responses that focused heavily on the primacy of state sovereignty. Attitudes that sought to preserve the country's position with regards to refugee protection thus featured heavily in the refugee protection discourse during the Rohingya refugee crisis as evidenced by the use of national immigration laws to deal with the refugees. Secondly, another reason for the employment of national immigration laws to deal with refugee law lies in the fact that a non-ratification of the 1951 Convention results in 
the lack of national refugee protection regimes, and this may explain the turn to punitive measures when dealing with the Rohingya.

However, this thesis has also proposed that to approach an analysis of Southeast Asia's attitudes towards refugee protection from the argument that the non-ratification of international refugee law results in lower levels of protection may be counter-productive here. Countries such as Thailand and Malaysia do not completely disregard the 1951 Convention. Both have shown an inclination to engage with the Refugee Convention, but only on grounds that suit them. To argue that Southeast Asia attitudes towards refugee protection are low because of a non-ratification is erroneous - such attitudes are informed by other considerations such as socio-political issues, regional and international influences.

Third, the labelling of the refugee in both regional and national discourse has a direct impact on how refugee protection efforts are operationalised. The characterisation of refugees as economic or illegal migrants has remained fairly consistent across the two case studies examined here. Again, the function of domestic immigration law is central to how refugee protection is conducted in the region. The state's interest in maintaining its control over the regulation of documented and undocumented individuals retains much influence over its attitudes towards refugee protection. As such, refugees are now processed under the framework of transnational crime and illegal trafficking.

Fourthly, regional dynamics in Southeast Asia are important determinants of refugee protection attitudes among Southeast Asian countries. The practice of non-interference continues to inform attitudes towards refugee protection regionally, and it varies accordingly to the socio-political context of the refugee crisis. This thesis has questioned the assumption that non-interference as a fixed principle guiding relations between states in Southeast Asia. In the Indochinese refugee crisis, Southeast Asian countries' interference in Vietnam, Cambodia and Laos through proxy wars and support for counter-communist forces contributed to the exacerbation of refugee numbers at that time. More importantly, the strategic dimensions of manipulating refugee flows as evidenced by Thailand's purposive sheltering of the Cambodian refugees along its border suggests that refugees were seen as interventionary tools to counter the Communist threat in Indochina. At the same time, Malaysia's interpretation of the Vietnamese refugees as a Communist invasion subsequently informed their policy of boat pushbacks. 
The regional dynamics surrounding non-interference have not changed during the Rohingya boat crisis. While ASEAN as a regional organisation has remained largely intransigent on Myanmar's role in the Rohingya refugee crisis, individual countries such as Malaysia have recently broken from the regional consensus on non-interference. Islam had a role in influencing its decision to criticise Myanmar and send aid to the Rohingya in Rakhine. However, Thailand's silence on the matter bears the possibility of a wide variety of refugee protection attitudes in Southeast Asia, one that might be informed by religious considerations at this time. At the same time, contemporary developments on the Rohingya issue show an increasing tendency to resolve the refugee crisis through multilateral channels of transnational crime and human trafficking, stripping away the humanitarian element of this issue which is essentially a humanitarian one. This will continue to guide and influence Southeast Asian countries' attitudes towards refugee protection, by steering it towards an approach that remains grounded in arguments of national sovereignty and security.

Finally, the findings on the role of the international community in this thesis demonstrate that countries such as Southeast Asia continue to rely on international aid and resettlement across both case studies. As guarantees for refugee resettlement during the Indochina Refugee Crisis were higher as compared to the Rohingya Boat Crisis, the degree in which Rohingya refugees have been accepted for first asylum have been limited. As the international commitment to the Indochinese refugees were also informed by the ideological divide between Capitalism and Communism, the lack of such an issue fails to offer impetus to refugee resettlement efforts to the Rohingya. Furthermore, the gravity of the Syrian Refugee Crisis has also taken away much attention from the Rohingya issue. Arguably, this situation puts Southeast Asian countries in a position where they are left unrestrained to do whatever they want with the Rohingya, accounting for the inconsistent and varied attitudes towards refugee protection for the Rohingya case study.

This thesis has started off with a set of ambitious aims. It goes beyond a simple critical analysis by arguing for a more comprehensive approach to assess how refugee protection norms have evolved in Southeast Asia over the last five decades. It has investigated each factor that affects the level of refugee protection in depth, by evaluating domestic, regional and international refugee protection framework and practice, analysing historical and recent developments in refugee protection. The concluding chapter of this thesis has demonstrated that refugee protection attitudes may have varied depending on evolving socio-political norms, but they have not changed in terms of the outcome for refugees. The evolution of refugee 
protection attitudes is contingent on socio-political issues that vary across context and time periods, but such attitudes continue to inform practices that are inconsistent and ad-hoc. The five key factors analysed in this thesis also supports the mutually reinforcing nature of sociopolitical issues on regional dynamics and conceptualisation of the refugee across the two case studies. Furthermore, any legal obstacles to refugee protection, international or domestic, refugee or illegal immigrant are highly dependent on each other in creating attitudes towards refugee production.

In social science, it is virtually impossible to single out which of these five factors is the most important in determining attitudes towards refugee protection in Southeast Asia. This thesis does not pretend to have all the answers, but it aims to explain the problems with refugee protection in Southeast Asia as completely as possible. Certainly, an understanding of one particular issue cannot be divorced from an analysis of others, as these factors interact with each other to produce inconsistent and poor practices in refugee protection across the two case studies analysed in this thesis.

\section{Limitations and Contributions of This Study}

As an exploration of attitudes towards refugee protection in Southeast Asia, this thesis seeks the lay the groundwork for a more expansive study on what makes countries more inclined to offer asylum to refugees. However, the study is far from conclusive. In addition to certain limitations inherent in the research design, some additional actors or factors should be listed to guide future research.

The greatest limitation of this study is how the State continues to serve as a reference point for charting attitudes towards refugee protection. This implies that a rights-based protection approach to refugees continues to be articulated through modalities of state sovereignty and power. While the State does retain considerable power in deciding the level of refugee protection in terms of how it participates in the global refugee protection regime and regulates the movement of asylum seekers within its borders, the role of non-governmental organisations, religion and domestic opinion on refugee attitudes in Thailand and Malaysia also help shape the level of refugee protection in these countries as well. Notwithstanding the broad range of results achieved in the qualitative analyses, failure to consider these dynamics in greater depth makes the study less comprehensive. 
Furthermore, because of space constraints, this thesis has selected the countries of Thailand and Malaysia because refugee crises in the region have had the most impact on them. Therefore, it is unable to truly chart the level of refugee protection attitudes in Southeast Asia due to its omission of other ASEAN nations. If the attitudes and policies of other Southeast Asian countries were considered, it is possible that differing sentiments on refugee politics could be elucidated. For example, the inclusion of Cambodia or the Philippines would allow us to examine whether ratification of the 1951 Convention does make a difference to refugee protection attitudes.

This thesis raises an important topic for further research on the securitisation of humanitarian concerns in Southeast Asia. There is a dearth of literature that examines the securitisation of humanitarian issues in Southeast Asia. Most literature has focused on the regional security architecture in ASEAN, one that revolves around how non-interference norms continue to influence levels of regional cooperation. The studies that come closest to broaching the topic of refugees; have focused mainly on the effectiveness of the ASEAN Intergovernmental Commission on Human Rights (AICHR) and ASEAN Human Rights Declaration (AHRD), revealing how differing attitudes towards human rights held among different ASEAN countries might threaten the 'ASEAN consensus'. Therefore, little attention has been paid to how states in Southeast Asia have strategically engaged with issues of refugee crisis. This thesis makes an important contribution to the discussion by drawing on insights on refugee protection from the region of Southeast Asia. A starting point would be to develop arguments and an understanding of how states in Southeast Asia might be engaging in the process of securitising humanitarian issues, one so evident in the recent Rohingya boat crisis.

There is the possibility of this thesis making a contribution to norm literature in Southeast Asia. It is generally held that international humanitarian norms have yet to take hold in Southeast Asia, and any move towards the embrace of humanitarian ideals remains either piecemeal or selective. As evidenced in the Rohingya Boat Crisis, any efforts to deal with the humanitarian crisis were constantly referred to the Bali Process, a framework that sought to deal with the refugee influx as a matter of transnational crime, smuggling and trafficking. While Southeast Asia and the countries analysed in this thesis remain uncooperative with international refugee law, it is plausible that the constant reference of asylum matters to a transnational framework that looks at refugees as a security issue may suggest how states in Southeast Asia are attempting to localise refugee protection norms in their own regional context. This allows them to deal with humanitarian issues, but under the guise of transnational 
cooperation in matters of crime, prevents them violating the principle of non-interference. However, the nature of this study is only exploratory at this point, and while there is potential for such an idea to be developed, more research needs to be directed to studying this phenomenon.

Fifty years have passed since the Second Indochina War, it is disheartening to see that attitudes towards refugee protection in Southeast Asia have not changed much. At the very best, the countries selected in this study have demonstrated a propensity to selectively engage with refugee law only when it suits them. This scenario is actually not dissimilar from other countries around the world. A continued violation of international refugee law around the world, by European countries during the Syrian refugee crisis and Australia's continued insistence to process refugees on Nauru and Manus are clear indications that refugee protection, globally, is being eroded.

Considering that Asia is the only continent that has neither regional refugee protection mechanisms nor an authoritative regional convention on refugees currently, it would not be unreasonable to expect that attitudes towards refugee protection will continue to remain poor. On the other hand, it might be counterproductive to argue that Southeast Asian countries' poor attitudes towards refugee protection is entirely due to the lack of ratification of the 1951 Convention. The different socio-political interests that Southeast Asian states hold help shape attitudes towards refugee protection in Southeast Asia. Efforts at refugee protection become compromised when these interests permeate the national discourse on state sovereignty. International refugee law thus loses its crucial influence on regulating refugee protection attitudes in states and becomes circumstantial when states start exhibiting interest seeking behaviour. The selective engagement with the 1951 Convention by Thailand and Malaysia is a clear example of this. Given the diversity of race, religion, political and legal practices in Southeast Asia, the inconsistent and poor attitudes towards refugee protection reflects the profound divergences within Southeast Asia about the idea and practice of refugee protection, and seem likely to continue for the foreseeable future. 


\section{Reference List}

Abad, Jr. M.C. 2004. "Prospects for UN-ASEAN Cooperation In Conflict Management?" Paper presented at the Third UN-ASEAN Conference on Conflict Prevention, Singapore, 1719 February 2003, cited in Beverley Loke, 2004, "The 'ASEAN Way': Towards Regional Order and Security Cooperation?” Melbourne Journal of Politics 30: 8-38.

Abdul Aziz, Fauwaz. 2015. "Corruption, fraud alleged in Rohingya registration." Malaysiakini, August 15. Accessed June 16, 2016. https://www.malaysiakini.com/news/55415.

Acharya, Amitav. 2009. Whose Ideas Matter?: Agency and Power in Asian Regionalism. Ithaca: Cornell University Press.

Agence France-Presse. 1979. Vietnam helping to purge Chinese from Kampuchea. June 6. Singapore: The Straits Times Microfilms.

Agence France-Presse. 2005. "Malaysia to allow thousands of refugees to work to solve labour crunch." Accessed June 16, 2016. http://reliefweb.int/report/indonesia/malaysiaallow-thousands-refugees-work-solve-labour-crunch.

Agence France-Presse. 2009. "Burmese migrants say cast adrift by Thais: Indonesia navy." Sydney Morning Herald, February 4. Accessed June 17, 2016.

http://www.smh.com.au/world/burmese-migrants-say-cast-adrift-by-thais-indonesia-navy20090203-7wuo.html.

Agence France-Presse. 2014. "Malaysia police detain 15 Burmese over series of gruesome murders." The Guardian, December 5. Accessed October 23, 2016.

https://www.theguardian.com/world/2014/dec/05/malaysian-police-detain-15-burmesemurders-penang.

Agreement between the United Nations High Commissioner for Refugees and the Government of Thailand. 1975, cited in W. Courtland Robinson, 1998, Terms of Refuge: The Indochinese Exodus and the International Response. London: Zed Books.

Ahmad, Zakaria Haji. 1979. "Vietnamese Refugees and ASEAN." Contemporary Southeast Asia 1 (1): 66-74.

Al Jazeera. 2014. "UN Calls for Full Rohingya Citizenship.” Al Jazeera, December 30. Accessed July 29, 2016. http://www.aljazeera.com/news/americas/2014/12/un-calls-fullrohingya-citizenship-myanmar-monks-rakhin-2014123044246726211.html.

Al-Jazeera. 2017. "Malaysian ship with aid for Rohingya docks in Myanmar." Al-Jazeera News, February 10. Accessed February 17, 2017.

http://www.aljazeera.com/news/2017/02/malaysian-ship-aid-rohingya-docks-myanmar170209090106480.html. 
Al-Mahmood, Syed Zain and Anita Rachman. 2015. "Indonesia, Malaysia Agree to Help Migrants Stranded at Sea." The Wall Street Journal, May 20. Accessed June 16, 2016. http://www.wsj.com/articles/indonesia-malaysia-to-help-migrants-stranded-at-sea1432106129.

Amnesty International. 2010. "Abused and Abandoned: Refugees Denied Rights in Malaysia." Accessed June 16, 2016.

https://www.amnesty.org/en/documents/ASA28/010/2010/en/.

Anand, JP. 1978. "Refugees from Burma." Economic and Political Weekly 12: 1100-1101.

Areethamsirikul, Sarinna. 2009. "Rohingya, the charter's first challenge." Bangkok Post, February 24. Accessed October 28, 2016.

http://www.burmanet.org/news/2009/02/24/bangkok-post-rohingya-the-charters-firstchallenge-\%E2\%80\%93-sarinna-areethamsirikul/.

Asian-African Legal Consultative Organisation (AALCO). 1966. "Bangkok Principles on the Status and Treatment of Refugees.” Accessed May 13, 2016.

http://www.refworld.org/docid/3de5f2d52.html.

Asian-African Legal Consultative Organisation (AALCO). n.d. "About AALCO.” Accessed May 13, 2016. http://www.aalco.int/scripts/view-posting.asp?recordid=1.

Association of Southeast Asian Nations (ASEAN). 1971. "1971 Zone of Peace, Freedom and Neutrality Declaration." Accessed July 28.

http://www.icnl.org/research/library/files/Transnational/zone.pdf.

Association of Southeast Asian Nations (ASEAN). 1979. 1979 Joint Communique of the Twelfth ASEAN Ministerial Meeting. https://cil.nus.edu.sg/rp/pdf/1979\%20Joint\%20Communique\%20Of\%20The\%20Twelfth\%20 ASEAN\%20Ministerial\%20Meeting-pdf.pdf.

Association of Southeast Asian Nations (ASEAN). 2008. The ASEAN Charter. Accessed September 2016. http://asean.org/wp-content/uploads/images/archive/publications/ASEANCharter.pdf

Association of Southeast Nations (ASEAN). 2012. ASEAN Human Rights Declaration. http://www.asean.org/storage/images/ASEAN_RTK_2014/6_AHRD_Booklet.pdf.

Association of Southeast Asian Nations (ASEAN). 2015. ASEAN Plan of Action Against Trafficking in Persons, Especially Women and Children. Accessed October 18, 2016. http://www.asean.org/wp-content/uploads/2015/12/APA-FINAL.pdf.

ASEAN Parliamentarians for Human Rights. 2014. "Proposed law restricting inter-faith marriage in Myanmar is dangerous, discriminatory and unnecessary, ASEAN MPs warn." Accessed October 30, 2016. http://aseanmp.org/2014/03/26/proposed-law-restricting-interfaith-marriage-in-myanmar-is-dangerous-discriminatory-and-unnecessary-asean-mps-warn/. 
Azam, Suhaini and Michael Vatikiotis. 1990. Malaysia, Indonesia at centre of boat people row. Far Eastern Economic Review, May 3. Factiva.

Bali Process. n.d. "About the Bali Process.” Accessed November 11, 2016.

http://www.baliprocess.net/.

Bali Process. 2009. Third Bali Regional Ministerial Conference on People Smuggling, Trafficking in Persons and Related Transnational Crime.

http://www.baliprocess.net/UserFiles/baliprocess/File/Co\%20chairs\%20statement\%20BRMC $\% 20$ III_FINAL.pdf.

Bali Process. 2016. Bali Declaration on People Smuggling, Trafficking In Persons and Related Transnational Crime, Sixth Ministerial Conference.

http://www.baliprocess.net/UserFiles/baliprocess/File/Bali\%20Declaration\%20on\%20People $\%$ 20Smuggling\%20Trafficking\%20in\%20Persons \%20and\%20Related\%20Transnational $\% 20$ Crime\%202016.pdf.

Bangkok Post. 2009. "Malaysia: Prime Minister Abdullah urges firmness in turning back Rohingya refugees." Bangkok Post, February 27. Accessed 20 June, 2016. https://www.pressreader.com/thailand/bangkok-post/20090227/281492157222599.

Bangkok Post. 2013a. "Paradon rules out Rohingya refugee status." Bangkok Post, February 1. Accessed June 17, 2016. http://www.bangkokpost.com/print/333676/.

Bangkok Post. 2013b. "PM taps navy to head off illicit migrant 'surge'." Bangkok Post, January 16. Accessed 19 June, 2016. http://www.bangkokpost.com/print/330975/.

Banglapedia, The National Encyclopaedia of Bangladesh, s.v. "Rohingya," Accessed October 18, 2016. http://en.banglapedia.org/index.php?title=Rohingya.

Beh, Lih Yi. 2004. "Nazri warns of possible influx of refugees." Malaysiakini, November 25. Accessed July 28, 2016. https://m.malaysiakini.com/news/31661.

Bercowtch, Jacob, Oishim Mikio and Kamarulzaman Askandar. 2002. "The ASEAN way of conflict management: Old Patterns and New Trends." Asian Journal of Political Science 10 (2): $21-42$.

Betts, Alexander. 2006. Comprehensive Plans of Action: Insights from CIREFCA and the Indochinese CPA. http://www.unhcr.org/43eb6a152.pdf.

Blitz, Brad K. 2010. "Rescue for the Rohingya.” World Today 66 (5): 30.

Bohning, W.R. 1998. "Conceptualising and Stimulating the Impact of the Asian Crisis on Filipino's Employment Opportunities Abroad." Asian and Pacific Migration Journal 7 (2/3): 339-367. 
Borneo Post. 2015. "Rohingya welfare body pressures UNHCR to expedite refugee resettlement."Accessed September 28, 2016.

http://www.theborneopost.com/2015/05/21/rohingya-welfare-body-pressures-unhcr-toexpedite-refugee-resettlement/.

British Broadcasting Corporation (BBC) News. 2015. "Why are so many Rohingya migrants stranded at sea?" BBC Asia News, May 18. Accessed May 19, 2016.

http://www.bbc.com/news/world-asia-32740637.

Brown, William A. 1988. "Indochinese Refugees and Relations with Thailand." Statement of State Bulletin, February 24. Proquest.

Chambers, Paul. 2015. "Thailand Must End Its Own Rohingya Atrocity.” Accessed June 17, 2016. http://thediplomat.com/2015/10/thailand-must-end-its-own-rohingya-atrocity/.

Chatelard, Geraldine. 2006. "Jordan as a transit country: semi-protectionist immigration policies and their effects on Iraqi forced migrants." Accessed July 21, 2016.

http://www.unhcr.org/research/working/3d57aa757/jordan-transit-country-semi-protectionistimmigration-policies-and-effects.html.

Cheung, Samuel. 2011. "Migration Control and the Solutions Impasse in South and Southeast Asia: Implications from the Rohingya Experience." Journal of Refugee Studies 25 (1): 50-70.

Chia, Jasmine. 2016. “The truth about Myanmar's Rohingya Issue.” Accessed October 30, 2016. http://thediplomat.com/2016/03/the-truth-about-myanmars-rohingya-issue/.

Chimni, B.S. 1998. "The Geopolitics of Refugee Studies: A View from the South.” Journal of Refugee Studies 11 (4): 350-374.

Coe, Brooke. 2015. "Sovereignty Regimes and the Norm of Noninterference in the Global South." Global Governance 21 (2): 275-298.

Cooke, Richard. 2015. "Nope, Nope, Nope: Why Australia won't help the Rohingya." Accessed October 30, 2016.

https://www.themonthly.com.au/issue/2015/august/1438351200/richard-cooke/nope-nopenope.

Cooper, Robert. 1986. "The Hmong of Laos: Economic Factors in Refugee Exodus and Return." In The Hmong in Transition, edited by Glenn L. Hendricks, Bruce T. Downing and Amos S. Deinard, 23-40. New York: The Center for Migration Studies of New York.

Corben, Ron. 2009. "Thailand: Thailand to Investigate Rohingya Refugee Abuse Claims." VOA News, January 20. Accessed June 18. http://www.voanews.com/english/2009-01-19voa28.cfm?rss=thailand.

Crock, Mary. 2014. "Shadow Plays, Shifting Sands and International Refugee Law:

Convergences in the Asia Pacific." International \& Comparative Law 63 (2): 247-280.

Dalglish, Carol. 1989. Refugees from Vietnam. London: Macmillan 
Das, K. 1979. ASEAN Hits Back at Hanoi. Far Eastern Economic Review, June 22. Proquest.

Dauvergne, Catherine. 2000. "The Dilemma of Rights Discourses for Refugees." UNSW Law Journal 23 (3): 56-74.

Davies, Mathew. 2013. "The ASEAN Synthesis: Human rights, Non-intervention and the ASEAN Human Rights Declaration." Georgetown Journal of International Affairs 14 (2): 518.

Davies, Mathew. 2014. "States of Compliance? Global Human Rights Treaties and ASEAN Member States." Journal of Human Rights 13 (4): 414-433.

Davies, Sara E. 2006. "Saving refugees or saving borders? Southeast Asian States and the Indochinese refugee crisis." Global Change, Peace \& Security 18 (1): 3-24.

Davies, Sara E. 2008. "Realistic yet humanitarian? The Comprehensive Plan of Action and Refugee Policy in Southeast Asia.” International Relations of the Asia-Pacific 8 (2): 191-217.

Davies, Sara E. 2008. Legitimising rejection: international refugee law in Southeast Asia. Boston: Martinus Nijhoff.

Dunford, Jack. 2000. "Principles Relating to Humanitarian Assistance: Dealing with Sovereignty: Burma." Refugee Survey Quarterly 19 (2): 159-169.

Dupont, Alan. 2000. “ASEAN's Response to the East Timor Crisis.” Australian Journal of International Affairs 54 (2): 163-170.

Feller, Erika. 2001 "The Evolution of the International Refugee Protection Regime." Washington University Journal of Law and Policy 5 (1): 129-143.

Frost, Frank. 1980. "Vietnam, ASEAN and the Indochina Refugee Crisis." Southeast Asian Affairs 347-367.

Gatrell, Peter. 2013. The Making of the Modern Refugee. New York: Oxford University Press.

George, Alexander L. and Andrew Bennett. 2005. Case Studies and Theory Development in the Social Sciences. Cambridge, MA: MIT Press.

Ghazali, Rahmah. 2014. "Parliament: Malaysia most humane to refugees, says Shahidan." The Star, April 8. Accessed 28 June, 2016.

http://www.thestar.com.my/news/nation/2014/04/08/parliament-shahidan-refugee/.

Global Centre for the Responsibility to Protect. 2015. Policy Brief: Persecution of the Rohingya in Burma/Myanmar and the Responsibility to Protect.

http://www.globalr2p.org/media/files/2015-march-burma-brief-1.pdf. 
Goh, Melissa. 2015. "ASEAN to set up joint task force, fund to combat human trafficking." Channel Newsasia, July 2. Accessed October 18, 2016.

http://www.channelnewsasia.com/news/asiapacific/asean-to-set-up-joint/1956660.html.

Gordenker, Leon. 1987. Refugees in International Politics. New York: Columbia University Press.

Head, Jonathan. 2009. "Thailand's deadly treatment of migrants.” BBC News, January 17. Accessed 17 June, 2016. http://news.bbc.co.uk/2/hi/south_asia/7834075.stm.

Head, Jonathan. 2015a. "Ten deaths on stranded Myanmar migrant boat." BBC News, May 14. Accessed October 21, 2016. http://www.bbc.com/news/world-asia-32733963.

Head, Jonathan. 2015b. "Thousands of Rohingya and Bangladeshi migrants stranded at sea." BBC News, May 11. Accessed October 21, 2016. http://www.bbc.com/news/world-asia32733963.

Helton, Arthur C. 1990. "The Comprehensive Plan of Action for Indo-Chinese Refugees: An Experiment in Refugee Protection and Control.” New York Law School Journal of Human Rights 8 (1): 111-148.

Helton, Arthur C. 1991a. "The Malaysian Policy to Redirect Vietnamese Boat People: NonRefoulement as a Human Rights Remedy." New York University Journal of International Law \& Politics 24 (3): 1203-1218.

Helton, Arthur C. 1991b. "Judicial Review of the Refugee Status Determination Procedure for Vietnamese Asylum Seekers in Hong Kong: The Case of Do Giau." Brooklyn Journal of International Law 17 (2): 263-292.

Helton, Arthur C. 1993. "Refugee Determination under the Comprehensive Plan of Action: Overview and Assessment." International Journal of Refugee Law 5 (4): 544-558.

Hindstrom, Hanna. 2012. "ASEAN 'cannot' press Burma on Rohingya citizenship." http://reliefweb.int/report/myanmar/asean-\%E2\%80\%98cannot\%E2\%80\%99-press-burmarohingya-citizenship.

Hookaway, James. 2015. "Southeast Asia Seeks Regional Solution to Refugee Crisis." The Wall Street Journal, May 29. Accessed June 14, 2016. http://www.wsj.com/articles/refugeecrisis-requires-regional-solution-thailand-says-1432875766.

Human Rights Watch. 1996. "Burma: The Rohingya: Ending a Cycle of Exodus?” Accessed October 12, 2016. http://www.refworld.org/docid/3ae6a84a2.html.

Human Rights Watch. 2000a. "Burmese Refugees in Bangladesh." Accessed October 10, 2016. http://www.hrw.org/en/reports/2000/05/01/burmese-refugees-bangladesh-0 
Human Rights Watch. 2000b. "Malaysia's Treatment of Undocumented Rohingya." Accessed July 17, 2016. https://www.hrw.org/reports/2000/malaysia/maybr008-02.htm.

Human Rights Watch. 2012. Ad Hoc and Inadequate: Thailand's Treatment of Refugees and Asylum Seekers. https://www.hrw.org/sites/default/files/reports/thailand0912.pdf.

Human Rights Watch. 2013. "All You Can Do is Pray: Crimes Against Humanity and Ethnic Cleansing of Rohingya Muslims in Burma's Arakan State.” Accessed June 15, 2016. https://www.hrw.org/report/2013/04/22/all-you-can-do-pray/crimes-against-humanity-andethnic-cleansing-rohingya-muslims.

Human Rights Watch. 2014. "Burma: Government Plan Would Segregate Rohingya."Accessed June 16, 2016. https://www.hrw.org/news/2014/10/03/burmagovernment-plan-would-segregate-rohingya.

Hunt, Richard A. 2015. Melvin Laird and the Foundation of the Post-Vietnam Military: 1969-1973.

http://history.defense.gov/Portals/70/Documents/secretaryofdefense/OSDSeries_Vol7.pdf.

Huxley, Tim. 1987. “ASEAN's Prospective Security Role: Moving Beyond the Indochina Fixation." Contemporary Southeast Asia 9 (3): 194-207.

IRIN. 2009. "Key Asian meeting fails to resolve Rohingya issue." IRIN, April 17. Accessed June 19, 2016. http://www.irinnews.org/news/2009/04/17/keyasian-meeting-fails-resolve-rohingya-issue.

Jacobsen, Karen. 2001. The Forgotten Solution: Local Integration for Refugees in Developing Countries. http://www.unhcr.org/3b7d24059.pdf.

Jones, Lee. 2007. "ASEAN intervention in Cambodia: from Cold War to conditionality." The Pacific Review 20 (4): 523-550.

Jones, Lee. 2010. "ASEAN's unchanged melody? The theory and practice of noninterference in Southeast Asia." Pacific Review 23 (4): 479-502.

Jones, Lee. 2013. "Sovereignty, intervention, and social order in revolutionary times." Review of International Studies 39 (5): 1149-1167.

Lavoie, Caroline and Raymond B. Knock. 1990. "The ASEAN and International Response to the Southeast Asian Refugee Crisis: A Canadian Perspective." Southeast Asian Journal of Social Science 18 (1): 43-65.

Lee, Kuan Yew. 1979. Transcript of Press Conference Held By Prime Minister Lee Kuan Yew in London on 21 June, 1979.

http://www.nas.gov.sg/archivesonline/data/pdfdoc/lky19790621.pdf.

Kalra, Priyanka. 2013. State of the Stateless Rohingyas. New Delhi: Delhi Press. 
Kasem, Supamart. 2007. 40 Rohingya forced to Burma. Bangkok Post, July 28. Proquest.

Kassim, Yang Razali. 2012. "Plight of the Rohingya: ASEAN Credibility Again at Stake." Accessed June 19, 2016. http://reliefweb.int/report/myanmar/plight-rohingya-aseancredibility-again-stake.

Kiernan, Ben. 2004. How Pol Pot Came to Power: Colonialism, Nationalism, and Communism in Cambodia, 1930-1975. New Haven: Yale University Press.

Kiernan, Ben. 2008. The Pol Pot Regime: Race, Power and Genocide in Cambodia Under the Khmer Rouge, 1975-79. New Haven: Yale University Press.

Kingdom of Thailand. 1979. Immigration Act 1979, Chap 2. Accessed September 2016. http://www.refworld.org/docid/46b2f9f42.html.

Kingston, Lindsey N. 2015. "Protecting the world's most persecuted: the responsibility to protect and Burma's Rohingya minority." The International Journal of Human Rights 19 (8): $1163-1175$.

Kipgen, Nehginpao. 2014. "Addressing the Rohingya Problem.” Journal of Asian and African Studies 49 (2): 234-247.

Kneebone, Susan. 2016. "Comparative regional protection frameworks for refugees: norm and norm entrepreneurs.” The International Journal of Human Rights 20 (2): 143-172.

Kramer, Barry. 1980. Bending with the wind. The Wall Street Journal, January 22. Proquest.

Kumar, Prem. 2015. "Malaysian states refuse to shelter Rohingya migrants." Anadolu Agency, May 24. Accessed October 23, 2016. http://aa.com.tr/en/world/malaysian-statesrefuse-to-shelter-rohingya-migrants/43913.

Kumin, Judith. 2008. "Orderly Departure from Vietnam: Cold War Anomaly or Humanitarian Innovation?” Refugee Survey Quarterly 27 (1): 104-117

Lamb, Kate. 2015. "They hit us, with hammers, by knife: Rohingya migrants tell of horror at sea." The Guardian, May 17. Accessed October 21, 2016.

https://www.theguardian.com/world/2015/may/17/they-hit-us-with-hammers-by-kniferohingya-migrants-tell-of-horror-at-sea.

Lewa, Chris. 2009. "North Arakan: a open prison for the Rohingya in Burma." Forced Migration Review 1 (32): 11-3.

Lin, Mayuri Mei. 2016. "UNHCR barred from issuing ID cards, minister says.” The Malay Mail Online, July 20. Accessed October 30, 2016.

http://www.themalaymailonline.com/malaysia/article/unhcr-barred-from-issuing-id-cardsminister-says. 
Linter, Bertil. 1991. Diversionary Tactics: Anti-Muslim campaign seen as effort to rally Burmans. Far Eastern Economic Review, August 29. Proquest.

Loescher, Gil and James Milner. 2005. Protracted Refugee Situations: Domestic and International Security. London: Routledge.

Mahtani, Shibani and Myo Myo. 2015. "Myanmar Threatens Boycott of Migration Meeting." The Wall Street Journal, May 17. Accessed October 30, 2016.

http://www.wsj.com/articles/myanmar-threatens-boycott-of-migration-meeting-1431849696.

Malaysia. 1959. Immigration Act 1959/1963, Act 53. Accessed September 28, 2016. http://www.unhcr/org/refworld/docid/3ae6b54c0.html.

MAP Foundation. 2014. "Migrant worker policies." Accessed September 23, 2016. http://www.mapfoundationcm.org/Eng/registration.html.

Martin, Philip. 2007. The economic contribution of migrant workers to Thailand: Towards policy development. Bangkok: ILO.

Mathew, Penelope and Tristan Harley. 2014. Refugee Protection and Regional Cooperation in Southeast Asia: A Fieldwork Report.

http://www.mcrg.ac.in/WC_2015/Reading/D_RefugeeProtection.pdf.

May, Sandy. 2012. 'UNHCR seeks 'true' community reconciliation in Rakhine State." Myanmar Times, July 16. Accessed June 15, 2016.

http://www.mmtimes.com/index.php/national-news/yangon/395-unhcr-seeks-true-

community-reconciliation-in-rakhine-state.html.

McConnachie, Kirsten. 2014. "Forced Migration in South East Asia and East Asia." In The Oxford Handbook of Refugee and Forced Migration Studies, edited by Elena FiddianQasmiyeh, Gil Loescher, Katy Long and Nando Sigona, 626-638. Oxford: Oxford University Press.

McCoy, Alfred. 2006. “America's Secret War in Laos, 1955-75." In A Companion to the Vietnam War, edited by Marilyn Young and Robert Buzzanco, 283-314. Oxford: Blackwell Publishing.

McGurn, William. 1988. Asia: Dishonest Deterrence: Redefining the Refugee. The Wall Street Journal, July 27. Proquest.

McLaughlin, Tim and Nyan Lynn Aung. 2014. "Government succeeds in keeping Rohingya off ASEAN Summit agenda." Myanmar Times, May 12. Accessed October 30, 2016. http://www.mmtimes.com/index.php/national-news/nay-pyi-taw/10324-govt-succeeds-inkeeping-rohingya-off-asean-summit-agenda.html. 
Miller, Karl. 2015. "From Humanitarian to Economic: The Changing Face of Vietnamese Migration.” Accessed July 4, 2016. http://www.migrationpolicy.org/article/humanitarianeconomic-changing-face-vietnamese-migration.

Mizzima. 2009. "ASEAN summit concludes, shuns handling Burma crisis.” Mizzima, March 3. Accessed October 28, 2016. http://www.burmanet.org/news/2009/03/02/mizzima-news14th-asean-summit-a-reality-check-\%E2\%80\%93-mungpi/.

Mizzima. 2010. "Malaysia struggles to meet refugee needs: rights report." Mizzima News, December 17. Accessed June 16, 2016. http://www.mizzima.com/news/regional/4686malaysia-struggles-to-meet-refugee-needs-rights-report-html.

Moni, Dipu. 2009. "Bangladesh Foreign Minister Statement on Rohingya. ” Accessed July 28, 2016. http://www.mofa.gov.bd/index.php?option=com_wrapper\&Itemid=552.

Moretti, Sebastien. 2015. "The Challenge of Durable Solutions for Refugees at the ThaiMyanmar Border.” Refugee Survey Quarterly 34 (3): 70-94.

Muntarbhorn, Vitit. 1992. The Status of Refugees in Asia. New York: Oxford University Press.

Nakavachara, Neptnapis and John Rogge. 1987. "Thailand's Refugee Experience." In Refugees: A Third World Dilemma, edited by John Rogge, 269-281. New Jersey: Rowman \& Littlefield.

Narine, Shaun. 2005. "Humanitarian Intervention and the Question of Sovereignty." Perspectives on Global Development and Technology 4 (3/4): 465-485.

$\mathrm{Ng}$, Desmond. 2017. "Why Buddhism, a religion of tolerance, is falling prey to hate speech." Channel Newsasia, Feb 9. Accessed February 14, 2017.

http://www.channelnewsasia.com/news/asiapacific/why-buddhism-a-religion-of-tolerance-isfalling-prey-to-hate/3503836.html.

Ninh, Thien-Huong T. 2015. "The Forgotten Ones: Vietnamese Catholics in Cambodia and Their Quest for Reconciliation.” In Forced Migration, Reconciliation, and Justice, edited by Megan Bradley, 106-122. Montreal: McGill-Queen's University Press.

Office of the High Commissioner for Human Rights (OHCHR). 2015. "High Commissioner Zeid: Pushbacks endanger thousands in Bay of Bengal." OHCHR News, May 15. Accessed June 16, 2016.

http://www.ohchr.org/en/NewsEvents/Pages/DisplayNews.aspx?NewsID=15960\&LangID=E

Operation Centre for Displaced Persons. 1980. Too long to wait: displaced persons from Indochina in Thailand. Bangkok: Thai Ministry of the Interior. 
Osborne, Milton. 1980. "The Indochinese Refugees: Causes and Effects." International Affairs 56 (1): 37-53.

Osborne, Milton. 1981. "Kampuchean Refugees: The Continuing Evolution of a Humanitarian and Political Problem.” In Refugees: Four Political Case-Studies, edited by Milton Osborne, Beverley Male, Gordon Lawrie and W.J. O’Malley, 1-36. Canberra: Australian National University.

Osman, Nurfika. 2009. "Thai FM Agrees to Use Bali Process to Solve Rohingya Issue." Jakarta Globe, February 20. Accessed October 30, 2016.

http://jakartaglobe.beritasatu.com/archive/thai-fm-agrees-to-use-bali-process-to-solverohingya-issue- $/$.

Osornprasop, Sutayut. 2012. "Thailand and the Secret War in Laos: the origins of engagement." In Cold War Southeast Asia, edited by Malcolm H. Murfett, 165-194. Singapore: Marshall Cavendish.

Oucho, John O. 2002. "Refugees and Internally Displaced Persons." In Global Changes in Asylum Regimes, edited by Daniele Joly, 154-178. New York: Palgrave.

Palansamy, Yiswaree. 2015. "Dr M: Malaysia must interfere in 'genocide' against Rohingya." The Malay Mail Online, June 12. Accessed June 6, 2016. http://www.themalaymailonline.com/malaysia/article/dr-m-malaysia-must-interfere-ingenocide-against-rohingya.

Palansamy, Yiswaree. 2017. "DPM: 300 Rohingya Refugees allowed to work legally in March.” The Malay Mail Online, February 2. Accessed February 17, 2017. http://www.themalaymailonline.com/malaysia/article/dpm-govt-to-hire-300-rohingyarefugees-starting-march.

Paribatra, Sukhumbhand. 1984. "Strategic Implications of the Indochina Conflict: Thai Perspectives." Asian Affairs 11(3): 28-46.

Perlez, Jane. 2014. "Rise in Bigotry Fuels Massacre Inside Myanmar." The New York Times, March 1. Accessed October 18, 2016. http://www.nytimes.com/2014/03/02/world/asia/risein-bigotry-fuels-massacre-inside-myanmar.html.

Perlez, Jane and Wai Moe. 2016. "Violence Escalates Between Myanmar Forces and Rohingya." The New York Times, November 13. Accessed February 14, 2017. https://www.nytimes.com/2016/11/14/world/asia/violence-escalates-between-myanmarforces-and-rohingya.html?_r=0.

Petty, Martin. 2012. "Rohingya Muslims 'persecuted' after Myanmar crackdown: report." Reuters, July 31. Accessed June 14, 2016. http://www.reuters.com/article/us-myanmarviolence-idUSBRE87005A20120801.

Phung, Adrian. 2016. "Malaysia, UNHCR forms joint task force on migration issue." The Sun Daily, August 18. Accessed October 29, 2016. http://www.thesundaily.my/node/388692. 
Ponniah, Kevin. 2017. "Who will help Myanmar's Rohingya?” BBC News, January 10. Accessed February 18, 2017. http://www.bbc.com/news/world-asia-38168917.

PTI. 2015. "UNHCR adopts resolution on Myanmar's Rohingya Muslims." The Times of India, July 3. Accessed October 30, 2016. http://timesofindia.indiatimes.com/world/rest-ofworld/UNHRC-adopts-resolution-on-Myanmars-Rohingya-

Muslims/articleshow/47927074.cms.

R Abrar, Chowdhury. 2001. "Legal protection of refugees in South Asia." Forced Migration Review, no.10: 21-3.

Rachagan, S. Sothi. 1987. "Refugees and illegal immigrants: the Malaysian experience with Filipino and Vietnamese Refugees." In Refugees: A Third World Dilemma, edited by John R. Rogge, 253-268. New Jersey: Rowman \& Littlefield.

Rahman, Utpala. 2010. "The Rohingya Refugee: A Security Dilemma for Bangladesh." Journal of Immigrant and Refugee Studies 8 (2): 233-239.

Raksasataya, Amara. 1974. Foreign aid to Public Administration in Thailand in the 1980s. New York: Asia Society.

Robinson, W. Courtland. 1996. Double vision: A History of Cambodian refugees in Thailand. Bangkok: Asian Research Center for Migration, Chulalongkorn University.

Robinson, W. Courtland. 1998. Terms of Refuge: The Indochinese Exodus and the International Response. London: Zed Books.

Robinson, W. Courtland. 2004. "The Comprehensive Plan of Action for Indochinese Refugees, 1989-1997: Sharing the Burden and Passing the Buck." Journal of Refugee Studies 17 (3): 319-33.

Royal Thai Government. 2009. "PM urges 4 nations to jointly solve Rohingya problem." Accessed June 19, 2016. http://reliefweb.int/report/myanmar/pm-urges-4-nations-jointlysolve-rohingya-problem.

Royal Thai Government. 2015. "Thailand: Armed Forces Chief says Thailand to work with Malaysia on appropriate measure for Rohingya refugees.” Thai Government News, May 15. Accessed 21 June, 2016. http://thainews.prd.go.th/website_en/news/news_detail/WNPOL5805150010017.

Reuters. 2017. "More than 1,000 Rohingya feared killed in Myanmar crackdown, say UN officials." The Guardian, February 9. Accessed February 17, 2016. https://www.theguardian.com/world/2017/feb/09/more-than-1000-rohingya-feared-killed-inmyanmar-crackdown-say-un-officials.

Reuters. 2017. "Myanmar rebuffs Malaysia for organising OIC meeting on Rohingya." Reuters, January 21. Accessed March 1, 2017. http://www.reuters.com/article/us-myanmarrohingya-idUSKBN15508H. 
Russell, Sharon Stanton. 2002. "Refugees: Risks and Challenges Worldwide.” Accessed May 18, 2016. http://www.migrationpolicy.org/article/refugees-risks-and-challenges-worldwide.

S.Bedi, Rashvinjeet. "UNHCR: Release Rohingya refugees from detention." The Star, June 8. Accessed November 18, 2016. http://www.thestar.com.my/news/nation/2016/06/08/unhcrrelease-rohingya-refugees/.

Sangiam, Tanakorn. 2015. "DPM stressed local authorities practices for Rohingya refugees." National News Bureau of Thailand, May 18. Accessed June 17, 2016.

http://thainews.prd.go.th/website_en/news/news_detail/WNPOL5805180010012.

Santiago, Charles. 2015. “As UN Security Council member, M'sia must act.” Malaysiakini, May 18. Accessed June 16, 2016. https://www.malaysiakini.com/news/298695.

Schell, Jonathan. 1987. The Real War: The Classic Reporting on the Vietnam War with a New Essay. New York: Pantheon Books.

Schissler, Matt, Matthew J Walton and Phyu Phyu Thi. 2015. "The Roots of Religious Conflict in Myanmar." Accessed October 30, 2016. http://thediplomat.com/2015/08/theroots-of-religious-conflict-in-myanmar/.

Secretary of Foreign Affairs, Republic of Philippines and E. Schlatter. to UNHCR Deputy High Commissioner and United Nations Vientiane, Laos, Correspondence, (2 Jul. 1956 and 28 Jan. 1967), cited in Sara E. Davies, 2006, "Saving refugees or saving borders? Southeast Asian States and the Indochinese refugee crisis." Global Change, Peace \& Security 18 (1): 56.

Shawcross, William. 1979. Sideshow: Kissinger, Nixon, and the Destruction of Cambodia. New York: Cooper Square Press.

Singh, Bilveer. 2014. "Asean, Myanmar and the Rohingya Issue.” Himalayan and Central Asian Studies 18 (1/2): 5-20.

Sivanandam, Hemananthani. 2012. "Time to modernise archaic laws, says Nazri." Accessed October 30, 2016.

http://www.malaysianbar.org.my/legal/general_news/time_to_modernise_archaic_laws_says nnazri.html.

Smith, Martin. 1999. Burma: Insurgency and the Politics of Ethnicity. London: Zed Books.

St Cartmail, Keith. 1983. Exodus Indochina. Auckland: Heinemann Publishers.

Stein, Barry. 1979. "The Geneva Conferences and the Indochinese Refugee Crisis." The International Migration Review 13 (4): 716-723.

St Cartmail, Keith. 1983. Exodus Indochina. Auckland: Heinemann.

Suhrke, Astri. 1993. "The high-politics of population movements." In International migration and security, edited by Myron Weiner, 179-200. Boulder: Westview Press 
Suhrke, Astri and Aristide R. Zolberg. 1999. "Issues in contemporary refugee policies." In Migration and Refugee Policies: An Overview, edited by Ann Bernstein and Myron Weiner, 143-180. New York: Continuum.

Szep, Jason and Marshall, Andrew R.C. 2013. "Thailand secretly supplies Myanmar refugees to trafficking rings." Reuters, December 4. Accessed August 9, 2016.

http://www.reuters.com/article/us-thailand-rohingya-special-reportidUSBRE9B400320131205.

Tan, Vivian. 2014. "As thousands continue to flee Myanmar, UNHCR concerned about growing reports of abuse." Accessed August 1, 2016.

http://www.unhcr.org/news/latest/2014/6/5396ee3b9/thousands-continue-flee-myanmarunhcr-concerned-growing-reports-abuse.html.

Terry, Fiona. 2002. The Paradox of Humanitarian Action: Condemned to Repeat? New York: Cornell University Press.

Thalang, Chanintira Na. 2017. "Malaysia's role in two South-East Asian Insurgencies." Australian Journal of International Affairs 71 (1): 1-16.

The Economist. 2015. "The most persecuted people on Earth?” The Economist, June 13. Accessed October 10, 2016. http://www.economist.com/news/asia/21654124-myanmarsmuslim-minority-have-been-attacked-impunity-stripped-vote-and-driven.

The Nation. 2009a. "Thailand/Indonesia: Rohingya refugee issue to be part of Thai Prime Minister's discussion with Indonesian authorities.” Accessed 28 June, 2016.

http://reliefweb.int/report/indonesia/thailand-meets-regional-ambassadors-over-refugee-issue.

The Nation. 2009b. "No sanctuary: Trafficking of Burmese people at the Thai-Malay border." Accessed June 20, 2016. http://www.burmanet.org/news/2009/02/13/the-nationthailand-no-sanctuary-trafficking-of-burmese-people-at-the-thaimalay-border-\%E2\%80\%93elaine-pearson/.

The Nation. 2013. "Call for regional help to deal with Rohingya." The Nation, January 22. Accessed June 17, 2016. http://www.nationmultimedia.com/national/Call-for-regional-helpto-deal-with-Rohingya-30198388.html.

The Quran 9:6 (Surah Al-Tawbah).

Towle, Richard. 2006. "Processes and Critiques of the Indo-Chinese Comprehensive Plan of Action: An Instrument of International Burden-Sharing?" International Journal of Refugee Law 18 (3/4): 537-570.

Towle, Richard. 2017. "Challenges and Way Forward in Handling Rohingya Refugees in Malaysia.” Accessed February 2, 2017. https://www.unhcr.org.my/News_Views-@ Challenges_and_Way_Forward_in_Handling_Rohingya_Refugees_in_Malaysia.aspx.

Tran, Peter. 1996 "Rohingya refugees: An ambivalent future." Migration World Magazine 24: 29. 
Tripp, Peter. 1979. “Thailand Today.” Asian Affairs 10 (3): 252-259.

Unger, Daniel. 2003. “Ain't Enough Blanket: International and Humanitarian Assistance and Cambodian Political Resistance." In Refugee Manipulation: War, Politics and the Abuse of Human Suffering, edited by Stephen John Stedman and Fred Tanner, 17-56. Washington: Brookings Institution Press.

United Nations Economic and Social Council (UNECOSOC). 1949. Report of the International Refugee Organization (IRO), E/1334. https://documents-ddsny.un.org/doc/UNDOC/GEN/GL9/911/84/PDF/GL991184.pdf?OpenElement.

United Nations High Commissioner for Refugees (UNHCR). n.d.b. "Asylum Seekers." Accessed May 18, 2016. http://www.unhcr.org/en-au/asylum-seekers.html.

United Nations High Commissioner for Refugees (UNHCR). n.d.a. "States Parties to the 1951 Convention relating to the Status of Refugees and the 1967 Protocol." Accessed May 12. 2016. http://www.unhcr.org/protection/basic/3b73b0d63/states-parties-1951-conventionits-1967-protocol.html.

United Nations High Commissioner for Refugees (UNHCR). 1979. "Weekly Notes 29 june to 5 July 1979." cited in Sara E. Davies, 2006, "Saving refugees or saving borders? Southeast Asian States and the Indochinese refugee crisis." Global Change, Peace \& Security 18 (1): 56.

United Nations High Commissioner for Refugees (UNHCR) 2000. The State of The World's Refugees 2000: Fifty Years of Humanitarian Action. http://www.unhcr.org/3ebf9bad0.pdf.

United Nations High Commissioner for Human Rights (UNHCR). 2000. State of the World's Refugees. London: Oxford University Press.

United Nations High Commissioner for Refugees (UNHCR). 2000. Flight from Indochina. http://www.unhcr.org/3ebf9bad0.pdf.

United Nations High Commissioner for Refugees (UNHCR) Regional Office for Southeast Asia. 2014. "UNHCR Factsheet September 2014.” Accessed May 12, 2016.

http://www.unhcr.org/519f67fc9.html.

United Nations High Commissioner for Refugees (UNHCR). 2015a. UNHCR Global Trends: Forced Displacement in 2014. http://www.unhcr.org/556725e69.pdf.

United Nations High Commissioner for Refugees (UNHCR). 2015b. "UNHCR Mid-Year Trends." Accessed May 18, 2016.

http://www.unhcr.org/statistics/unhcrstats/56701b969/mid-year-trends-june-2015.html.

United Nations High Commissioner for Refugees (UNHCR) Regional Office for Southeast Asia. 2015. "Mixed Maritime Movements in South-East Asia." Accessed May 12, 2016. http://unhcr.atavist.com/mmm2015. 
United Nations High Commissioner for Human Rights (UNHCR) 2016a. "Figures at a Glance: Malaysia.” Accessed October 21, 2016. http://www.unhcr.org.my/about_us-@_ figures_at_a_glance.aspx.

United Nations High Commissioner for Human Rights (UNHCR) 2016b. “Operations: Thailand." Accessed October 22, 2016.

http://reporting.unhcr.org/node/2552\#_ga=1.71782611.115658321.1465183170.

United Nations General Assembly (UNGA). 1977. "Summary Record of the $285^{\text {th }}$ Meeting held on 5 October 1977." cited in Sara E. Davies, 2006, "Saving refugees or saving borders? Southeast Asian States and the Indochinese refugee crisis." Global Change, Peace \& Security 18 (1): 5-6.

United Nations General Assembly (UNGA). 1978. "Report on UNHCR Assistance Activities in 1977-1978 and Proposed Voluntary Funds Programmes and Budget for 1979 Addendum 1." Submitted by the High Comissioner, Executive Committee of the High Commissioner's Programme, Twenty-Eighth Session, 3 October 1978, quoted in Sara E. Davies, 2008 Legitimising Rejection: International Refugee Law in Southeast Asia. Boston: Martinus Nijhoff.

United Nations General Assembly (UNGA). 1979. Meeting on Refugees and Displaced Persons in South-East Asia, convened by the Secretary-General of the United Nations at Geneva, on 20 and 21 July 1979, and subsequent developments: Report of the SecretaryGeneral. http://www.refworld.org/docid/3ae68f420.html.

United Nations General Assembly (UNGA). 1979. 'Background Note Dated 9 July 1979 Prepared by the United Nations High Commissioner for Refugees for the Meeting on Refugees and Displaced Persons in South-East Asia' cited in Sara E. Davies, 2006, "Saving refugees or saving borders? Southeast Asian States and the Indochinese refugee crisis." Global Change, Peace \& Security 18 (1): 5-6.

United Nations General Assembly (UNGA). 1979. 'Report on UNHCR Assistance Activities in 1978-1979 and Proposed Voluntary Funds Programmes and Budget for 1980', cited in Sara E. Davies, 2008, Legitimising Rejection: International Refugee Law in Southeast Asia. Boston: Martinus Nijhoff.

United Nations General Assembly (UNGA). 1989. Draft Declaration and Comprehensive plan of Action Approved by the Preparatory meeting for the international conference on Indochinese refugees on 8 March 1989.4-5, 1989a, cited in Sarah E. Davies, 2008, "Realistic yet humanitarian? The Comprehensive Plan of Action and Refugee Policy in Southeast Asia." International Relations of the Asia-Pacific 8 (2): 191-217.

United Nations General Assembly (UNGA). 1989. Declaration and Comprehensive Plan of Action of the International Conference on Indo-Chinese Refugees, Report of the Secretary General (A/44/523). http://www.refworld.org/docid/3dda17d84.html.

United Nations Office on Drugs and Crime. 2012. Transnational Organised Crime Threat Assessment - East Asia and the Pacific.

http://www.unodc.org/documents/toc/Reports/TOCTA-EA-Pacific/TOCTA_EAP_c04.pdf. 
United Nations Refugee Convention. 1951. Convention and Protocol Relating to the Status of Refugees, July 28, 1951. Accessed May 12. 2016. http://www.unhcr.org/3b66c2aa10.

United States Committee on Foreign Relations. 2009. "A Report to the Committee on Foreign Relations United States Senate, Trafficking and Extortion of Burmese Migrants in Malaysia and Southern Thailand." Accessed October 18, 2016. http://www.gpo.gov/fdsys/pkg/CPRT-111SPRT48323/html/CPRT-111SPRT48323.htm.

United States Committee for Refugees and Immigrants. 2002. "World Refugee Survey 2002." Accessed May 15, 2016. http://refugees.org/WRS2002.cfm.

United States Office of the Vice President's Press Secretary. 1979. Speech prepared for delivery by Vice President Walter F. Mondale to the U.N. Conference on Indochinese Refugees. http://nakbaeducation.com/wp-content/uploads/UNSpeech19MONDALE.pdf.

Van Evera, Stephen. 1997. Guides to Methods of Students of Political Science. Ithaca: Cornell University Press.

Van der Kroef, Justus M. 1979. "The Vietnamese Refugee Problem.” World Affairs 142 (1): 3-16.

Van der Kroef, Justin M. 1980. "The Indochina Tangle: The Elements of Conflict and Compromise.” Asian Survey 20 (5): 477-494.

Van der Kroef, Justus M. 1983. "Refugees and Rebels: Dimensions of the Thai-Kampuchean Border Conflict.” Asian Affairs 10 (1): 19-36.

Vas Dev, Sanjugta. 2009. "Accounting for State Approaches to Asylum Seekers in Australia and Malaysia: The Significance of 'National' Identity and 'Exclusive' Citizenship in the Struggle Against 'Irregular' Mobility'.” Identities 16 (1): 33-60.

Vejjajiva, Abhisit. 2009. "Chairman's Statement of the $14^{\text {th }}$ ASEAN Summit." Accessed October 30, 2016. http://www.thaigov.go.th/en/council-house/item/57371chairman\%E2\%80\%99s-statement-of-the-14th-asean-summit.html.

Vinayak, HV. Fraser Thompson and Oliver Tonby. 2014. "Understanding ASEAN: Seven things you need to know." Accessed June 21, 2016.

http://www.mckinsey.com/industries/public-sector/our-insights/understanding-asean-seventhings-you-need-to-know.

Vieria de Mello, Sergio. 1989. "Recommended Opening Speech for Kuala Lumpur Meeting, 7-9 March.” Memo to Refeeudin Ahmed, Secretary-General's Office, cited in Alexander Betts, 2006, Comprehensive Plans of Action: Insights from CIREFCA and the Indochinese CPA. http://www.refworld.org/pdfid/4ff163c82.pdf.

VOA News. 2013. "Thailand: Thailand to Deport Rohingya Muslim Asylum Seekers." VOA News, January 2. Accessed 18 June, 2016. http://www.voanews.com/a/thailand-to-deportrohingya-muslim-asylum-seekers/1576203.html.

Wain, Barry. 1979. “The Indochina Refugee Crisis.” Foreign Affairs 58 (1): 160-180. 
Wickramasekara, Piyasiri. 2002. "Asian Labour Migration: Issues and Challenges in an Era of Globalization.” Accessed June 8, 2016. http://www.ilo.org/wcmsp5/groups/public/---asia/--ro-bangkok/documents/publication/wcms_160632.pdf.

Weng, Lawi. 2009. "Thais Protest Idea of Rohingya Refugee Center.” The Irrawaddy, February 4. Accessed October 23, 2016.

http://www2.irrawaddy.com/article.php?art_id=15060.

World Bank. 2016. "Overview: Thailand.” Accessed September 23, 2016.

http://www.worldbank.org/en/country/thailand/overview.

World Bank. 2016. “Overview: Malaysia.” Accessed September 23, 2016.

http://www.worldbank.org/en/country/malaysia/overview.

Yap, Mun Ching. 2004. "Rohingya Discontent Troubles Malaysia." The Irrawaddy, August 24. Accessed October 23, 2016.

http://www2.irrawaddy.com/opinion_story.php?art_id=3828\&page=1.

Yunus, Arfa. 2016. "Najib tells Suu Kyi 'enough is enough' at Rohingya solidarity rally." New Straits Times, December 4. Accessed February 17, 2017.

http://www.nst.com.my/news/2016/12/194271/najib-tells-suu-kyi-enough-enough-rohingyasolidarity-rally-video.

Zappei, Julia. 2010. "Malaysia shelves plan to issue IDs to refugees." Associated Press, June 16. Accessed June 16, 2016. https://www.highbeam.com/doc/1A1-D9GCBC282.html. 